Paulo Yun Cha

Estratégias de preço na difusão de inovação: Simulação baseada em agentes aplicado ao mercado brasileiro de carros elétricos 

Paulo Yun Cha

\section{Estratégias de preço na difusão de inovação: Simulação baseada em agentes aplicado ao mercado brasileiro de carros elétricos}

Dissertação apresentada à Escola de Artes, Ciências e Humanidades da Universidade de São Paulo como requisito para obtenção do título de Mestre em ciências do Programa de Pós-graduação em Modelagem de Sistemas Complexos

Orientador:Prof. Dr. Carlos de Brito Pereira

Brasil

2016 
Autorizo a reprodução e divulgação total ou parcial deste trabalho, por qualquer meio convencional ou eletrônico, para fins de estudo e pesquisa, desde que citada a fonte.

CATALOGAÇÃO-NA-PUBLICAÇÃO

(Universidade de São Paulo. Escola de Artes, Ciências e Humanidades. Biblioteca)

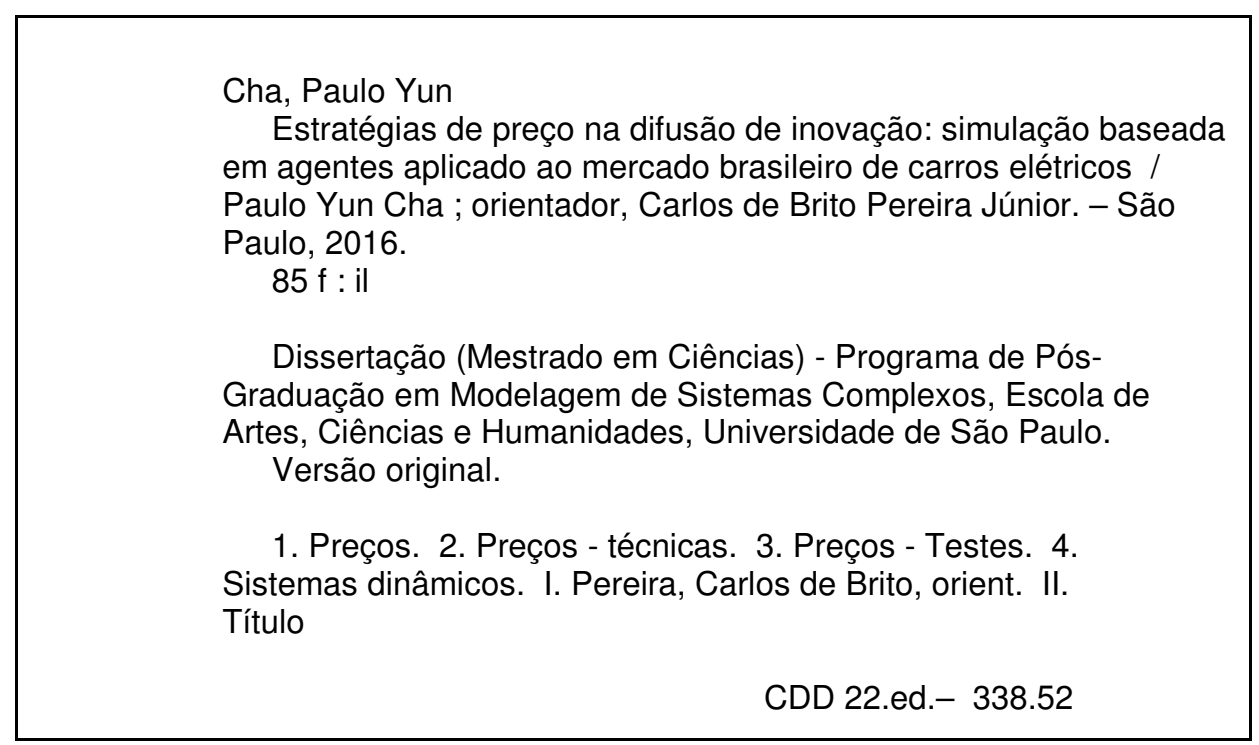




\title{
Estratégias de preço na difusão de inovação: Simulação baseada em agentes aplicado ao mercado brasileiro de carros elétricos
}

\author{
Dissertação apresentada à Escola de Ar- \\ tes,Ciências e Humanidades da Universidade \\ de São Paulo como requisito para obtenção \\ do título de Mestre em ciências do Programa \\ de Pós-graduação em Modelagem de Siste- \\ mas Complexos
}

Trabalho aprovado. São Paulo, xx de janeiro de 2016:

Prof.Dr Carlos Brito de Pereira

Orientador

Prof.Dr

Convidado 1

Prof.Dr

Convidado 2

Brasil

2016 

Para minha querida avó Kim Sa-Nyo 



\section{Agradecimentos}

Primeiramente, ao meu orientador, Professor Doutor Carlos de Brito Pereira, pelo seu apoio total,palavras de estímulo(inúmeras) e disponibilidade em trabalharmos juntos. Agradeço imensamente por ter me aceitado como seu orientando e pela grande paciência do senhor frente as minhas dificuldades nessa longa jornada.

Ao corpo docente do programa de Modelagem de Sistemas Complexos, especialmente aos quais tive honra em ser aluno e que muito ajudou em desenvolver este trabalho : Camilo R. Neto, Fernando F. Ferreira, Francisco J.S.M. Alvarez, Masayuki Hase, Paulo Sinisgalli,Renato Vicente e à Professora Doutora Flávia Mori Sarti.

A todos os amigos-colegas com os quais tive o prazer de frequentar a pós-graduação, em especial aos alunos Daniel Chamorro,Moshe Choque,Rolf Simões e Sandro Dias e, que além da amizade, me incentivaram e dividiram os momentos alegres e os não tão alegres na sala 328 .

Aos meus pais, Sr. Sung e Sr.a Hae, pelo carinho,orientação e amor incondicional. Espero educar meus futuros filhos com a mesma dedicação e atenção.

Às minhas irmãs, Catarina e Fabiana, pelo apoio direto e indireto ao seu irmão muitas vezes ausentes por causa dos estudos.

Por fim, não posso deixar de agradecer com carinho especial a toda comunidade EACHiana, pois se trata certamente de minha segunda casa nesses últimos 8 anos de graduação e pós-graduação.Aos inúmeros colaboradores,funcionários da pós-graduação e graduação,biblioteca e professores.

Algumas poucas palavras reservadas nesta seção, certamente não serão suficientes para agradecer as inúmeras pessoas com as quais pude me apoiar nesta empreitada. Seguramente eu efetuei alguma injustiça em não mencioná-las, por isso me desculpo de antemão.Concluo que esta minha sorte em contar com tantas pessoas boas e dispostas em ajudar, decerto me ajudaram a persistir com um semblante de felicidade nesta etapa. 

"Nada lhe posso dar que já não exista em você mesmo.

Não posso abrir-lhe outro mundo de imagens, além daquele que há em sua própria alma.

Nada the posso dar a não ser a oportunidade,o impulso, a chave. Eu o ajudarei a tornar visível o seu próprio mundo, e isso é tudo. 



\section{Resumo}

CHA, YUN. Estratégias de preço na difusão de inovação: Simulação baseada em agentes aplicado ao mercado brasileiro de carros elétricos. 2016. 85 f. Dissertação (Mestrado em Ciências) - Escola de Artes, Ciências e Humanidades, Universidade de São Paulo, São Paulo, 2016. Versão original.

No contexto dos sistemas complexos, o presente trabalho investiga 3 estratégias de precificação:(1)desnatação,(2) penetração e (3)aprendizado, na difusão de carros elétricos em diferentes contextos.Por meio da modelagem baseada em agentes, o primeiro modelo testa três situações relacionados à demanda energética:(1)desabastecimento,(2)estabilidade e (3)crescimento moderado da demanda.A forte escassez de energia estimulou a rápida migração dos agentes aos carros elétricos. As três estratégias de precificação exibiram resultados similares em termos de faturamento e \% na participação do mercado, no entanto a estratégia de penetração foi capaz de capturar uma parcela maior do mercado em menor tempo.No segundo modelo, 3 diferentes comportamentos sociais são aplicadas aos agentes: (1)conservador, (2)racional e (3) social,em diferentes proporções afim de avaliar a influência da composição social na dinâmica difusora.No que concerne ao faturamento e \% na participação do mercado, o segundo modelo detectou diferenças estatisticamente significativas para cada estratégia de precificação.Em sociedades proeminentemente conservadoras, as três estratégias não apresentaram indícios de diferença significativa no tocante relação ao faturamento, $\%$ na participação final do mercado e taxa de adoção média.Sociedades compostas majoritariamente por agentes racionais, apresentaram a mais rápida convergência aos carros elétricos,sendo este, o veículo mais caro.Isto se deve à percepção positiva do custo/benefício ao longo prazo.O maior faturamento é proveniente das sociedades compostas preponderantemente por agentes com atitudes sociais dado à compra e troca mais recorrente entre diferentes veículos no decorrer das interações.A estratégia de desnatação demonstrou maior versatilidade ao exibir performance superior com maior regularidade no que tange em faturamento em todas as composições sociais testadas.A estratégia de penetração exibiu índices maiores em taxa de adoção e faturamento em redes compostas integralmente por agentes com comportamentos sociais iguais,mas não foi possível detectar este padrão em redes parciais. Por fim, a estratégia de aprendizado apresentou o menor faturamento em todos os cenários, no entanto, sua taxa de adoção similar à estratégia de penetração, pode ser a estratégia de precificação mais crível e eficiente para empresas iniciantes.

Palavras-chaves: Difusão de inovação, sistemas complexos, modelagem por agentes, sistemas dinâmicos, preços-técnicas, carros elétricos 



\section{Abstract}

CHA, YUN. Pricing strategies at innovation diffusion process: Agent-based model simulation applied to brazilian's market of electric car. 2016. 85 p. Thesis (Master of Science) - School of arts, Sciences and Humanities, University of Sao Paulo, São Paulo, 2016. Original version.

In the context of complex systems, the following research investigated 3 pricing strategies:(1)skimming,(2)penetration and (3)learning, at electric car diffusion in several different scenarios. Through the agent-based modelling, the first model tested 3 situations related to energy demand:(1)severe shortage,(2)stability and (3)moderate growing of demand. The strong shortage of energy forced an fast-paced migration of agents towards the electric cars. The 3 strategies showed up similar results in terms revenues and market share, however the penetration strategy was able to capture a large part of the market faster than others. At the second model, 3 different social behaviors were implemented in each agent:(1)conservative,(2)rational and (3)social,in different proportions in order to assess social composition and its influence in the innovation diffusion process. Revenue and market share as concerned, the second model detected significant statistic difference for each pricing strategy. For societies predominantly conservative, all strategies did not show significant differences evidences regarding to revenue,market share and average adoption rate. Societies comprised mostly of rational agents presented the quickest convergence to electric cars, which it is the most expensive car. This is because a positive perception of benefits over cost in the long term. The largest revenue were derived from societies primarily composed of agents with social behaviors due to recurrent purchase and exchange between different vehicles over the interactions. Skimming strategy demonstrated greater versatility by displaying superior performance more regularly in terms of revenue in every social composition simulated. Penetration strategy exhibited highest rates of adoption and revenue in social networks composed entirely of agents with same social behavior, but it was not possible to detect such pattern at partial social networks. Finally, the learning strategy reported the lowest revenues at every scenario, none the less, its rate of adoption was equivalent to penetration's strategy rates, this strategy could be the most feasible and efficient to startups and small companies.

Key-words: Diffusion of innovation, complex systems, agent-based model ,dynamic systems,pricing-techniques ,electric cars 



\section{Lista de ilustrações}

Figura 1 - Redes regulares . . . . . . . . . . . . . . . . 28

Figura 2 - Rede regular e rede small world . . . . . . . . . . . . . . . . . . 29

Figura 3 - Formato regular e Scale free . . . . . . . . . . . . . . . . . 30

Figura 4 - Distribuição de grau para rede aleatória e scale free . . . . . . . . . . . 30

Figura 5 - Difusão de novos produtos na rede . . . . . . . . . . . . . 31

Figura 6 - Diagrama de fluxos do modelo baseado em agentes . . . . . . . . . . . 44

Figura 7 - Curva de demanda energética para veículos leves . . . . . . . . . 46

Figura 8 - Curva de precificação - Desnatação . . . . . . . . . . . . . . . . 49

Figura 9 - Curva de precificação - penetração . . . . . . . . . . . . . . 51

Figura 10 -Curva de precificação - Aprendizado . . . . . . . . . . . . . . . 52

Figura 11 -Distribuição de grau . . . . . . . . . . . . . . . . . 53

Figura 12 - Curva de adoção no cenário de desabastecimento . . . . . . . . . . . 53

Figura 13 -Curva de adoção no cenário de crescimento moderado . . . . . . . . . . 54

Figura 14 -Curva de adoção no cenário de estabilidade . . . . . . . . . . . . . . 54

Figura 15 - Tabela de desempenho - Cenário de desabastecimento . . . . . . . . . . 55

Figura 16 -Tabela de desempenho - Cenário de estabilidade . . . . . . . . . . . . 55

Figura 17 -Heat map para desabastecimento . . . . . . . . . . . . . . 56

Figura 18 -Curva parcialmente conservadora - 60\% dos agentes são conservadores . 59

Figura 19 -Curva parcialmente racional - 60\% dos agentes são racionais . . . . . . 59

Figura 20 -Curva parcialmente social - 60\% dos agentes são sociais . . . . . . . . . 60

Figura 21 -Histórico conservador . . . . . . . . . . . . . . . . . . . 61

Figura 22 -Historico racional . . . . . . . . . . . . . . . . 61

Figura 23 -Historico social . . . . . . . . . . . . . . . . . . 62

Figura 24 -Curva parcialmente $\mathrm{x}$ total conservadora . . . . . . . . . . . . . 64

Figura 25 -Curva parcialmente $\mathrm{x}$ total racional . . . . . . . . . . . . . . 64

Figura 26 -Curva parcialmente $\mathrm{x}$ total social . . . . . . . . . . . . . 65

Figura 27 -Tabela de performance - Conservador x Parcialmente conservador . . . 65

Figura 28 -Tabela de performance - Racional x Parcialmente racional . . . . . . . 65

Figura 29 -Tabela de performance - Social x Parcialmente social . . . . . . . . . . 66

Figura 30 -Dendograma . . . . . . . . . . . . . . . 66

Figura 31 -Grupo formado pela análise de agrupamento - K=4 . . . . . . . . . 67

Figura 32 -BoxPlot . . . . . . . . . . . . . . . . . . . 68

Figura 33 -Intervalo de confiança . . . . . . . . . . . . . . . . 69 



\section{Lista de tabelas}

Tabela 1 - Parâmetros gerais . . . . . . . . . . . . . . . 4 45

Tabela 2 - Tecnologias de energia utilizadas como referência para a simulação . 47

Tabela 3 - Composição social dos agentes . . . . . . . . . . . . . . . 48

Tabela 4 - Parâmetros da curva de logística geral para Desnatação . . . . . . . . 50

Tabela 5 - Parâmetros da curva de logística geral para Desnatação . . . . . . . . . 51

Tabela 6 - Teste ANOVA sobre formato de rede:Aglomerado x Não-aglomerado . 57

Tabela 7 - Teste ANOVA sobre formato de rede:Aglomerado x Não-aglomerado . 57

Tabela 8 - Teste Fischer sobre estratégia de preço . . . . . . . . . . 58

Tabela 9 - Tabela de processo Fischer . . . . . . . . . . . . . 58

Tabela 10 -Teste ANOVA sobre composição social:parcial x integral . . . . . . . 63

Tabela 11 - Tabela de processo Fischer $-\operatorname{Sim} 2 \ldots \ldots$. . . . . . . 68 



\section{Sumário}

1 Introdução . . . . . . . . . . . . . . . . 21

1.1 Estrutura da dissertação . . . . . . . . . . . . . . . . . . . . 23

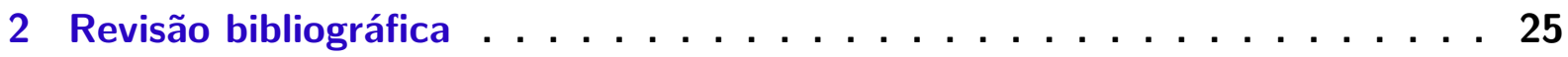

2.1 Sistemas complexos e suas características gerais . . . . . . . . . . . 25

2.1.1 Não-linearidade e emergência . . . . . . . . . . . . . . . 25

2.1.2 Feedback,interações e heterogeneidade . . . . . . . . . . . . . 25

2.1.3 Robustez e falta de controle central . . . . . . . . . . . . . 26

2.1.4 Organização hierárquica . . . . . . . . . . . . . . 27

2.2 Redes complexas . . . . . . . . . . . . . . . . . . 27

2.2.1 Redes regulares e redes aleatórias . . . . . . . . . . . . . . 28

2.2 .2 Redes Small World . . . . . . . . . . . . . . . . . . 28

2.2 .3 Redes Scale Free . . . . . . . . . . . . . . . . . . . 29

2.3 Difusão de inovações . . . . . . . . . . . . . . . . . . . . 30

2.3.1 Difusão de novos produtos - Uma breve revisão . . . . . . . . . . 30

2.3.2 Difusão baseada na modelagem por agentes - uma diferente perspectiva . . . . . . . . . . . . . . . . . 32

2.3.3 Componentes da difusão de novos produtos . . . . . . . . . . . . . 33

2.3.3.1 Externalidades de rede . . . . . . . . . . . . 33

2.3.3.2 Sinais sociais e heterogeneidade dos consumidores . . . . . 35

2.3.3.3 Pontos críticos de crescimento e desaceleração na difusão . 36

2.3.3.4 Geração tecnológica . . . . . . . . . . . . . 37

2.4 Gestão de marketing na difusão de novos produtos . . . . . . . . . . . . 38

2.4.1 Tipos de produtos - Social e não-social . . . . . . . . . . . . . . 39

2.4 .2 Estratégias de precificação . . . . . . . . . . . . . . . . 40

2.4.2.1 Estratégia de precificação para produtos inovadores sem os efeitos de rede . . . . . . . . . . . . . . . . . . 44 41

2.4.2.2 Estratégia de precificação para produtos inovadores considerando os efeitos de rede . . . . . . . . . . . . . . . 41

3 Metodologia - Simulação computacional em ciências sociais aplicadas . . . 43

3.0.3 Contexto e objetivo geral da simulação . . . . . . . . . . . . . . . . 44

3.0.3.1 Passo a passo da regra de decisão . . . . . . . . . . . . . 44

3.0.3.2 Curva de custo de combustíveis e tecnologias de energia . 45

3.0.3.3 Número de agentes e tecnologia . . . . . . . . . . . . . 46

3.0.3.4 Comportamento de adoção . . . . . . . . . . . . . . 47 
3.0.3.5 Modelo - Estratégia de precificação . . . . . . . . . . . . . 48

3.1 Análise dos dados . . . . . . . . . . . . . . . . . . . . . 52

3.1.1 Teste de parâmetros gerais . . . . . . . . . . . . . . . 52

3.1.2 Simulação I: Difusão em diferentes condições de demanda energética 53

3.1.3 Simulação II: Difusão em diferentes composições sociais . . . . . . . 59

4 Conclusão . . . . . . . . . . . . . . . . . . . 71

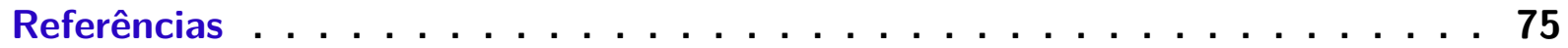




\section{Introdução}

Brett Tjaden, cientista em computação da Universidade da Virgínia, propôs expor o quão o ator americano Kevin Bacon está próximo de outros atores ao redor do planeta por meio do The Oracle of Bacon (LÓPEZ; SANJUÁN, 2002). O modelo de Tjaden consiste em uma base de dados com filmes e seus respectivos atores de todo o mundo o qual calcula o menor número de ligações necessárias para alcançar o ator. Por exemplo, a atriz brasileira Fernanda Montenegro mesmo que nunca tenha contracenado com o ator em questão, estes atores são muito próximos por estarem apenas separados por um colega de trabalho em comum.

Embora o Oracle of Bacon seja um jogo muito interessante, ao demonstrar as conexões muitas vezes improváveis entre os atores, intuitivamente conhecemos pessoas em nosso dia-a-dia com um círculo de conhecidos maior. Também podemos imaginar que eles possuem contatos com um maior número de outros grupos sociais. Esta percepção é familiar para muitas pessoas, ademais, muitas informações sobre como as sociedades são estruturas em redes podem ser encontradas nestas relações(MCCARTY; KILLWORTH; RENNELL, 2007).

Diversos estudos com o intuito de analisar as redes foram desenvolvidas especialmente no campo da sociologia (KILLWORTH et al., 1990; BERNARD et al., 1990; VALENTE, 1995). Porém, se antes havia um grande foco em redes sociais composta por algumas poucas dezenas de pessoas, repentinamente, trabalhos investigativos analisando grandes redes somaram-se ao arcabouço.Iniciou-se com a estatística mecânica (GOLDBERGER et al., 2000), em seguida, a biologia (BARABASI; OLTVAI, 2004), epidemiologia(GRIMM et al., 2005), ciência da computação (JENNINGS, 2001),nutrição (TENG; LIN; ADAMIC, 2012) e redes de colaboração (ADAMIC et al., 2008).

Esta mudança no tipo e tamanho do objeto de pesquisa tem mérito a partir dos trabalhos de Watts e Strogatz (1998), ao atrair outros campos da ciência e também o interesse do público geral sobre o tema (BARABÁSI; ALBERT, 1999; MOORE; NEWMAN, 2000).Os principais motivos que levaram outros campos da ciência a enveredar neste assunto está em explicar fenômenos complexos através de modelos e regras simples.Além disso, também são passíveis de serem testados empiricamente. Outro aspecto fundamental está na formalização de grandes redes adequando-os conforme modelo (NEWMAN, 2001).

Nas ciências sociais aplicadas também não foi diferente.A modelagem de dinâmicas sociais tem atraído a atenção de muitos cientistas, em especial, pesquisadores da área de exatas.Eles trazem consigo novos paradigmas de investigação, centrados na descrição quantitativa de fenômenos através de modelos que zelam pela simplicidade (CASTEL- 


\section{LANO; FORTUNATO; LORETO, 2009).}

Esta junção é mais contundente na economia.Diversos esforços estão sendo feitos para diminuir a distância entre as perspectivas micro e macro. Esta lacuna é calcada vastamente em construções teóricas formado por "caixas pretas"pouco elucidativas,a priori, sobre a convergência de micro fenômenos em padrões de maior escala (ABELL; FELIN; FOSS, 2007; KLEIN; DANSEREAU; HALL, 1994).Um dos caminhos para diminuir esta janela está no foco das ações individuais de múltiplos agentes e o resultado das interação entre eles (PENTLAND; FELDMAN, 2007; ARTHUR, 1999; CHANG, 1991; KEEN, 2001; BEINHOCKER, 2006).Porém,só recentemente estas duas áreas de pesquisa começaram a convergir, uma vez que a complexidade inerente de unificá-las apenas pôde ser atacada pela difusão de máquinas com alta capacidade de processamento e o consequente uso de novos métodos computacionais, como as simulações por agentes (MITCHELL, 2006).

Portanto nessa junção de linhas de pesquisa, o principal propósito deste trabalho é investigar a difusão de novos produtos - mais especificamente, carros com matriz energética 100\% elétrica no mercado nacional - utilizando arcabouço teórico e aplicado dos sistema complexos (DELRE, 2007; ECK; JAGER; LEEFLANG, 2011; DEFFUANT; HUET; AMBLARD, 2005).Maior ênfase será dada nas variáveis controladas diretamente pelas empresas no processo de difusão.Para tanto,serão investigados 3 aspectos principais: (1) Qual a influência das diferentes estratégias de precificação no processo de adoção?,

(2) Formatos de rede possuem influência significante sobre as estratégias de precificação? e (3)Diferentes estruturas comportamentais dos agentes modificam o desempenho das empresas? 


\subsection{Estrutura da dissertação}

No primeiro capítulo deste trabalho,a revisão bibliográfica é dividida em três seções.Os sistemas complexos, mais especificamente as redes complexas, suas principais características e os algoritmos de geração empregados são abordados na primeira seção do capítulo de revisão bibliográfica.Na segunda seção, a difusão de novos produtos e a importância de sua compreensão são revisados. O modelo de Bass e suas variações serão revisados e contrastados com a modelagem baseada por agentes. Por fim, os componentes que fazem parte deste fenômeno, serão descritos e analisados. Na terceira seção, os componentes estratégicos em marketing controláveis pelas empresas - tipo de produto e estratégia de precificação - serão investigados acerca de sua influência no processo de difusão.

No segundo capítulo, pressupostos gerais, modelos, parâmetros e a metodologia de trabalho utilizada serão apresentados.O terceiro capitulo análise os dados resultantes dos modelos simulados.Por fim, o capítulo 4 é dedicado à conclusão e as considerações finais. 



\section{Revisão bibliográfica}

\subsection{Sistemas complexos e suas características gerais}

A modelagem em sistemas complexos é um campo da ciência que investiga como diferentes partes de um sistema interagem e criam comportamentos coletivos. O estudo de sistemas complexos é sobre compreender problemas em que as causas e efeitos não são obviamente relacionados (BERTALANFFY, 1973). Sua definição formal ainda não está delimitada mas há algumas características partilhadas por este tipo de sistema que serão demonstradas nos próximos tópicos.

\subsubsection{Não-linearidade e emergência}

A não-linearidade é tido como relevante para complexidade. Um sistema é linear se as soluções decorrentes das equações descritas, apresentam proporcionalidade ao multiplicar/dividir qualquer solução por qualquer fator.Não-linearidade significa que esses princípios não são aplicáveis(DHEBAR; OREN, 1986; MITCHELL, 2006; BARABÁSI; ALBERT, 1999).

Pequenas diferenças de valores nas condições iniciais podem gerar macro-estados radicalmente diferentes em equações não-lineares. Na literatura, em contexto popular e filosófico sobre sistemas complexos, muitas discussões foram fomentadas sobre linearidade e não-linearidade. Por exemplo, Mainzer (2007) cita a obsolência no pensamento linear.

Há muitas discussões sobre o tema, e a não-linearidade deve ser considerado como importante parte na teoria da complexidade, pois muitos sistemas complexos são nãolineares (DOROGOVTSEV; MENDES, 2002; BOCCALETTI et al., 2006). Assim como, também há muitos sistemas dinâmicos não-lineares que não consistem necessariamente em um sistema complexo (BOCCALETTI et al., 2006).

Em geral, feedbacks podem levantar a complexidade mesmo em sistemas lineares. Nem dinâmicas não-lineares ou dinâmicas lineares são necessários para complexidades, pois cientistas também estudam estruturas estatísticas que podem vir somente por dinâmicas não-lineares e lineares simultaneamente (KOCSIS; KUN, 2008; STERMAN, 1994).

\subsubsection{Feedback,interações e heterogeneidade}

Feedback é uma condição necessária e primordial para a dinâmica dos sistemas complexos. Uma parte do sistema recebe feedbacks de seus vizinhos, da qual, sua resposta depende de como eles interagiram em tempos anteriores(CHARLET; LÉVINE; MARINO, 
1989). Exemplo frequentemente utilizado, na revoada de pássaros,cada membro do grupo realiza um percurso que dependerá da proximidade e ritmo de pássaros ao seu redor. Após os ajustes do percurso, todos os seus vizinhos também realizarão modificações em resposta aos outros pássaros; assim, quando ao realizarem as próximas movimentações, os pássaros levarão em conta o comportamento passado de seus vizinhos(URRY, 2005).

A diversidade de possíveis reações em cada agente pode ser computada como heterogeneidade. Por exemplo, ao contrário da homogeneidade, na qual os agentes possuem comportamentos e padrões de respostas similares, consumidores podem ter diversos graus de aceitação em inovação, sensibilidade ao preço e necessidades (GOLDER; TELLIS, 1997; SONG; CHINTAGUNTA, 2003).

Somente a presença de feedback e heterogeneidade no sistema não é suficiente para complexidade, pois os indivíduos precisam fazer parte um grupo suficientemente grande para exibir complexidade, e também porque os feedbacks precisam levar a algum tipo de associação de nível mais elevado. Por exemplo, as formigas individualmente ainda que não tenham ideia do que estão fazendo, são capazes de completar tarefas complexas como a construção de pontes e canais. Ela comportam deste jeito devido as interações com seus pares(PARUNAK, 1997).

\subsubsection{Robustez e falta de controle central}

Sistemas complexos são tidos como robusto, pois eles não são produzidos centralmente, tornando-se assim estável frente as pertubações aleatórias do sistema (PAGE, 2010). No exemplo dado sobre revoada de pássaros, ainda que os indivíduos apresentem comportamentos erráticos, eles são estáveis no senso de que o tempo para ajuste é adequado para que não ocorra batidas entre eles.

Um sistema com controle central por outro lado, pode ser vulnerável por causa do mal funcionamento de algumas poucas peças. Enquanto a falta de um controle central é um aspecto de sistemas complexos, não obstante, ele por si só não é um determinante suficiente pois há sistemas não-complexos que também apresentam inexistência de controle central.

Um sistema pode manter sua ordem utilizando mecanismos de auto-correção. Robustez parece ser uma peça importante mas não suficiente para complexidade, uma vez que, um sistema aleatório pode ser chamada de robusto em determinado contexto dado que as pertubações não o afetam (WANG; CHEN, 2002).

Um bom exemplo de robustez é a estrutura climática da terra e as estações. Ela é relativamente estável e regular ao estimar o contexto dinâmico não-linear da velocidade do vento, temperatura, pressão e umidade (ANDERIES; JANSSEN; OSTROM, 2004; LEVIN; LUBCHENCO, 2008; CILLIERS; SPURRETT, 1999). 


\subsubsection{Organização hierárquica}

Há muitas vezes, variados níveis de organização que podem ser imaginadas como hierarquias de sistemas e sub-sistemas complexos, tal como proposto por Herbert Simon em "arquitetura da complexidade"(SIMON, 1991).

Emergência ocorre devido as interações entre partes com níveis hierárquicos menores e a robustez está dentro de um regime particular destas interações (BARABÁSI; ALBERT, 1999).A título de exemplo, a interação entre os neurônios impulsiona a emergência da cognição (o cérebro e as faculdades mentais) ,mas somente possui robustez operacional em uma escala de temperatura até 3 graus Celsius a mais que a temperatura normal do corpo humano.

O resultado geral observado nos sistemas complexos é que os agentes organizamse em níveis variados de estrutura e propriedades, sendo alguns com níveis superiores e inferiores,marcados por diferentes tipos de simetria, ordens e comportamentos periódicos (GRIMM et al., 2005). Um exemplo não-vivo desta organização são os cosmos, em suas estruturas de átomos, moléculas, gases, líquidos, tipos químicos e geológicos, e por último as estrelas e galáxias (BOCCALETTI et al., 2006).

\subsection{Redes complexas}

Em uma breve definição, uma rede é composto por elementos interconectados. As redes tratam-se de abstrações das variadas relações presentes na natureza (BARABÁSI, 2014). Encontradas na química e física ,nas ligações atômicas; passando pela biologia,nas vias metabólicas, sistema circulatório e neurônios do cérebro; pela tecnologia, estradas, distribuição de energia e internet; as redes são onipresentes em nossa representação de mundo, até mesmo nas relações sociais.

A origem das redes como objeto de investigação é atribuído a Leonard Euler e a sua representação gráfica das pontes de Königsberg no século 18. O conjunto de pontes foram denominadas como grafos, um conjunto de nós (vértices) conectados por ligações (arestas). Desde então, a chamada Teoria dos Grafos, área da matemática discreta que estuda estas estruturas, é a principal linguagem de descrição das propriedades das redes (NEWMAN, 2001; WATTS; STROGATZ, 1998)

Utilizando o ferramental dos grafos para investigação das redes sociais, a análise de redes sociais (SCOTT; CARRINGTON, 2011) surge por volta da primeira metade do século 20, com maior interesse na sociologia. Seus pesquisadores desenvolveram técnicas de levantamento empírico de pequenos grupos e papel dos indivíduos, com destaque para medidas de posicionamento e centralidade.

Recentemente, porém, a atenção se voltou para as redes complexas (DOROGOVT- 
SEV; MENDES, 2002; BARABÁSI; ALBERT, 1999; BOCCALETTI et al., 2006), em que combina-se investigação empírica de largas redes e desenvolvimento do arcabouço teórico.

\subsubsection{Redes regulares e redes aleatórias}

Redes regulares são compostos por vértices conectados pelo mesmo número de arestas $K$. Assim, por exemplo, redes regulares $K=2$ apresentarão vértices conectado a outros dois outros vértices.

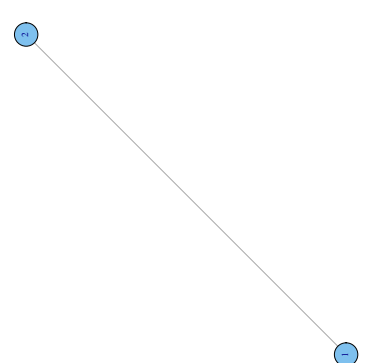

(a) $\mathrm{K}=1$

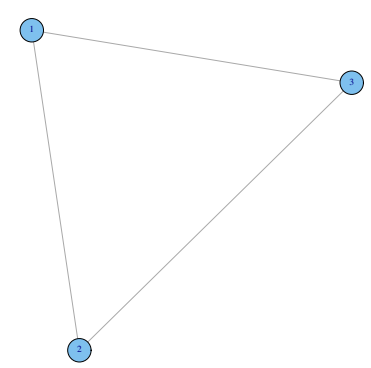

(b) $\mathrm{K}=2$

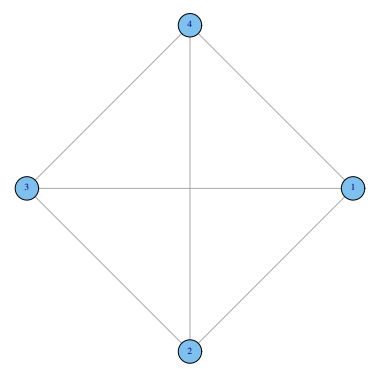

(c) $\mathrm{K}=3$

Figura 1 - Redes regulares

As redes aleatórias desenvolvidas por Erdos e Rényi (1960), exibem grafos com $n$ vértices e $k$ arestas, da qual, cada aresta conecta-se com probabilidade $p$ igual a qualquer vértice $G(n, p)$. Ela pode ser descrita por uma distribuição binomial sendo $\mathrm{n} \rightarrow+\infty$ :

$$
p(k)=\left(\begin{array}{c}
n-1 \\
k
\end{array}\right) p^{k}(1-p)^{n-1-k}
$$

Apesar destas estruturas de rede não corresponderem aos levantamentos empíricos de redes reais ,o estudo das redes aleatórias trouxe uma noção conceitual sobre as redes, ao demonstrar que redes não apresentam crescimento linear conforme $p$, mas sim de maneira errática e abrupta posteriormente identificados em redes small worlds e scale free worlds(ERDŐS; RÉNYI; SÓS, 1966).

\subsubsection{Redes Small World}

As redes small worlds podem ser definidas pela combinação de caminhos curtos entre as vértices, característica presente em redes aleatórias, e um alto coeficiente de aglomeração, exibido em redes regulares (WATTS; STROGATZ, 1998). Oriundo do processo de interpolação entre uma rede regular e uma rede aleatória, origina-se uma rede small worlds, em que cada aresta é religada com probabilidade $P_{\mathrm{r}}$ a um vértice aleatoriamente escolhido: 


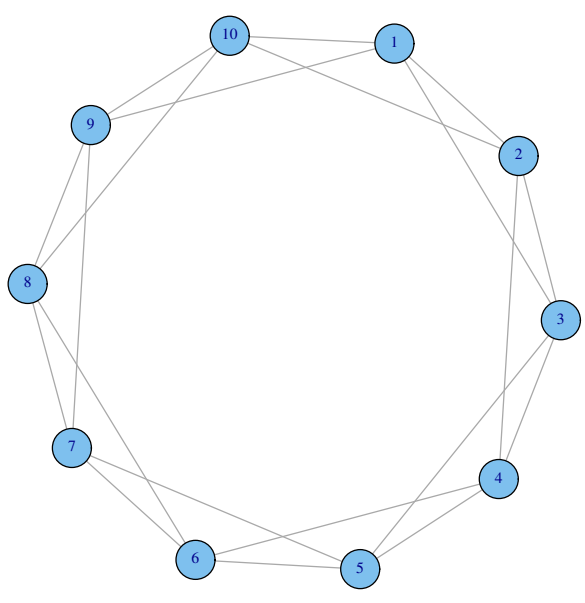

(a) $P_{\text {relig }}=0$

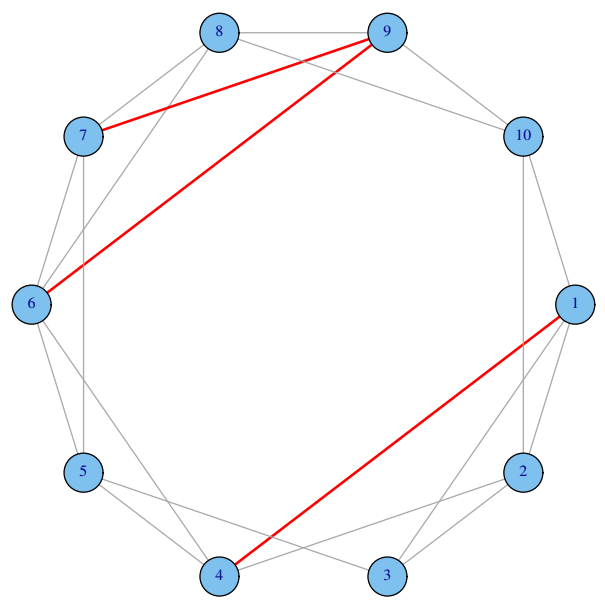

(b) $P_{\text {relig }}=0.01$

Figura 2 - Rede regular e rede small world

A distância $L$ entre duas vértices aleatórias cresce logaritmicamente conforme o número de vértices $N$. Ou seja, a distância média entre os vértices decai e estabiliza rapidamente conforme $P_{r}$,enquanto o coeficiente de aglomeração decai suavemente.

$$
L \infty \log N
$$

Este tipo de rede também foi encontrado em diversos outros ramos como biológicas e tecnológicas. De acordo com Watts e Strogatz, estas redes de alguma maneira se encontravam a meio caminho entre a regularidade e a aleatoriedade.

\subsubsection{Redes Scale Free}

Muitas redes investigadas apontavam distribuições de grau $K$ regidas pela lei de potência, Barabási e Albert (1999) propôs um modelo conceitual que gere redes com os dois seguintes atributos: crescimento contínuo e ligação preferencial.

Inicia-se um grafo com $n$ vértices, esta rede cresce conforme adiciona-se repetidamente um novo vértice à vértices já presentes na rede utilizando-se ligação preferencial. A ligação preferencial constitui-se em selecionar uma vértice com probabilidade $p$, sendo esta proporcional ao $k$ de conexões totais.

A distribuição de grau também é notavelmente diferente entre redes aleatórias e redes scale free conforme gráfico abaixo sendo a primeira semelhante a distribuição normal e a segunda pela distribuição marcada pela lei da potência: 


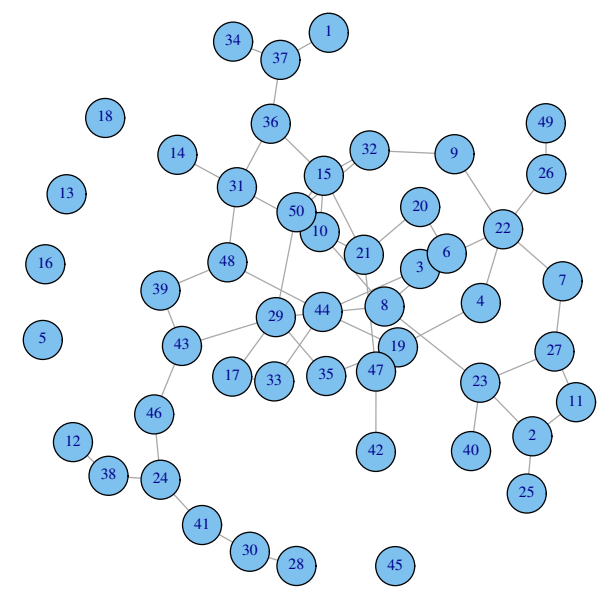

(a) Formato aleatório

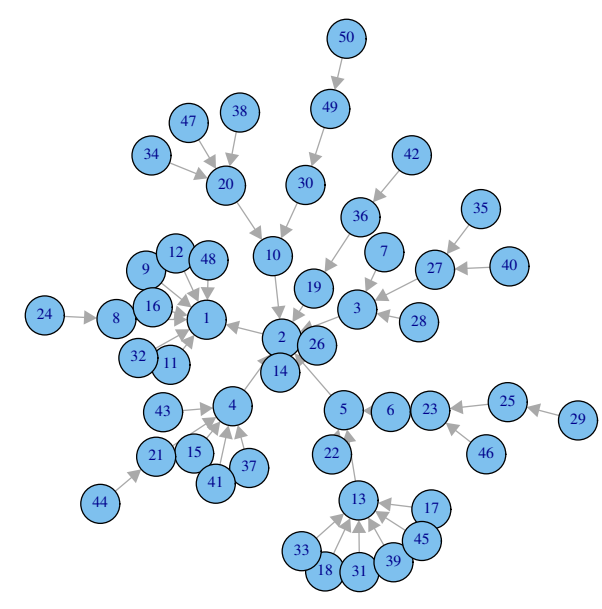

(b) Formato free scale

Figura 3 - Formato regular e Scale free

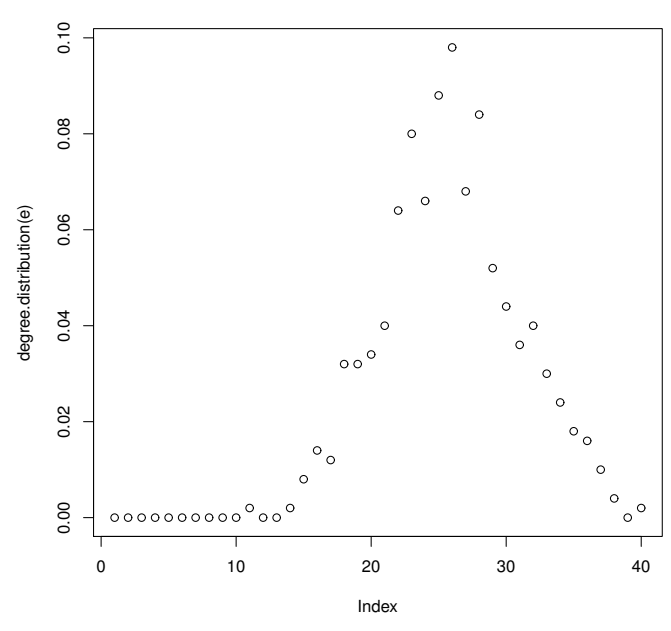

(a) Distribuição aleatória

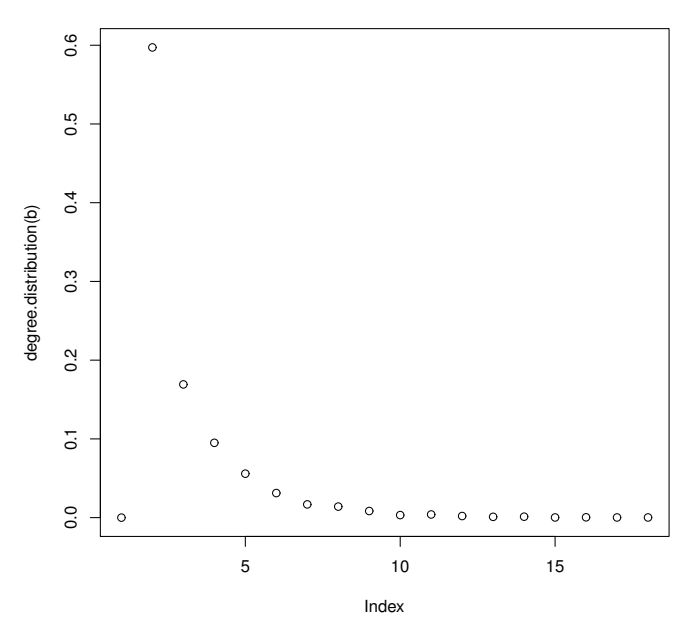

(b) Distribuição free scale

Figura 4 - Distribuição de grau para rede aleatória e scale free

\subsection{Difusão de inovações}

\subsubsection{Difusão de novos produtos - Uma breve revisão}

A propagação de uma inovação no mercado é comumente denominada como "difusão de novos produtos". As pesquisas em difusão buscam entender a propagação de inovação modelando o ciclo de vida do produto (CVP), ponderando as diferentes percepções dos consumidores.

O lançamento de novos produtos desempenha papel crucial entretanto as empresas estão sujeitas a inúmeros riscos dado sua impredicabilidade frente aos resultados (COOPER, 2001; WHEELWRIGHT, 2010). Sendo o lançamento de produtos uma etapa 
importante e consumidora de recursos, seu objetivo maior é capturar o maior número de adotantes possíveis conforme ilustra a figura 5b.

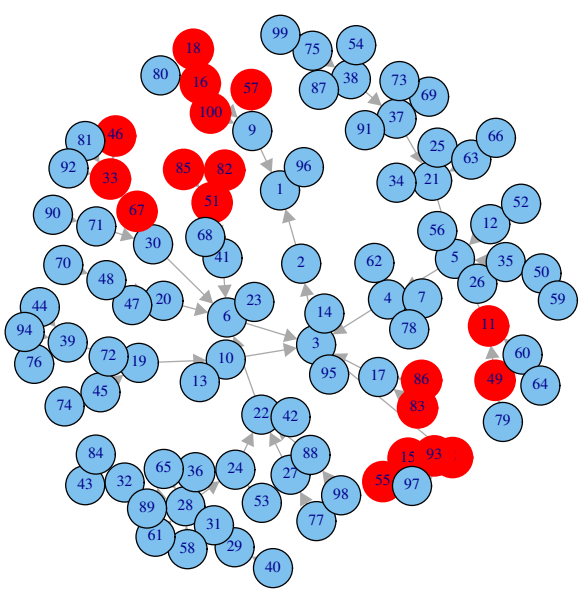

(a) Difusão falha

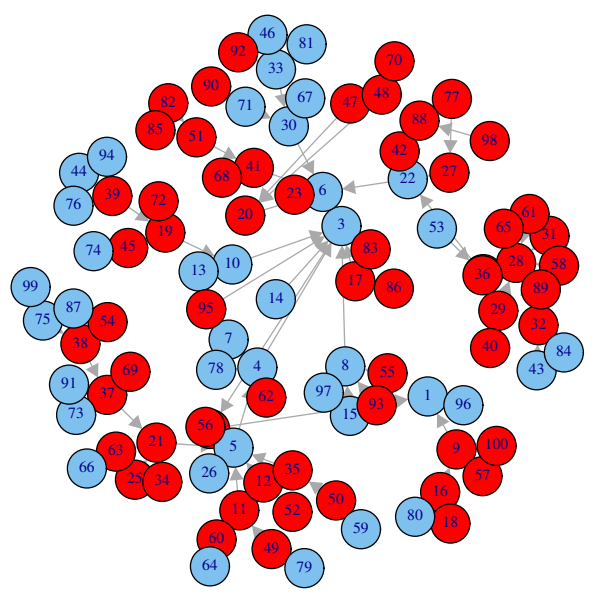

(b) Difusão com sucesso

Figura 5 - Difusão de novos produtos na rede

Bass (2004) iniciou o desenvolvimento formal de métodos preditivos por meio de equações capazes de inferir o sucesso de produto a partir sua penetração inicial no mercado (MAHAJAN; MULLER; BASS, 1990) conforme 2.3.

$$
N_{t}=\left(m+p+q N_{t}\right)\left(m+1-N_{t}\right)
$$

Na qual a versão diferenciada da equação é dada como:

$$
d N_{t}=p\left(m-N_{t}\right)+(q / m) N_{t}\left(m-N_{t}\right)
$$

Sendo N o número acumulativo de adotantes em (t). Já $p$ é o coeficiente de inovação, implicando que uma certa porcentagem de agentes adotam o produto de forma independente em cada salto de (t). O coeficiente de imitação, q, representa o efeito do boca a boca em que os já adotantes propagam informações à potenciais adotantes em (t).O total de adotantes sobre (t) é representado pelo coeficiente m.O modelo de Bass declara que a possibilidade de um indivíduo adotar uma inovação se dá linearmente, pois baseia-se no número anterior de adotantes. Os parâmetros $\mathbf{p}, \mathbf{q}$ e $\mathbf{m}$ podem ser estimados empiricamente Jiang, Bass e Bass (2006).

No entanto, a proliferação de novos produtos em comunicação, entretenimento e informação somado as tendências de globalização, resultaram em processos de difusão que vão além dos cenários clássicos descritos nos modelos de Bass.

A proposta desta seção é revisar a teoria de difusão sobre a ótica dos sistemas complexos, mais especificamente,pela teoria das redes complexas. A teoria de difusão derivado 
dos modelos de Bass é fortemente baseado na comunicação interpessoal (MAHAJAN; MULLER; BASS, 1990; BASS; JAIN; KRISHNAN, 2000), por outro lado, os sistemas complexos estendem sua estrutura teórica para diferentes elementos sociais interdependentes (BULTE; LILIEN, 2001; GOLDENBERG et al., 2009).

O quadro 2.3.1 pontua resumidamente as diferenças teóricas entre o modelo de Bass e suas variações, e o ponto de vista dos sistemas complexos.

\begin{tabular}{cc}
\hline Foco anterior & Sistemas Complexos \\
\hline Crescimento uniforme da curva de penetração & Irregularidades no crescimento \\
Modelos de análise agregado & Modelos de análise individual \\
Agentes conectados integralmente & Parcialmente conectados \\
Temporalidade na difusão & Espacialidade \\
\hline
\end{tabular}

\subsubsection{Difusão baseada na modelagem por agentes - uma diferente perspectiva}

O modelo de difusão desenvolvido por Norton e Bass (1987), foi capaz de chamar atenção para este campo, encoranjando o desenvolvimento sucessivo de ferramentas preditivas em diversos campos da ciência, tais como: epidemiologia (MORRIS, 1993), logística (HO; SAVIN; TERWIESCH, 2002) e marketing (BASS; JAIN; KRISHNAN, 2000).

No entanto, os pressupostos implícitos do modelo suas muitas outras extensões (JIANG; BASS; BASS, 2006; BASS, 2004; MAHAJAN; MULLER; BASS, 1990) suscitam inúmeros questionamentos. Modelos agregados de difusão possuem vantagens e pontos fracos: eles são parcimoniosos e requerem um conjunto pequeno de dados para estimação dos parâmetros e predição; por outro lado, eles dispõe de poucas informações de como as interações individuais estão ligados com o macro comportamento do mercado(PARKER, 1994).

Um vasto número de pesquisas em redes sociais atestam nossa percepção cotidiana de que as pessoas não são homogêneas e muito menos possuem elos com todas as outras pessoas (KOSSINETS; WATTS, 2006) - pressupostos inerentes do modelo de Bass - pesquisas sobre difusão estão gradualmente estendendo seu escopo ao avaliarem perspectivas ao nível do indivíduo.

Um dos métodos para descrever a tomada de decisão por cada indivíduo e analisar o seu resultado coletivo, é através da modelagem por agentes.Ela é capaz de descrever o mercado como uma coleção de elementos individuais (entidades, agentes ou nós), interagindo entre eles através de conexões. O comportamento de cada indivíduo é determinado por um conjunto de regras pré-estabelecidos (RAND; RUST, 2011).Tal modelo pode superar as limitações levantadas dos modelos de difusão. 
Primeiramente, ao estabelecer conexões entre as decisões individuais e os seus efeitos sobre o macro mercado, esta perspectiva disponibiliza maior poder explicativo a respeito dos fatores influenciadores.Por exemplo, atividades de marketing podem alterar as regras de decisão em cada consumidor de forma distinta e consequentemente modificar performance geral.

Segundo, esta abordagem permite distinguir a interdependência entre os agentes. Por exemplo, Goldenberg et al. (2009) explora a heterogeneidade dos agentes ao adicionar diferentes graus de aceitação em inovação em cada um. Outra vantagem da modelagem baseada por agentes é a sua habilidade em considerar aspectos espaciais da difusão,usualmente denominado de topologia.Kiesling et al. (2012) efetua uma meta-análise sobre a literatura em difusão de produtos e considera a topologia como elemento-chave na difusão (BARABÁSI; ALBERT, 1999; NEWMAN, 2003).

Por fim, o modelo pode ser adaptado afim de incluir aspectos diversos em seus agentes,tais como: resposta individual para propagandas (LIBAI; MULLER; PERES, 2005), presença sobre comunicação negativa do boca-boca (GOLDENBERG et al., 2007), atitude intrínseca em inovação para cada agente (GOLDENBERG; LIBAI; MULLER, 2002), presença de grandes usuários e conectores (KUMAR; PETERSEN; LEONE, 2007) e o papel dos especialistas na propagação do produto (GOLDENBERG et al., 2009).

\subsubsection{Componentes da difusão de novos produtos}

\subsubsection{Externalidades de rede}

Externalidade de rede existe quando a utilidade de um produto para o consumidor aumenta, a medida que mais consumidores adotam os novos produtos (ROHLFS; HOFFMEISTER, 2003).Externalidades de redes são contabilizados como benefícios diretos,se a utilidade é diretamente atrelado ao número de outros usuários adotantes.Por exemplo, produtos de telecomunicação e serviços como e-mail, aplicativos de conversa, telefone e banco possuem este atributo.

Externalidades de rede podem também afetar indiretamente se, a sua utilidade aumenta com o número de usuário de produtos complementares. Por exemplo, o aumento da adoção de aplicativos de conversa aumenta com a penetração de celulares mais tecnológicos (BINKEN; STREMERSCH, 2009).

Comunicação interpessoal não é realmente necessário para que haja externalidade de rede. Adotadores em potencial podem descobrir sobre o nível de penetração do produto pela mídia ou simplesmente observando as ofertas no varejo. Por exemplo, durante a transição entre os celulares para os smartphones,o consumidor tinha que simplesmente andar pelas lojas e observar o espaço devotado para smartphones para entender que o smartphones era o novo padrão. 
A dinâmica da externalidade de redes tem recebido considerável atenção nas duas décadas passadas (STREMERSCH; TELLIS, 2002).Ainda assin, não há consenso sobre o efeitos da externalidade de rede na taxa de crescimento. A sabedoria convencional sugere que os efeitos de rede dirigem à um crescimento mais rápido do mercado dado aos maiores retornos associados com o processo (NAIR; CHINTAGUNTA; DUBÉ, 2004).

No entanto, rede também pode criar o efeito contrário, freando o crescimento com o que foi denominado como "inércia excessiva"(SRINIVASAN; LILIEN; RANGASWAMY, 2004). No começo do ciclo de vida produto, muitos consumidores visualizam pouca utilidade no produto assim como eles são poucos adotadores;muitos irão ter a atitude de esperar e observar até que haja mais adotadores.

Portanto, difusão inicial pode ser bem lenta e ocorrer primariamente entre alguns poucos consumidores que antevem utilidade no produto mesmo com a falta de adoção pelos outros. Em geral, o processo pode ser caracterizado por uma combinação de inércia excessiva e excesso de oferta. Por exemplo, baixo crescimento seguido por uma onda de crescimento (BULTE; STREMERSCH, 2006).

Este padrão de crescimento pode ocorrer em diferentes tipos de externalidades de rede. No caso de efeitos diretos, o número de adotantes dirige a utilidade diretamente porque a utilidade aumenta com o seu respectivo número de adotantes. Um endereço eletrônico não é útil se quase ninguém o possui. Em relação aos efeitos indiretos da rede, como o caso de sistemas operacionais para celulares (por exemplo, quantidade de aplicativos para determinados sistemas operacionais) que é o resultado do número de adotantes(PAN; AHARONY; PENTLAND, 2011).

Consumidores geralmente esperam para adotar equipamentos até que haja programas suficiente para fazer valer a pena. Em adição à isso, na competição por padrões, adotantes iniciais arriscam-se em escolher padrões que podem não se consolidar e ficar obsoletos, assim muitos consumidores esperaram para ver definições claras do padrão consolidar e, mais importante, qual padrão ou plataforma não será continuado.

O impacto da externalidade de rede na taxa de crescimento pode ser determinado pela fonte de externalidades sobre o exame global ou local. Sobre a externalidade global, o consumidor considera o sistema social inteiro quando avalia a utilidade de um produto em termos de números de adotantes, enquanto sobre externalidade local, o consumidor considera a adoção em relação à sua rede social mais próxima. Pesquisas estão gradualmente considerando externalidades globais em externalidades locais (BINKEN; STREMERSCH, 2009; DELRE; JAGER; JANSSEN, 2007).

As decisões de marketing que a empresa toma podem influenciar os tipos de externalidade que podem ser relevantes: crescimento na competição por padrões pode provavelmente invocar um efeito sobre global pois o veredito sobre o que eventualmente 
transformou-se em padrão depende do número de usuários totais. Em contraste, um programa de pacote de telefone móvel para os integrantes de uma família possuem efeitos locais pois ela envolve somente uma parte do sistema social.

O desafio está em integrar externalidades de redes em modelos de difusão sobre os múltiplos efeitos dos adotantes inicias na taxa de crescimento. Estes usuários geralmente influenciam a taxa de crescimento por meio do boca-boca e imitação, da qual são tipicamente reduz o risco e custo de procura.

Ainda, a mera adoção aumenta os efeitos da rede, consequentemente incrementando seu crescimento. A literatura na modelagem de difusão de inovação geralmente não separa estes dois fatores, e um único parâmetro para influência interna é usada para capturar os efeitos da comunicação interpessoal e as externalidades da rede (BINKEN; STREMERSCH, 2009).

Goldenberg et al. (2009) separou os dois efeitos ao propor na literatura de ações coletivas relacionado aos efeitos de rede com os limiares de adoção para os consumidores individuais. Foram descobertos que as externalidades de rede possuem um efeito de preparação da rede sem incrementar o número de usuários iniciais, seguido por uma onda de difusão mais agressiva e consistente (GATIGNON, 2010; RAND; RUST, 2011).

\subsubsection{Sinais sociais e heterogeneidade dos consumidores}

Sinais sociais relacionam-se com informações sociais que indivíduos inferem a partir da adoção por outros agentes. Estes sinais são transmitidos para outros indivíduos, que seguem o comportamento de pessoas pertencentes a grupos aos quais aspiram vincular-se (SIMMEL, 1957).

Sinais sociais operam vertical e horizontalmente. Um sinal social vertical indica status do adotante. Pesquisas recentes indicam que a competição por status é um importante fator de crescimento, algumas vezes, mais importante que as relações interpessoais e a utilidade técnica do produto, e a velocidade de difusão aumenta em sociedades sensíveis às diferenças de status (BULTE; STREMERSCH, 2006).

Sinais sociais também são transmitidos horizontalmente para indicar comunhão coletiva. A adoção de uma inovação por um agente pertencente em determinado grupo sinaliza aos seus outros membros a adotarem também a inovação afim de fortalecer esta identidade comunitária e diferenciar das demais (BERGER; HEATH, 2008).

Distinções podem ser realizadas entre sinais sociais e outros tipos de sinais, tais como os sinais funcionais. Sinais funcionais contém informações em relação à percepção do mercado sobre os atributos e funcionalidades de um produto, tal como a qualidade ou a quantidade de risco envolvido em sua adoção, por outro lado,sinais sociais contêm informações relacionados as consequências e riscos sociais em adotar um produto. 
Apesar da crescente evidência sobre a importância da comunicação interpessoal na adoção de produtos, uma ramificação emergiu e ele argumenta que o principal condutor no crescimento de novos produtos é a heterogeneidade do consumidor (BOHLMANN; CALANTONE; ZHAO, 2010; GOLDER; TELLIS, 1997; IYENGAR; BULTE; VALENTE, 2011). Esta abordagem reivindica que cada agente são diferentes um dos outros em termos de sensibilidade ao preço,percepção e necessidades, conduzindo assim a diferentes ponderações na tomadas de decisão (BEMMAOR, 1994; SONG; CHINTAGUNTA, 2003).

\subsubsection{Pontos críticos de crescimento e desaceleração na difusão}

Na década passada, uma vertente da literatura em gestão de produtos emergiu em que se examina fases chaves em todo ciclo de vida do produto:decolagem e sela, e que não incluem a clássica curva de adoção suave (KIESLING et al., 2012; EMMANOUILIDES; DAVIES, 2007; GOLDBERGER et al., 2000).

O modelo clássico de Bass começa com uma adoção inicial por um grupo de adotantes espontaneamente mas não providencia explicações mais detalhadas a respeito dos mecanismos que guiam esta adoção inicial, ou decolagem(JIANG; BASS; BASS, 2006).

Golder e Tellis (1997) definem o tempo requerido para decolagem como o prazo em que há um incremento dramático em vendas, na qual, distinguem-se claramente as etapas de introdução e fase de crescimento do produto. A importância em compreender o tempo requerido de decolagem em uma companhia faz-se relevante em diversas ocasiões. A título de exemplo, um incremento rápido nas vendas pode requerer investimentos massivos em produção, distribuição e marketing, na qual muitas vezes envolve considerável tempo de espera para que as operações consolidem com sucesso.Os mesmos pesquisadores aplicaram um modelo de sobrevivência sobre os dados de 31 produtos inovadores de diversas categorias nos Estados Unidos entre 1898 e 1990. Eles descobriram que o tempo de decolagem para produtos introduzidos antes da segunda guerra mundial era de 6 anos e a média em $\%$ de participação no mercado antes da decolagem era de 1,7\%. O preço na fase de decolagem estava precificado em $63 \%$ do seu preço original. Estudos diversos investigam fatores e causam que influenciam o tempo requerido para decolagem. Redução de preço e o tipo de produto são importantes catalisadores.Por exemplo, a linha marrom de produtos tais como notebooks, televisores,sistemas de som e celulares possuem decolagem mais rápida do que a linha branca, composta por geladeira,fogão e depurador de ar,dado envolvimento social maior desta linha de produtos (TELLIS; GOLDER; FOSTER, 2004).

As decolagens não requerem qualquer tipo de interação inicial entre consumidores. Ao invés disso, eles são resultados da heterogeneidade do agente quanto à sensibilidade ao preço e risco, pois assim que o preço é reduzido, a dotação torna-se menos arriscada.A heterogeneidade é um condutor dominante, mas a interação entre consumidores torna-se a força imediata posteriormente. Como já iniciado pela revisão de Mahajan, Muller e Bass 
(1990), há uma necessidade em compreender a teoria que sonda o crescimento inicial, antes mesmo da decolagem.

Após a decolagem, os modelos de difusão retratam incremento suave das vendas. No entanto, em alguns mercados, um repentino decréscimo inicial pode resultar em crescimento consistente posteriormente. Este decréscimo em vendas foi observado por Moore e Benbasat (1991),eles categorizam este declive como lacuna entre o mercado inicial e o mercado principal, que posteriormente foi formalizado e explorado por Mahajan e Muller (1998), Goldenberg, Libai e Muller (2002), Tellis, Golder e Foster (2004), Vakratsas e Kolsarici (2008)

Goldenberg, Libai e Muller (2002) refere ao termo"sela"como a curvatura formada pelos picos iniciais de crescimento que antecedem quedas substanciais em vendas por um longo prazo, seguido pelo incremento de vendas que eventualmente excederia o pico inicial de vendas. A sela pode ser atribuída à mudanças de tecnologia,eventos macroeconômicos e interações entre consumidores.Tellis, Golder e Foster (2004), assim como Chandrasekaran e Tellis (2006), reivindicam que a sela pode ser elucidado respaldando-se na estrutura teórica de difusão da informação. Por exemplo, um grupo de adotantes em potencial, divididos em 2 turmas. Um dos agentes adotam a inovação as vendas,no entanto, há um baixo nível de comunicação entre eles, podendo assim apresentar um intervalo de adoção entre eles (GOLDENBERG; LIBAI; MULLER, 2002; GOLDENBERG et al., 2007; MULLER; YOGEV, 2006). Estas evidências demonstram como a combinação entre heterogeneidade e interação entre agentes é capaz de explicar fenômenos e particularidades desconsideradas no típico modelo com curva em formato de sino.

\subsubsection{Geração tecnológica}

O processo usual em difusão é encerrado pelo decaimento expressivo de novos adotantes e a saturação do mercado potencial. Na prática, no entanto, produtos são substituídos por novas gerações de produtos frequentemente. Novos produtos são introduzidos ao longo das sucessivas gerações tecnológicas e esta dinâmica acompanhou o interesse de acadêmicos na área de marketing tais como Jiang, Bass e Bass (2006), Bass (2004), Norton e Bass (1987).

Uma questão recorrentemente examinado é se a taxa de difusão torna-se mais célere ou retardada entre as gerações tecnológicas conseguintes. Esta questão coloca em pauta a importância da projeção ao desenvolver gerações mais avançadas do produto, e questionar se os parâmetros de difusão das gerações anteriores são ainda cabíveis. Outra relevante indagação refere-se ao sistema social.Ele melhora as habilidades de adoção entre as diversas gerações ou a difusão inicia novamente a partir do zero? Se há habilidades aprendidas, quão forte e em quais categorias eles estão? Stremersch e Tellis (2002) indicam que a literatura oferece respostas contraditórias. O ponto-chave ou pressupostos destes 
diversos estudos entre múltiplas categorias de produtos é que o parâmetro de crescimento são constantes entre as diversas gerações (BASS, 2004; KIM; CHANG; SHOCKER, 2000; MAHAJAN; MULLER; BASS, 1990).

Bayus (1994) por exemplo, usou modelos de sobrevivência para analisar o processo difusor de computadores pessoais com 4 gerações,ele apresenta indícios de que a vida média de cada geração não diminuiu ao longo do tempo. Isto era factível até mesmo para variáveis críticas incluídas na análise , tais como ano de entrada e tecnologia usada. No entanto, há da mesma forma, um grande arcabouço de evidências sugerindo que o padrão temporal de difusão das inovações acelera ao longo do tempo (BULTE; STREMERSCH, 2006; KOHLI; LEHMANN; PAE, 1999).Em análises mais recente, Bulte e Lilien (2001), Iyengar, Bulte e Valente (2011) possuem indicativos de que esta aceleração ocorre. Os pesquisadores fixaram o parâmetro interno de influência (p) em zero no modelo de Bass e ao simularem o modelo utilizando dados de trinta e uma categorias de produtos de consumo e produtos domésticos, obtiveram em $2 \%$ a média anual de aceleração entre 1946 e 1980.

Estas duas linhas de pesquisa formam um paradoxo intrigante: aparentemente, na mesma economia, a aceleração de difusão do produto sobre o tempo deve refletir na aceleração de difusão de tecnologias posteriores; no entanto, as taxas de difusão das tecnologias que sucedem uma à outra; permanecem constante. Uma possível resolução desta questão foi sugerido recentemente por Stremersch e Tellis (2002), ao notar uma constância nos parâmetros de crescimento, mas um encolhimento no comprimento de tempo para decolagem em cada geração sucessiva.

\subsection{Gestão de marketing na difusão de novos produtos}

A introdução com sucesso de novos produtos no mercado faz-se importante para a sobrevivência e crescimento das companhias. No entanto, muitos produtos falham e a taxa de insucesso aproxima-se dos 70\% (COOPER; EDGETT, 1996; COOPER; KLEINSCHMIDT, 2011; COOPER; EDGETT, 2012).

O tipo de estratégia empregado no lançamento é um fator determinante para o desempenho do novo produto. Um novo produto pode ser altamente inovador, embarcado em tecnologias superiores aos dos seus concorrentes, mas ainda assim, pode falhar devido a baixa performance no lançamento da inovação (YANG et al., 2012). Durante a introdução de novos produtos (antes da decolagem), pessimismo e pressão sobre os administradores aumentam. Durante a fase de crescimento (antes da frenagem), otimismo rodeia dos administradores e muitos estão ansiosos em aumentar capacidade e esforços de marketing para satisfazer a demanda. Predizer os pontos críticos de decolagem e desaceleração são essenciais para retiradas prematuras ou investimentos em excesso(ZHANG; ZHANG, 2007). 
Somado a isto,o nível e crescimento das vendas varia dramaticamente ao longo do ciclo de vida do produto. Administradores precisam entender estas mudanças apropriadamente, afim de planejar os níveis correspondentes de produção, inventário, venda da equipe, distribuição, marketing e comunicação(KOTLER; KELLER, 2006; MANGOLD; FAULDS, 2009).

Os preços decaem substancialmente ao longo do ciclo de vida, mais substancialmente, durante os estágios iniciais,à medida que novos concorrentes desembarcam. Em contraste, a sensibilidade ao preço aumenta para os consumidores no decorrer do ciclo (GOLDER; TELLIS, 1997; GOLDSMITH; NEWELL, 1997). Administradores precisam entender os padrões de venda e mudar suas estratégias conforme. Por causa do impacto crítico na estratégia de marketing, o ciclo de vida do produto se tornou peça central no marketing(ROGERS, 2010).

Apesar de muitos pesquisadores mirarem na identificação de quais são as estratégias de lançamento mais eficientes (ALI; KRAPFEL; LABAHN, 1995; DELRE; JAGER; JANSSEN, 2007; YOUNG, 2006; KOSSINETS; WATTS, 2006), a relação entre estratégias de lançamento e a performance de novos produtos ainda não são conclusivamente compreendidas.

Os pontos investigados neste tópico são variáveis de marketing concernentes ao nível táticas de produtos, fatores das quais podem ser controlados diretamente pelos tomadores de decisão. Para tanto, são explorados os pontos (1) tipo de produto e o comportamento social de consumo e (2) estratégias de precificação.

\subsubsection{Tipos de produtos - Social e não-social}

Há características de algumas categorias de produtos que exibem os efeitos de rede, causadores de dinâmicas competitivas únicas que podem mudar os padrões de respostas do consumidor. A literatura demonstra que o tempo para decolagem difere substancialmente para diferentes tipos de produtos (GOLDER; TELLIS, 2004).

As inovações tecnológicas conduzem o progresso da sociedade. A qualquer tempo, uma nova tecnologia, um novo aparelho, um novo produto aparece na sociedade, e seus membros possuem a chance de se tornarem conscientes da inovação e relatar-se à eles. Quando a inovação é um bem de consumo da qual seu consumo é individual, consumidores individuais podem decidir em adotar ou não.

O estudo dos padrões de difusão de novos produtos em sociedades de consumo, do seu lançamento com sucesso ou insucesso, está relacionado intimamente aos administradores e profissionais de marketing interessados em disseminar novos produtos na sociedade. Recentemente, o mercado tem dado atenção às inúmeras novas modas de alcance global e os inúmeros desdobramentos que a acompanham (LAMBERTINI; ORSINI, 2000). 
Aparentemente, em contextos propensos à atividades de cunho social tais como o mercado de roupas, muitos inovações surgem de pequenos eventos relacionados com a dinâmica de pequenas redes locais. Como mencionado anteriormente, através dessas compras, indivíduos podem sinalizar tanto diferenças sociais quanto identificações coletivas (BOURDIEU, 1984; SIMMEL, 1957).Desta forma, essa tendência em moda é adotada por alguns poucos adotantes iniciais,estes mais facilmente influenciáveis por novas tendências, e uma vez que a massa crítica é alcançada, a difusão alcança o seu pico pois quase todos os consumidores potenciais decidem se conformar assim como os agentes mais racionais e céticos (ROGERS, 2010; BOHLMANN; CALANTONE; ZHAO, 2010). Ademais, há outros mercados na qual os consumidores decidem somente de acordo com suas preferências pessoais sem considerar o que terceiros decidiram ou não.Os modelos de difusão propõe que as inovações frequentemente emergem e expandem rapidamente em mercados na qual consumidores tomam pesadamente as considerações dos outros. É muito acessível lançar modas, se a difusão é armado em sociedade altamente suscetíveis,tais como em grupos de jovens amigos que cuidadosamente observam uns aos outros.

Em particular, os modelos de simulação ignoram influências sociais que podem desempenhar um papel crítico na tomada de decisão do consumidor sobre um produto;por exemplo, em mercados de modas - os consumidores não trocam informações sobre produtos mas também normas inerentes ao comportamento social (CIALDINI; GOLDSTEIN, 2004). No mercado de roupas para esporte, muitas marcas recebem o endorso de pessoas ilustres . Estas pessoas famosas são os eixos de uma imensa rede, em razão do elevado número de pessoas que conhecem ele mas não vice-versa (VALENTE, 1995). Em outra mão, há mercados em que não há estes tipos de personalidades. Um exemplo é o mercado farmacêutico (HUNTINGTON; GILLAM; ROSEN, 2000).

\subsubsection{Estratégias de precificação}

Trabalhos anteriores sugerem que a estratégia de desnatação e busca por nichos apresentam as maiores taxas de sucesso aos produtos inovadores de alta tecnologia, especialmente sobre condições de baixa competição e em estágios iniciais no ciclo de vida do produto (BEARD; EASINGWOOD, 1996; HULTINK et al., 1997; ROGERS, 2010). Beard e Easingwood (1996) demonstra empiricamente que os produtos são geralmente lançados a um preço alto quando as incertezas do mercado e tecnologia são altas.

Preço é um dos fatores determinantes na escolha do comprador e também um dos mais importantes elementos pois ele determina muitas vezes a \% na quota do mercado e futuro faturamento (KOTLER; KELLER, 2006). Desta forma, há grande apreensão dos administradores sobre a condução das estratégias de precificação. 


\subsubsection{Estratégia de precificação para produtos inovadores sem os efeitos de rede}

A introdução de um produto inovador pode tradicionalmente depender das estratégias de desnatação, ao fixar preços iniciais altos para aumentar o faturamento junto aos inovadores pouco sensíveis aos preços, e então os preços decaem gradualmente para alcançar mercados mais abrangentes (DORWARD, 1987; GRUNENWALD; VERNON, 1988; KOTLER; KELLER, 2006; MURNANE; NELSON, 1984; NAGLE; HOGAN; ZALE, 2008).

Estudos empíricos sugerem que a estratégia de desnatação possui impacto positivo na performance de novos produtos (BEARD; EASINGWOOD, 1996; HULTINK; SCHOORMANS, 1995). Da perspectiva dos produtores, as estratégias de desnatação tipicamente são aplicados para novos produtos com certa características únicas (i.e:proteção por patente,desempenho excepcional e design) (VELTHUIS, 2013). As companhias também elegem altos preços para otimizar a receita antes que futuros entrantes aparecam no mercado (KOTLER; KELLER, 2006).

Sobre a perspectiva do consumidor, os preços providenciam uma fonte de informação para agentes que são propensos em julgar sua qualidade de acordo (NAGLE; HOGAN; ZALE, 2008), especialmente em casos na qual eles estão consumindo produtos altamente inovativos e a falta de conhecimento ou fonte comparativa transforma o preço em um forte balizador sobre qualidade(MALHOTRA, 2012).

\subsubsection{Estratégia de precificação para produtos inovadores considerando os efeitos de rede}

Produtos inovadores exibem efeitos de redes ao requererem investimentos complementares à infra-estrutura ou mesmo em ecossistemas digitais (i.e:portal para aplicativos de celular) para serem viavelmente comercializados e também para garantir que múltiplos padrões não concorram no mercado (BULTE; STREMERSCH, 2006; CUSUMANO; MYLONADIS; ROSENBLOOM, 1992).

O objetivo do produto em contar com o efeito da rede em sua estratégia não é primordialmente maximizar a receita nos estágios iniciais, mas sim, alargar a base instalada de lançamento do produto rapidamente. Posto isto, a estratégia de precificação por penetração desempenha um papel crítico no contexto do efeito de redes. Uma estratégia de penetração é favorecido quando uma empresa tenta explorar ganhos de escala ou operações mais robustas (CHANDY; TELLIS, 1998),para reduzir o ciclo de tempo e acelerar seu crescimento (COOKE; MORGAN, 1999; JONES; HESTERLY; BORGATTI, 1997).

$\mathrm{Na}$ presença do efeito de rede, uma empresa pode estrategicamente oferecer um preço vantajoso nos estágios iniciais do ciclo de vida do produto por um preço de penetração afim de estabelecer uma rede maior (HARTMAN; TEECE, 1990), criando expectativas para captar um mercado futuro maior e deter a entrada de competidores (HARTMAN; 
TEECE, 1990; COUGHLAN et al., 2006).

No longo prazo, no entanto, uma vez com a base instalada e o engajamento dos clientes indica consistência, o padrão e design dominante eventualmente poderá ter força de mercado para aumentar preços e coletar maiores margens. Clientes que derivam valor extrínseco dos produtos e não estão dispostos a trocar por alternativas mais baratas, podem estar dispostos em pagar uma preço mais elevado por variações do design dominante do mercado (BRYNJOLFSSON; KEMERER, 1996; HARTMAN; TEECE, 1990).

Incentivos pelo preço podem ser oferecidos aos adotantes iniciais com a intenção de atrair uma corrente de adotantes futuros, cada qual contribuindo em aumentar os benefícios diretos de todos os usuários locais e assim induzir a adoção adicional por outros(DHEBAR; OREN, 1986). Internet explorer, e posteriormente outros navegadores na internet, por exemplo, numa tentativa de se estabelecer como padrão entre os navegadores de internet, iniciaram suas atividades abrindo mão de faturamento ao disponibilizar gratuitamente seus serviços (ARTHUR, 1996).Mais recentemente, Linux, Google e outros programas gratuitos ameaçam a posição dominante da Microsoft no mercado corporativo ao abrirem mão de sua propriedade intelectual sobre códigos-fontes,permitindo que qualquer usuário realize modificações de acordo com sua necessidade (LEE; O'CONNOR, 2003). Em estudos posteriores sobre o mercado de e-mail, Economides e Himmelberg (1995) constataram que a estratégia de precificação por penetração foi mais efetiva ao considerar a expansão dos efeitos da rede.Desta forma, na presença dos efeitos da rede, espera-se melhor desempenho com a estratégia de penetração no lançamento de novos produtos. 


\section{Metodologia - Simulação computacional em ciências sociais aplicadas}

A simulação,mais especificamente a modelagem por agentes, pode trazer uma nova luz sobre os estudos em ciências sociais aplicadas especialmente economia e administração,pois ela pode superar limitações tidas como pressupostos necessários (KEEN, 2001; ARTHUR, 1994; MIROWSKI, 1991; BEINHOCKER, 2006; ARTHUR, 1999). O principal motivo está na dificuldade em analisar ambientes com características macroeconômicas oriundos das decisões e interações entre cada indivíduo dentro da perspectiva microeconômica (BEINHOCKER, 2006; BOWLES, 2009).

Uma das primeiras contribuições para contornar esta brecha veio do economista estadunidense Schelling (1971),profundo interessado na influência da dinâmica comportamental microeconômica na macroeconomia .Sem computadores mas sim usando um simples tabuleiro de madeira, ele simulou um modelo dinâmico de segregação urbana com resultados inesperados do ponto de vista analítico tradicional.Cada indivíduo mesmo sendo muito tolerante, ainda assim aglomera entre seus similares e segrega fortemente pessoas tidas como diferentes (VANY; LEE, 2001; VANY; WALLS, 1996).

Dito isso, a simulação apoiada pela capacidade processual na investigação nas ciências sociais aplicadas possui grande potencial para contribuir no maior entendimento de fenômenos entre a perspectiva micro e macro (VARIAN; REPCHECK, 2010; POWELL; WAKELEY, 2003; ZHANG; ZHANG, 2007).

Nota-se também crescimento significativo no emprego da simulação em marketing especialmente na difusão de inovações e produtos (EMMANOUILIDES; DAVIES, 2007; MACY; WILLER, 2002) por ele também partilhar de problemas similares aos enfrentados na economia. A modelagem por agentes pode auxiliar significativamente no esclarecimento muitas vezes obscuro entre o comportamento do consumidor e as métricas agregadas que avaliam a performance das empresas.

O modelo computacional deste trabalho é baseado na investigação de Chamorro e Gonçalves (2015) acerca do mercado nacional de lâmpadas. A estrutura de heterogeneidade e influência exógena sobre o preço de energia possuem intersecções com a presente investigação, ainda que seus objetivos,escopo de trabalho e parâmetros sejam diferentes.Será empregado o R(TEETOR, 2011) para confecção visual dos grafos e análises estatísticos com o pacote igraph, o interpretador Python junto com o pacote NetworkX (HAGBERG; SWART; CHULT, 2008) para composição, simulação e análise dos resultados. 


\subsubsection{Contexto e objetivo geral da simulação}

A mobilidade,especialmente dentro dos grandes centros urbanos, tornou-se uma questão periodicamente discutida especialmente pelos altos custos energéticos e ambientais envolvidos. A substituição do combustível fóssil pela energia elétrica em veículos leves pode ser um vetor atenuador deste cenário. Montadoras de veículos possuem em seu portfólio, veículos elétricos mas ainda não foram lançados com sucesso no mercado nacional. O objetivo deste modelo é prover uma ferramenta analítica capaz de investigar a difusão de veículos elétricos de passeio sobre a ótica dos sistemas complexos.

\subsubsection{Passo a passo da regra de decisão}

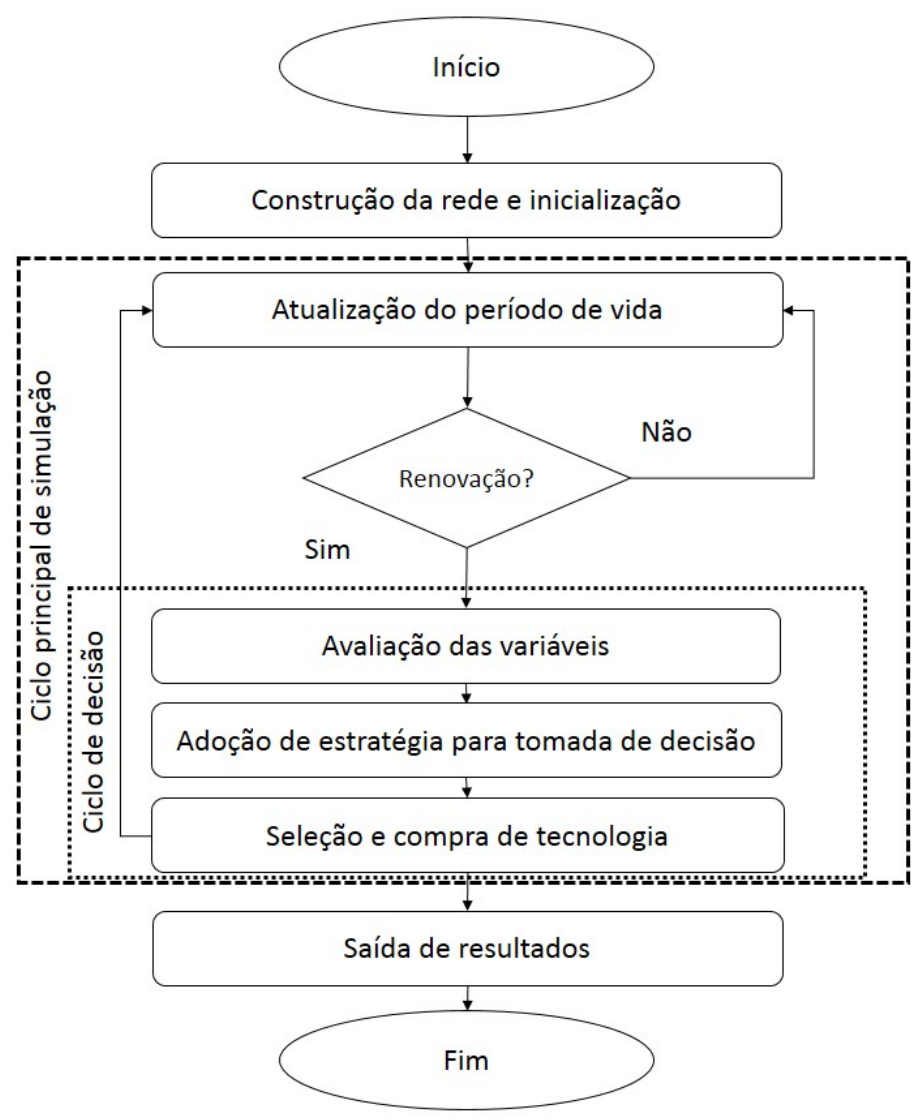

Figura 6 - Diagrama de fluxos do modelo baseado em agentes 
Respeitando os recursos limitados quanto ao processamento computacional fazse necessário delimitar pressupostos e parâmetros de algumas variáveis concernentes à simulação.

Pressuposto 1 - Mercado potencial é dividido entre pessoas que já possuem carro - claramente uma estratégia para buscar clientes que já possuem carros

Pressupostos 2 - Não há competição por preço dos outros concorrentes e outras matrizes de energia pelo espaço de 3 anos

Tabela 1 - Parâmetros gerais

\begin{tabular}{cc}
\hline Variável & Dados \\
\hline Nós e adjacências & Rede Scale Free com matriz de adjacências binário \\
Tecnologia & Tipo de carro:(1) gasolina (2)flex (3) elétrico \\
Tempo de vida & Número de períodos restantes para troca de veículo \\
Estratégia de compra & Comportamento do agente:(1) conservador (2)social (3)racional \\
Expectativa & Percepção do preço do combustível:(1)otimista (2)pessimista
\end{tabular}

Serão simulados 100 vezes para cada parâmetro pesquisado afim observar a cofluência da média e desvio-padrão em valores estáveis(MORENO; PASTOR-SATORRAS; VESPIGNANI, 2002).

Nesta simulação, cada salto discreto de tempo equivale a 1 semanas sendo $T_{\max }=144$ ou 3 anos, período máximo para constatar convergência dos resultados. Este valor foi escolhido pois o ciclo de vida médio de um modelo no mercado brasileiro sem mudanças incrementais no produto é de 3 anos, enquanto a vida total média é de 7 anos. O ciclo de vida de um carro é dividido em quatro etapas:(1)Lançamento, (2)ano/modelo, (3) remodelagem e (4) série limitada (STARK, 2011).A primeira e segunda etapas são marcadas por esforços de venda e comunicação. As novas tecnologias embarcadas e a contemporaneidade são os principais pontos ressaltados. Já nas outras 2 últimas etapas, com a parcial obsolência e saturação do mercado,mudanças incrementais de maior caráter estético no produto são realizadas para que mantenha o máximo de presença do mercado. Tendo em vista o propósito de investigar as estratégias de precificação sem alterações incrementais no produto, foi delimitado o período médio dos dois primeiros ciclos.

\subsubsection{Curva de custo de combustíveis e tecnologias de energia}

O consumo de Gasolina+Etanol representam $98 \%$ da matriz energética dos veículos nacionais de passeios segundo a agência nacional do petróleo(ANP). Desde 2000 até 2014, houve um incremento médio de $2,1 \%$ ao ano em seu preço.

O modelo utiliza como referência de custo o preço da gasolina e da eletricidade, providenciadas pela ANP e agência nacional de energia elétrica (ANEEL), respectivamente. 


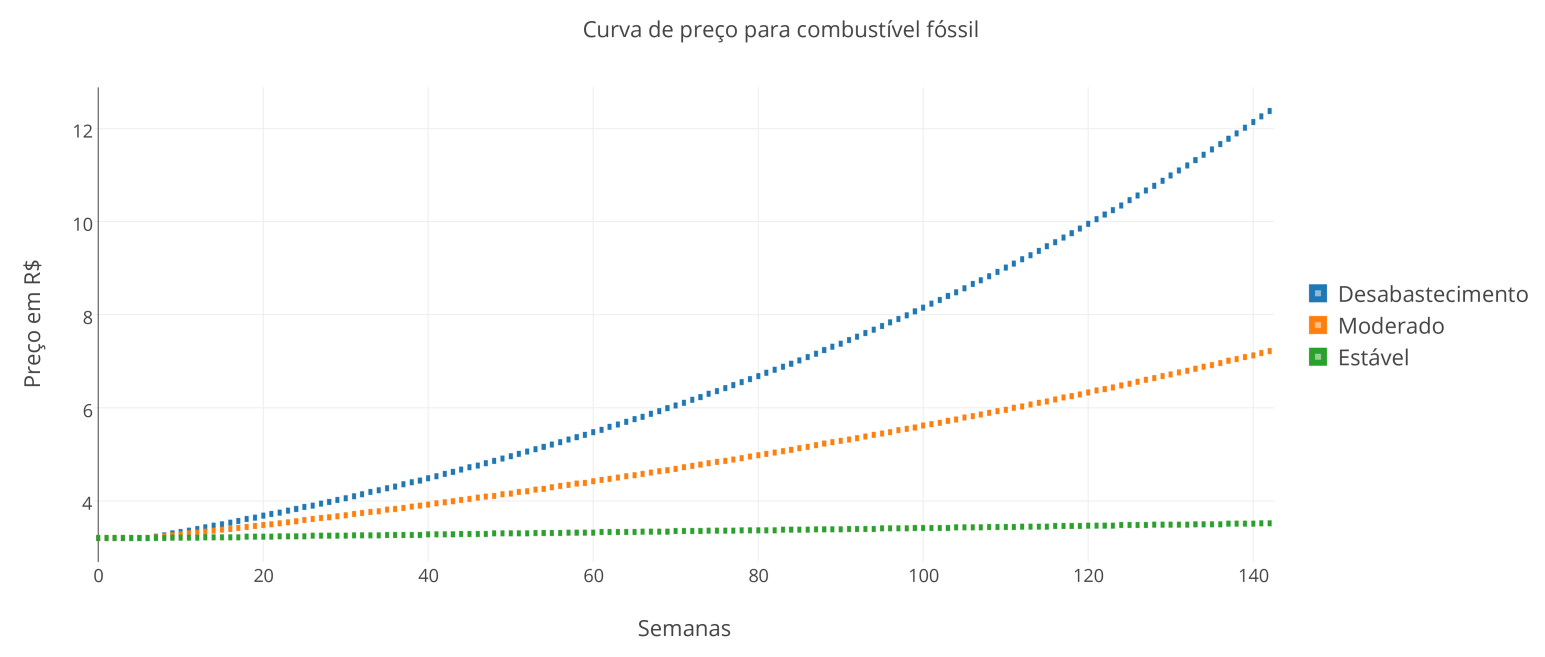

Figura 7 - Curva de demanda energética para veículos leves

Para efeito de normalização dos parâmetros de custo,tomou-se como medida padrão 1 litro de gasolina comum e este montante gera 9,6 Kilowatt-hora(Uni). O valores se expressam em reais $(\mathrm{R} \$)$ por Kilowatt-hora $\mathrm{R} \$ / \mathrm{kWh}$ e não contempla taxas, impostos e nem subsídios. A ANP e ANEEL providenciam um histórico de preços desde 2005 até 2014, na qual serão desenvolvidos três diferentes ajustes de preços da gasolina para obter diferentes cenários de análise relacionados à evolução do preço do combustível: estável, crescimento moderado da demanda e desabastecimento.

\subsubsection{Número de agentes e tecnologia}

O número total de veículos leves no mercado brasileiro é de 49,508,410 milhões de unidades de acordo como departamento nacional de trânsito (DENATRAN) em 2015. Sendo divididos em três fontes de combustível: Gasolina+Diesel, Elétrico e Flex Fluel(carros capazes de usar gasolina e etanol). Carros com motores Flex são a grande maioria, 88.21\%. Já a gasolina+diesel tem uma fatia de $11.76 \%$. Por fim, carros elétricos respondem por $0.03 \%$ de toda a frota.

De acordo com a literatura presente(NORTH; MACAL, 2007; KIESLING et al., 2012), recomenda-se empregar $N=2000$ agentes nas investigações de difusão ,sendo este valor suficiente para replicar modelos de difusão e percolação social em diferentes formatos de rede quando não há dados empíricos (DELRE; JAGER; JANSSEN, 2007).

No entanto, os dados empíricos levantados permitem dimensionar o tamanho da amostra através das proporções apontadas pela variável investigada dentro do intervalo de confiança em 100(1- $\alpha) \%$ (MALHOTRA, 2012; MCCLAVE; SINCICH, 2005).

$$
N=\frac{\left(Z_{a / 2}\right)^{2}(p q)}{E^{2}}
$$


O intervalo de confiança empregado foi de $95 \%$,tendo assim $Z_{a / 2}=1.96$. A margem de erro $\mathbf{E}$ é de $1 \%$. Os valores $\mathbf{p}$ são as proporções do tipo de combustível utilizado em cada matriz. Já q é o valor de (1-p). Desta forma, o número total de agentes empregados nas simulações será de 7992. 3987 serão usuários iniciais de carros com Gasolina+Diesel, 10 usuários de carros elétricos e 3995 usuários de carros Flex.

As características de 7992 veículos com um único dono foram coletadas aleatoriamente, estratificados por meio da matriz energética através do banco de dados aberto da empresa (https://carcheck.com.br/). Esta base digital concentra a população total de carros nacionais emplacados por meio do compartilhamento de outros bases.Foram coletadas variáveis de interesse para o modelo (1) eficiência energética média por unidade de energia, (2) quilometragem média realizada antes de sua venda ao mercado de usados (3) preço de compra de um modelo novo na montadora.

Tabela 2 - Tecnologias de energia utilizadas como referência para a simulação

\begin{tabular}{cccc}
\hline Tecnologia & Eficiência energética & Km médio & Preço \\
\hline Gasolina & $11 \mathrm{Km} /$ uni $^{*}$ & $100,000 \mathrm{Km}$ & $\$ 25,000$ \\
Flexivel & $12 \mathrm{Km} / \mathrm{uni}$ & $100,000 \mathrm{Km}$ & $\mathrm{R} \$ 35,000$ \\
Elétrico & $26 \mathrm{Km} /$ uni & $245,000 \mathrm{Km}$ & $\mathrm{R} \$ 100,000$
\end{tabular}

*9600 Watt/hora

\subsubsection{Comportamento de adoção}

Os agentes foram agrupados em três distintos comportamentos de consumo, sendo eles estáticos e fixados no início da simulação.

(1) Social: Agentes com estas características irão avaliar dentro de sua rede de contato direto qual a tecnologia mais utilizada e assim o adotará.

(2) Conservador: Agentes que possuem este comportamento, continuarão o uso da mesmo tipo de carro ao qual foram designados no início da simulação até o ciclo de vida do produto em uso. Ao terminar, o agente combinará o comportamento do agente social e racional. Caso os pressupostos dos dois comportamentos sejam preenchidos, ele irá adotar uma nova tecnologia. De outro modo, ele reiniciará com a tecnologia anterior.

(3) Racional: Ao esgotar o ciclo de vida do carro, o agente dotado deste comportamento irá avaliar todas as tecnologias disponíveis e selecionará a que possuir melhor desempenho considerando todos os gastos do ciclo do ciclo de vida anterior (CCV).

$$
C C V=C+\sum_{n=1}^{V N} E_{n} P_{n}(1+d)^{-n}+\sum_{i=1}^{V N} C N E_{n}(1+d)^{-n}
$$


Na qual C é o custo inicial pela tecnologia, $E_{n}$ é a energia consumida no período n, $P_{n}$ é o custo da energia consumida no período n, $C N E_{n}$ representa os custos não energéticos incorridos no período $\mathrm{n}$, d é a taxa de desconto do período n e VN é o tempo esperado de vida do produto.

Serão simulados 3 cenários sociais distintos, contendo diferentes proporções conforme tabela 3 .

Tabela 3 - Composição social dos agentes

\begin{tabular}{cccc}
\hline Tipo & racional & Social & Racional \\
\hline racional & $60 \%$ & $15 \%$ & $25 \%$ \\
Social & $25 \%$ & $60 \%$ & $15 \%$ \\
Racional & $15 \%$ & $25 \%$ & $60 \%$
\end{tabular}

Os veículos, em média, trafegam por $41 \mathrm{Km}$ diariamente tendo como desvio padrão da amostra $\sigma=10 \mathrm{Km}$, valor proveniente da Companhia ambiental do estado de São Paulo (CETESB). O intervalo de confiança pode ser mensurado conforme a equação 3.7:

$$
X_{b a r}+-Z_{a / 2} \frac{s}{\sqrt{n}}
$$

O valor de $Z_{a / 2}$ empregado é de 1.96 , ou seja $1-\alpha=0.95$. Desta forma, o intervalo de confiança é de 12,87km e 13,13km(MALHOTRA, 2012; MCCLAVE; SINCICH, 2005).

\subsubsection{Modelo - Estratégia de precificação}

O preço representa uma das variáveis mais importantes para a permanência da empresa a curto, médio e longo prazos (NICHELE; MILAN, 2006).

Segundo Kotler e Keller (2006), Ramos, Maya e Bornia (2005), a maneira mais rápida e mais eficaz para maximizar o lucro é fixar o preço de forma adequada. O preço também está fortemente correlacionado ao volume de vendas e a participação de mercado. Esta variável também pode ser modificada com relativa rapidez.

Nagle, Hogan e Zale (2008) investiga os fatores que determinam quais estratégias podem ser adotadas para a determinação dos preços. O autor apresenta quatro categorias de estratégias de preços: (i) para novos produtos e/ou serviços; (ii) preços competitivos; (iii) preços por linhas de produtos e/ou serviços; e (iv) preços baseados em custos. O modelo neste trabalho empregará três estratégias de precificação para novos produtos ou serviços: (1) Desnatação (2) Penetração e (3) aprendizado. 


\section{Estratégia de desnatação}

Na estratégia de desnatação, os preços estipulados inicialmente são altos com o objetivo de extrair maior receita dos clientes dispostos a pagar por um preço maior pelo novo produto. Posteriormente, os preços declinam à medida que segmentos com maior sensibilidade ao preço se tornam alvos. Desta forma, consumidores esperam que os preços eventualmente caiam.

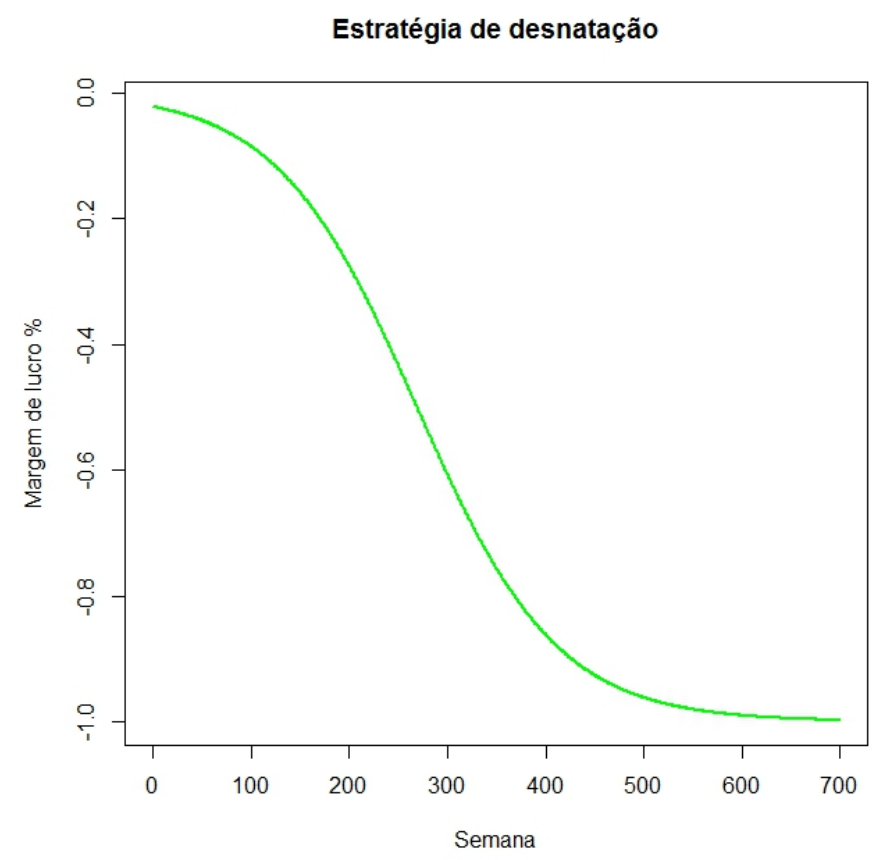

Figura 8 - Curva de precificação - Desnatação

Mahajan, Muller e Bass (1990), Nagle, Hogan e Zale (2008) cita que esta estratégia reduz risco sobre as incertezas da elasticidade da demanda, pois o mercado está mais disposto a reduzir os preços ao longo do tempo ao invés de aumentá-lo. Somado a isso, custos provavelmente serão reduzidos na medida do tempo tendo em conta a expansão do mercado e a melhora da eficiência dado os ganhos de escala e os efeitos da experiência nas operações. A estratégia de precificação que emprega a desnatação também contribuem na recuperação dos investimentos anteriores para o desenvolvimento e introdução do produto no mercado. Por outro lado, os alto preços são um chamariz para potenciais competidores caso as barreiras de entrada não estejam bem delineadas.

A curva de precificação na estratégia de desnatação para este modelo, seguirá a curva logística geral, também conhecida como curva de Richard - conforme na equação 3.4. Este é um dos modelos mais comuns usados na literatura de precificação e também na literatura de tomada de decisão de consumo (MOORE; BOULDING; GOODSTEIN, 1991).O ponto chave deste modelo está no resultado gerado em que a probabilidade de escolha de um estado ou valor contínuo, neste caso preço, decresce até alcançar um ponto 
alvo mínimo - sendo este um preço de acomodação até $\tau=144$.

$$
P_{t}=A+\frac{K-A}{\left(C+Q e^{B t}\right)^{1 / v}}
$$

Na qual $\mathrm{P}(\mathrm{t})$ representa o preço em $\tau$ com os 6 seguintes parâmetros:

Tabela 4 - Parâmetros da curva de logística geral para Desnatação

\begin{tabular}{cc}
\hline Parâmetro & Tipo \\
\hline$A$ & Assíntota superior ou maior preço alvo \\
$K$ & Assíntota inferior ou preço de capacidade mínima \\
$B$ & Taxa de decrescimento \\
$\nu>0$ & Afeta a taxa de decrescimento máximo da assíntota \\
$Q$ & representa o valor de $M_{t}$ quando $\tau=0$ \\
$C$ & valor constante de 1
\end{tabular}

\section{Estratégia de penetração}

$\mathrm{Na}$ estratégia de preço por penetração, o objetivo maior é entrar no mercado de forma agressiva por meio de preços menores. Algumas condições em que o preço de penetração pode ser considerado:

1. Sensibilidade ao preço dos consumidores nos principais segmentos

2. Características dos produtos lançados são facilmente compreendidos por grande parcela dos consumidores - sugerindo inovações incrementais sobre inovações de ruptura

3. Aumento na participação do mercado e formação de barreira sobre possíveis novos entrantes

Usualmente, estratégias de penetração podem requerer recursos para suportar o rápido crescimento na produção, distribuição e marketing para o produto. Os sacrifícios realizados no curto prazo tendo em vista futuros benefícios - em termos de baixo preço e uma forte posição no mercado, na qual serve como fonte de vantagem de competitividade. 


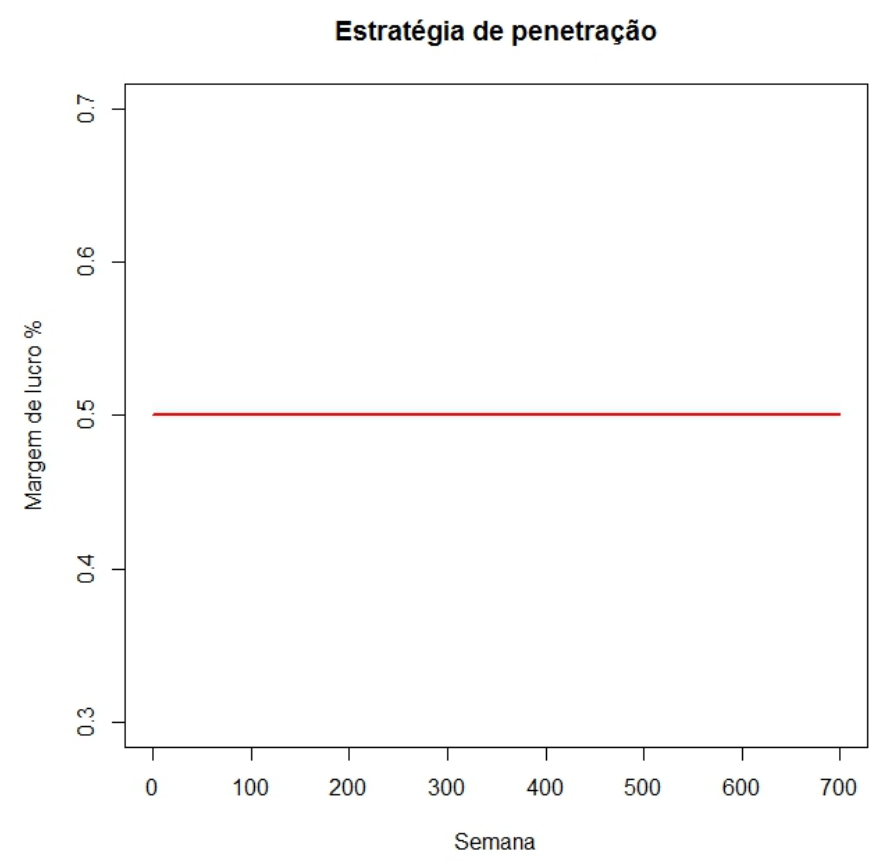

Figura 9 - Curva de precificação - penetração

Será simulado um preço fixo durante toda os saltos temporais de $\tau=0$ até $\tau=144$.

Tabela 5 - Parâmetros da curva de logística geral para Desnatação

\begin{tabular}{cc}
\hline Parâmetro & Tipo \\
\hline Preço $_{1}$ & $\mathrm{R} \$ 50,000$
\end{tabular}

\section{Estratégia por aprendizado}

Estratégia de penetração e a estratégia de precificação sobre aprendizado apresentam muitos aspectos similares especialmente sobre a capacidade de produção instalada. A distinção primária entre elas é a fonte da vantagem competitiva sobre custos - enquanto o conhecimento gerado pela experiência tem papel proeminente na curva de precificação por aprendizado, já a curva de penetração é gerada pelos ganhos de escala.

A curva de precificação na estratégia de aprendizado por curva será designada também pela curva logística geral mas pela sua inversa - conforme a equação 3.5. A medida que $\tau$ aumenta, os custos são comprimidos e a margem de lucro e receita da companhia aumentam.

$$
M_{t}=K+\frac{A-K}{\left(C+Q e^{B t}\right)^{1 / v}}
$$

Enquanto que o valor de A apresentava a assíntota superior na estratégia de desnatação, nesta estratégia ela será tida como assíntota inferior e o valor de K representará 


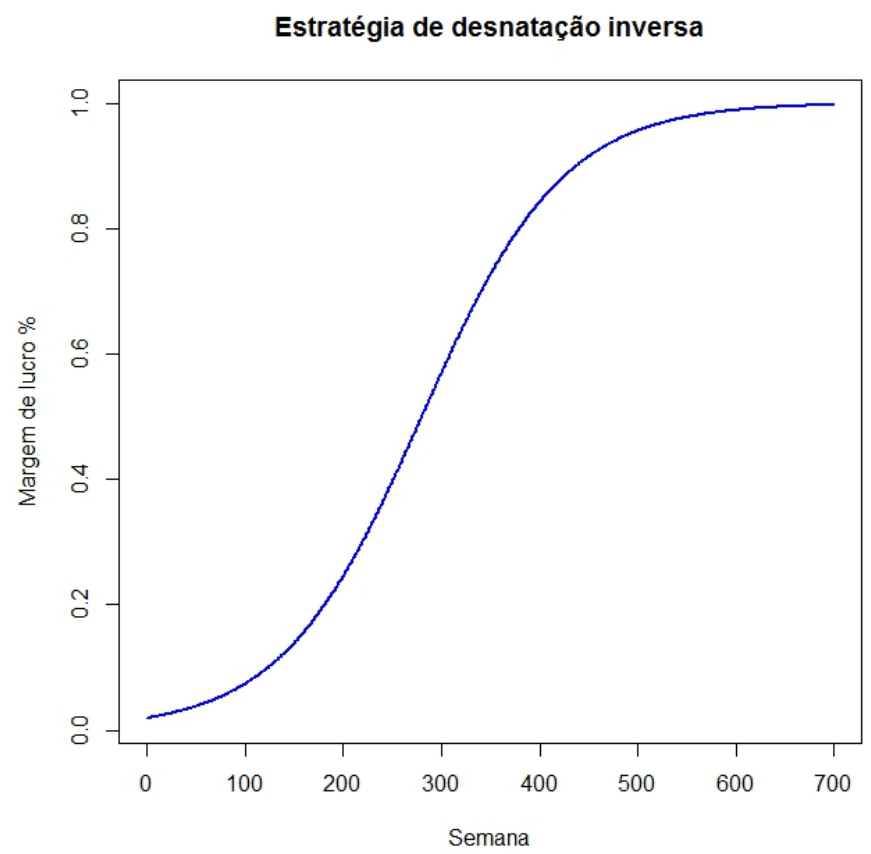

Figura 10 - Curva de precificação - Aprendizado

a assíntota superior de preço tendo o restante dos parâmetros iguais ao da estratégia de desnataçãoRogers (2010).

\subsection{Análise dos dados}

\subsubsection{Teste de parâmetros gerais}

A simulação avaliou o processo de adoção e difusão dos carros elétricos em três diferentes cenários sobre os preço de combustível fóssil:(1)estável (2) crescimento moderado e (3) desabastecimento. A figura 11 mostra a curva de concentração das redes utilizadas para a simulação. A análise foi realizada com $\mathrm{N}=8000$ agentes sendo simulado 50 vezes cada parâmetro adotado. A estrutura de rede teve formato scale free, sendo um altamente agrupado ( $\mathrm{N}=8000$, Alpha $=0.05$, Beta $=0.9$ e Gamma=0.05) e o outro com menor nível de agrupamento $(\mathrm{N}=8000, \mathrm{Alpha}=0.9$, Beta $=0.05$ e Gamma=0.05), possibilitando analisar a influência desse estrutura no comportamento social dos agentes. A taxa de retorno sobre o dinheiro adotado foi de $13 \%$ ao ano.

No gráfico 11, as curvas de concentração das redes utilizadas para a simulação são demonstradas. A curva azul $(\mathrm{N}=8000, \alpha=0.05, \beta=0.9$ e $\gamma=0.05)$ representa uma rede com formato scale free mais concentrada,tendo alguns poucos nós com elevado número de ligações com outros nós, se comparada a curva verde $(\mathrm{N}=8000, \alpha=0.9, \beta=0.05$ e $\gamma=0.05)$. 


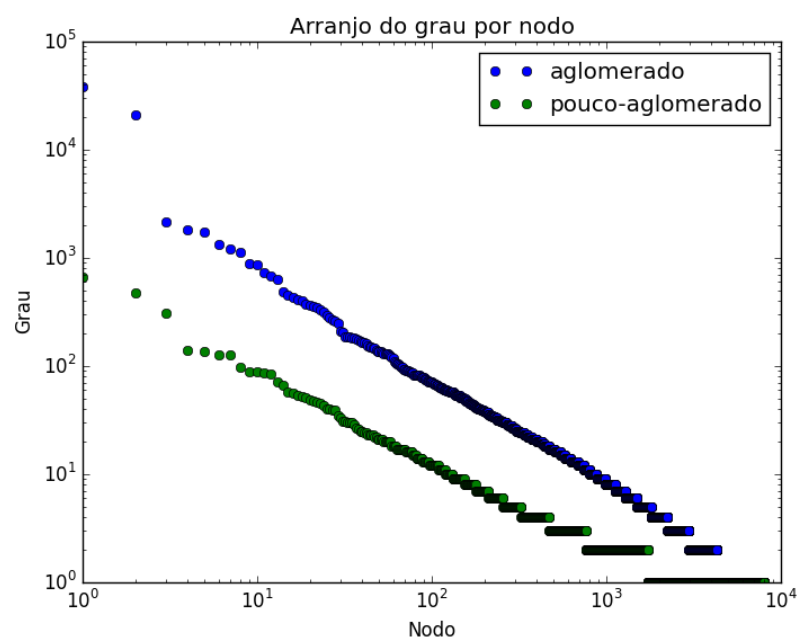

Figura 11 - Distribuição de grau

\subsubsection{Simulação I: Difusão em diferentes condições de demanda energética}

Simulações em 3 diferentes cenários para demanda sobre combustível foram realizados combinado com as três estratégias de precificação propostas. A composição social da rede permaneceu constante em todos os experimentos desta etapa - 33\% dos agentes possuíam atitude racional, $33 \%$ eram habilitados como agentes racionais e os $33 \%$ restante dos agentes eram detentores do comportamento social.

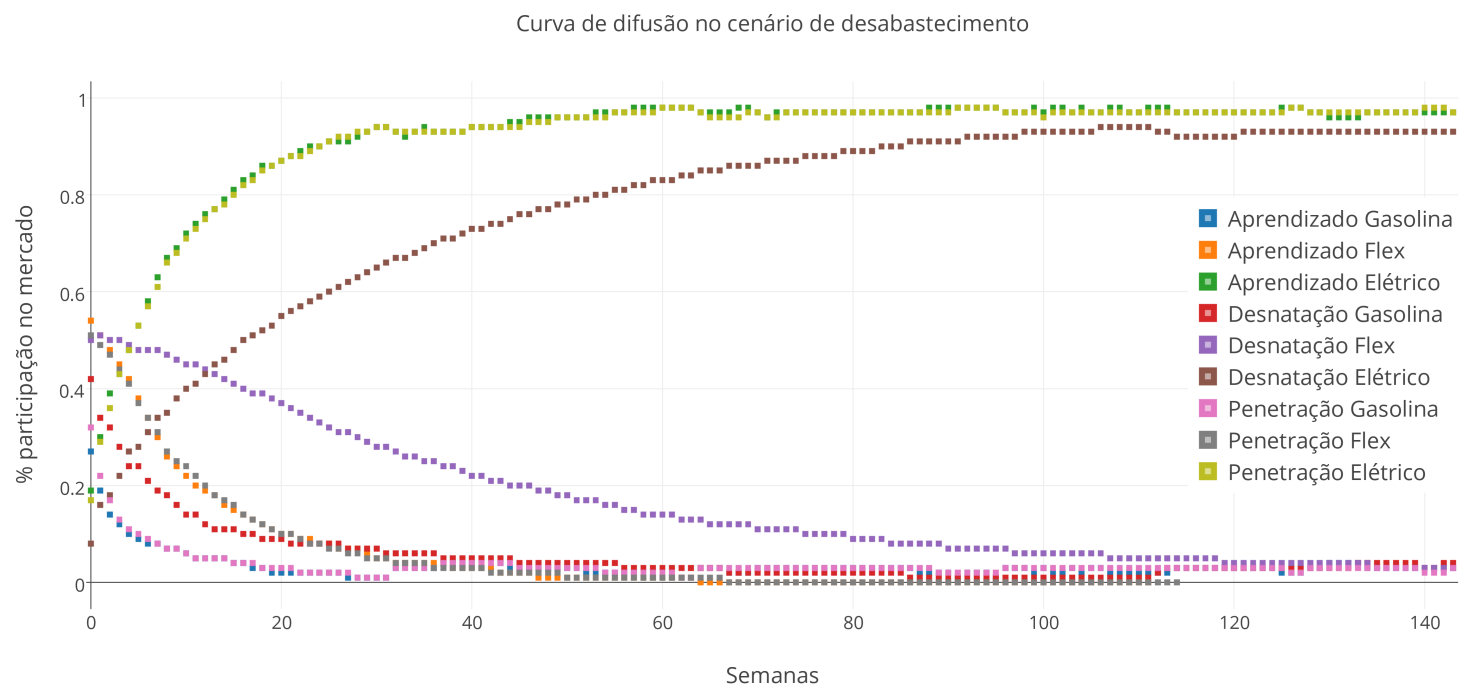

Figura 12 - Curva de adoção no cenário de desabastecimento

São destacados nas figuras 12,13 e 14, a convergência do carro elétrico em termos de participação no mercado em todas as estratégias de precificação articulada nos três cenários de demanda energética. 


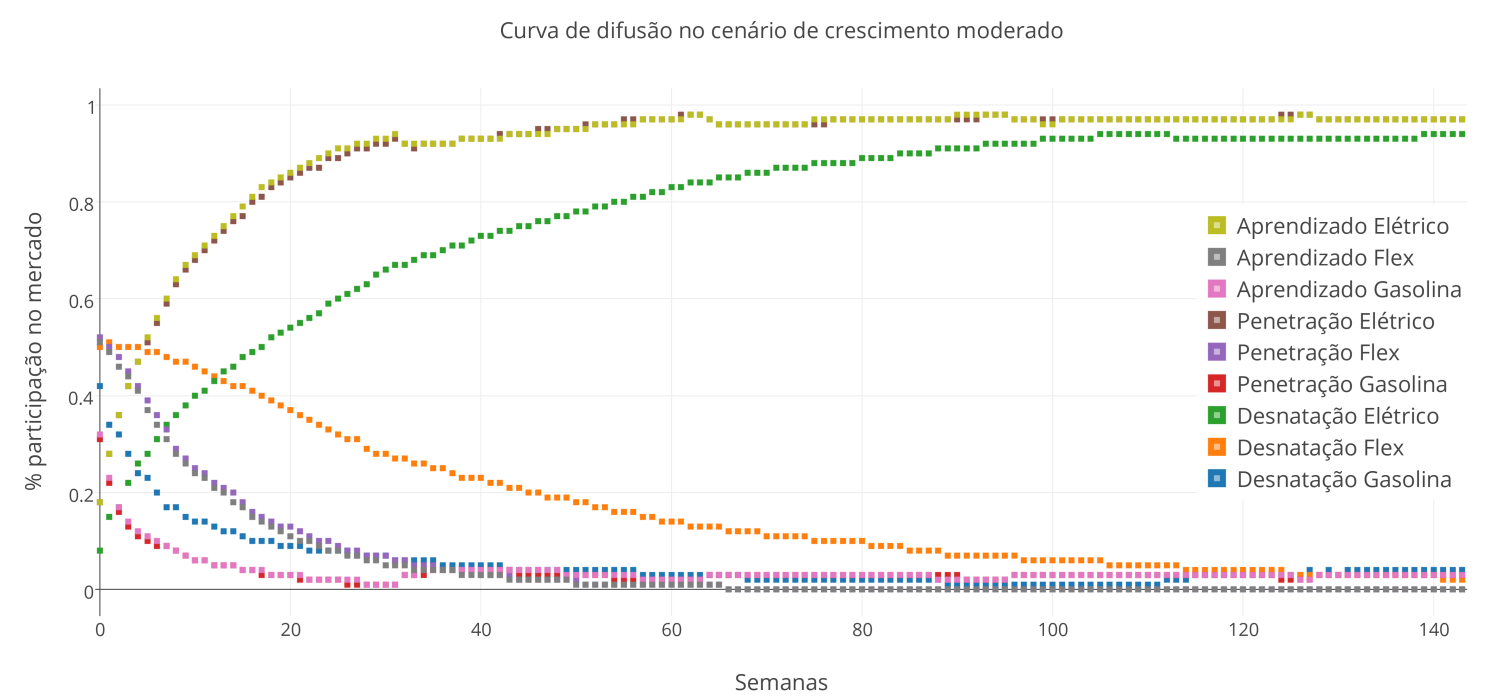

Figura 13 - Curva de adoção no cenário de crescimento moderado

Em todos os cenários apresentados, há maior rapidez em adoção do carro elétrico junto as estratégias de penetração e aprendizado, sendo elas com taxas de adoção muito similares.

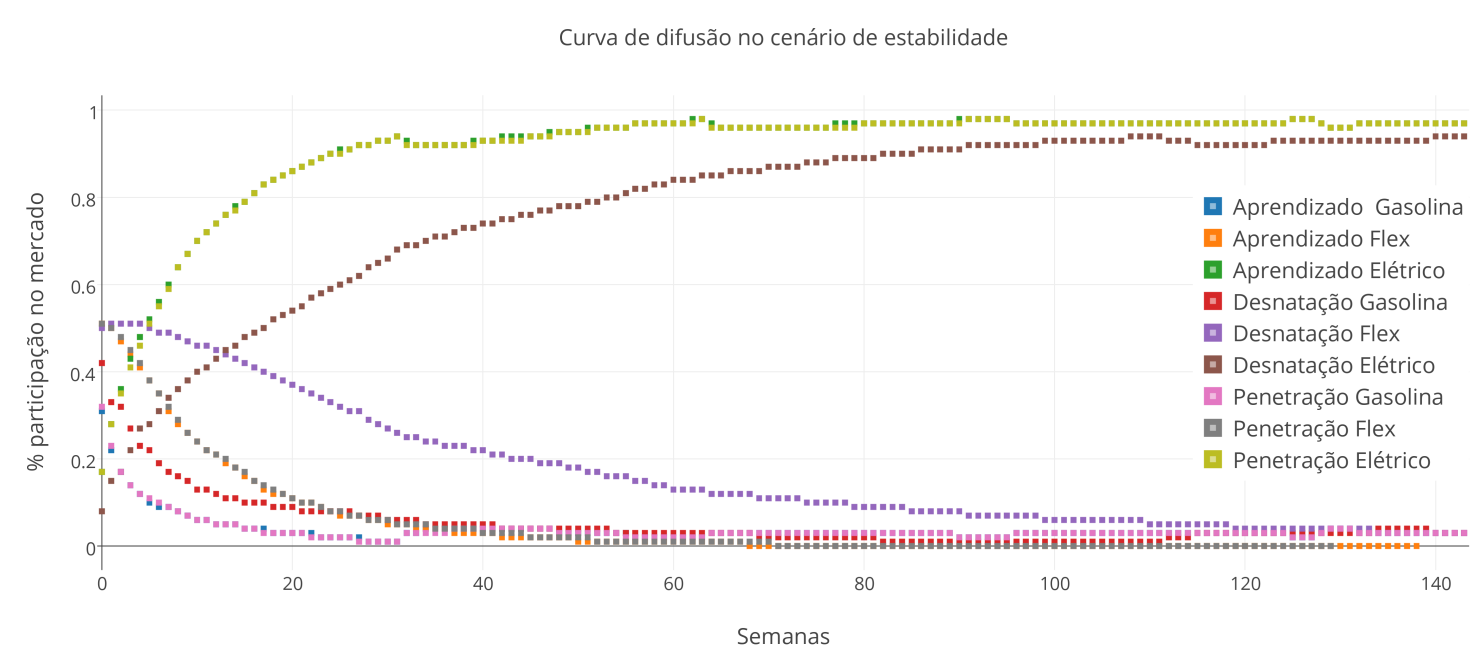

Figura 14 - Curva de adoção no cenário de estabilidade

A estratégia de desnatação apresentou um desenvolvimento da curva menos acentuadas do que as demais, no entanto ela apresentou melhor desempenho em termos de receita gerada em todos os cenários conforme 15,16 e 17. Também foi analisado o fator de aglomeração e não-aglomeração no desempenhos das estratégias em termos de participação porcentual do mercado e faturamento ao final de $\tau=144$ semanas. 


\begin{tabular}{|c|c|c|c|c|c|c|c|c|c|}
\hline \multicolumn{10}{|c|}{ Cenário com desabastecimento } \\
\hline \multicolumn{4}{|c|}{ \% Participação no mercado } & \multicolumn{6}{|c|}{ Faturamento bruto em $\mathrm{R} \$$} \\
\hline Tipo & Gasolina & Flex & Elétrico & & Gasolina & & Flex & & Elétrico \\
\hline Aprendizado aglomerado & $3.6 \%$ & $2.0 \%$ & $94.4 \%$ & $\mathrm{R} \$$ & $6,588,000.0$ & $\mathrm{RS}$ & $2,208,000.0$ & $\mathrm{RS}$ & $602,130,352.9$ \\
\hline Penetração aglomerado & $3.4 \%$ & $2.4 \%$ & $94.2 \%$ & $\mathrm{R} \$$ & $6,714,000.0$ & $\mathrm{RS}$ & $3,840,000.0$ & $\mathrm{RSS}$ & $605,809,068.8$ \\
\hline Desnatação aglomerado & $3.5 \%$ & $2.7 \%$ & $93.8 \%$ & $\mathrm{R} \$$ & $6,714,000.0$ & $\mathrm{R} \$$ & $832,000.0$ & $\mathrm{R} \$$ & $601,462,421.6$ \\
\hline Aprendizado não aglomerado & $0.4 \%$ & $3.0 \%$ & $96.6 \%$ & $\mathrm{R} \$$ & $1,710,000.0$ & $\mathrm{RS}$ & $6,592,000.0$ & $\mathrm{R} \$$ & $610,654,842.3$ \\
\hline Desnatação não aglomerado & $0.3 \%$ & $4.0 \%$ & $95.8 \%$ & $\mathrm{R} \$$ & $1,548,000.0$ & $R \$$ & $9,984,000.0$ & $\mathrm{R} \$$ & $588,531,456.8$ \\
\hline Penetração não aglomerado & $0.4 \%$ & $4.5 \%$ & $95.1 \%$ & $\mathrm{R} \$$ & $1,296,000.0$ & $\mathrm{R} \$$ & $12,800,000.0$ & $\mathrm{R} \$$ & $585,366,734.3$ \\
\hline
\end{tabular}

Figura 15 - Tabela de desempenho - Cenário de desabastecimento

O cenário de desabastecimento apresentou o maior volume de receita gerado dentre os três cenários e também foi o único a apresentar vendas,ainda que marginais, dos automóveis Flex em todas as estratégias. Isto se deve ao fato do combustível aumentar fortemente logo no início da simulação, forçando alguns agentes à comprarem um veículo mediano em suas configurações de preço e eficiência possuidores de apoio social de sua rede social direta.No entanto, ao longo das interações, com o aumento expressivo do combustível, foram identificados agentes que adquiriram dois carros elétricos no horizonte de $\tau=144$ semanas.

\begin{tabular}{|c|c|c|c|c|c|c|c|c|c|}
\hline \multicolumn{10}{|c|}{ Cenário com crescimento moderado } \\
\hline \multicolumn{4}{|c|}{ \% Participação no mercado } & \multicolumn{6}{|c|}{ Faturamento bruto em $\mathrm{R} \$$} \\
\hline Tipo & Gasolina & Flex & Elétrico & & Gasolina & & Flex & & Elétrico \\
\hline Aprendizado aglomerado & $2.6 \%$ & $0.0 \%$ & $97.4 \%$ & $\mathrm{R} \$$ & $14,688,000.0$ & $\mathrm{R} \$$ & - & $\mathrm{RS}$ & $387,351,311.7$ \\
\hline Penetração aglomerado & $2.7 \%$ & $0.0 \%$ & $97.3 \%$ & $\mathrm{R} \$$ & $15,237,000.0$ & $\mathrm{R} \$$ & - & $\mathrm{RS}$ & $389,125,173.1$ \\
\hline Desnatação aglomerado & $0.4 \%$ & $0.0 \%$ & $99.5 \%$ & $\mathrm{RS}$ & $30,600,000.0$ & $\mathrm{R} \$$ & - & $\mathrm{RS}$ & $445,038,376.0$ \\
\hline Aprendizado não aglomerado & $0.4 \%$ & $0.0 \%$ & $99.6 \%$ & $\mathrm{R} \$$ & $4,131,000.0$ & $\mathrm{R} \$$ & $112,000.0$ & $\mathrm{R} \$$ & $354,938,940.1$ \\
\hline Desnatação não aglomerado & $2.7 \%$ & $0.0 \%$ & $97.3 \%$ & $\mathrm{R} \$$ & $3,249,000.0$ & $\mathrm{R} \$$ & $240,000.0$ & $\mathrm{RS}$ & $363,419,041.6$ \\
\hline Penetração não aglomerado & $0.4 \%$ & $0.0 \%$ & $99.6 \%$ & $\mathrm{R} \$$ & $3,447,000.0$ & $\mathrm{RS}$ & $32,000.0$ & $\mathrm{RS}$ & $349,101,065.9$ \\
\hline
\end{tabular}

Figura 16 - Tabela de desempenho - Cenário de estabilidade

Nos outros dois cenários, moderado e estável, podemos identificar um pulo de geração tecnológica entre o motor de gasolina para o motor elétrico. Dada a percepção do preço do combustível ser acessível, muitos agentes permaneceram com seus carros flex e de gasolina. Ao constar aumento significativo do combustível ao longo das interações, muitos simplesmente pularam o carro flex e compraram o carro elétrico por causa de seu benefício/custo sobre o preço do combustível incorrido no momento.

A questão sobre substituição tecnológica surgiu ao relacionar à heterogeneidade da população na adoção. Goldenberg e Oreg (2007) propuseram a redefinição de agentes racionais ou adotantes atrasados; eles sugeriram que os agentes racionais das gerações anteriores de produtos podem muitas vezes se tornarem inovadores nas gerações posteriores.

Por exemplo, nos tempos iniciais da revolução sobre o MP3, um adotante inicial de MP3 pode ter sido usuário do tocador de fita portátil que não havia adotado a tecnologia dos CDs, e decidiu atualizar-se diretamente para um tocador de MP3. Consequentemente, 


\begin{tabular}{|c|c|c|c|c|c|c|c|c|c|}
\hline \multicolumn{10}{|c|}{ Cenário com estabilidade } \\
\hline \multicolumn{4}{|c|}{ \% Participação no mercado } & \multicolumn{6}{|c|}{ Faturamento bruto em $\mathrm{R} \$$} \\
\hline Tipo & Gasolina & Flex & Elétrico & & Gasolina & & Flex & & Elétrico \\
\hline Aprendizado aglomerado & $2.6 \%$ & $0.0 \%$ & $97.4 \%$ & $\mathrm{R} \$$ & $14,265,000.0$ & $\mathrm{R} \$$ & - & $\mathrm{R} \$$ & $302,740,000.0$ \\
\hline Penetração aglomerado & $2.7 \%$ & $0.0 \%$ & $97.3 \%$ & $\mathrm{RS}$ & $15,381,000.0$ & $\mathrm{R} \$$ & $16,000.0$ & $\mathrm{R} \$$ & $306,140,000.0$ \\
\hline Desnatação aglomerado & $2.7 \%$ & $0.0 \%$ & $97.3 \%$ & $\mathrm{RS}$ & $16,020,000.0$ & $\mathrm{R} \$$ & 0.0 & $\mathrm{RS}$ & $350,480,000.0$ \\
\hline Aprendizado não aglomerado & $0.4 \%$ & $0.0 \%$ & $99.6 \%$ & $\mathrm{RSS}$ & $3,393,000.0$ & $\mathrm{RS}$ & $64,000.0$ & $\mathrm{RS}$ & $282,840,000.0$ \\
\hline Desnatação não aglomerado & $0.4 \%$ & $0.0 \%$ & $99.6 \%$ & $\mathrm{RS}$ & $2,889,000.0$ & $\mathrm{R} \$$ & $432,000.0$ & $\mathrm{R} \$$ & $324,700,000.0$ \\
\hline Penetração não aglomerado & $0.3 \%$ & $0.0 \%$ & $99.7 \%$ & $\mathrm{R} \$$ & $3,096,000.0$ & $\mathrm{R} \$$ & - & $\mathrm{RS}$ & $281,860,000.0$ \\
\hline
\end{tabular}

Figura 17 - Heat map para desabastecimento

adotantes iniciais de tocadores de MP3 não são necessariamente inovadores, alguns podem simplesmente pular de gerações. Desta forma, as firmas podem se aproximar deles com uma estratégia de marketing adequada e não tratar eles como inovadores.

A entrada de novas gerações tecnológicas complica a dinâmica de crescimento e gera processos ligados ao consumidor que não são observados em uma única difusão.Primeiro, a entrada de uma nova geração é geralmente considerada para aumentar o mercado potencial. Somado a isto, consumidores podem atualizar e trocar um tecnologia antiga por uma nova. Na outra mão, indivíduos que pertencem ao mercado potencial aumentado podem decidir eventualmente adotar a geração antiga do produto, consequentemente, canibalizando o mercado potencial da nova tecnologia.

Se há 3 diferentes tecnologias cada qual em diferentes gerações tecnológicas, adotantes podem pular uma geração e seguirem para a mais avançada. Isto significa que a entrada de uma nova tecnologia revela heterogeneidade em uma população adotante, cuja suscetibilidade não foi detectada em uma única geração de tecnologia mas sim em três diferentes gerações.

Surpreendentemente, nenhum dos modelos de difusão ainda ofereceram um tratamento compreensivo destas dinâmicas. Estudos focam em 1 ou 2 aspectos, tais como as atualizações de produtos (BASS et al., 2001; NORTON; BASS, 1987) e canibalização (MAHAJAN; MULLER, 1998), mas não um tratamento teórico unificado sobre o tema.Diversos estudos tem investigado pontos ótimos de precificação assim como sobre substituição tecnológica (PADMANABHAN; BASS, 1993; DANAHER; HARDIE; JR, 2001). No entanto, com exceção de Lehmann e Esteban-Bravo (2006), estes estudos não relatam sobre a dinâmica específica do grupo dos adotantes. Este aspecto foi explorado com maior profundidade na página 59

Os efeitos do formato de rede: aglomerado e não-aglomerado foram testados afim de identificar se há diferença estatisticamente significativa entre as suas médias em termos de participação do mercado e faturamento.Para tanto, a análise de variância (ANOVA) foi selecionada por ela satisfazer três aspectos empregados neste modelo. Primeiro, as amostras são aleatórias e independentes. A amostra possui distribuição normal e a variância 
populacional são próximas. Foram analisados 120 resultados,sendo eles divididos entre 2 categorias (aglomerado e não-aglomerado) igualmente, subdivididos nas 3 categorias de precificação, conforme figura 6 .

Tabela 6 - Teste ANOVA sobre formato de rede:Aglomerado x Não-aglomerado

\begin{tabular}{ccc}
\hline Estratégia de precificação & Aglomerado & Não-aglomerado \\
\hline Desnatação & 20 & 20 \\
Penetração & 20 & 20 \\
Aprendizado & 20 & 20 \\
Sub-total & 60 & 60
\end{tabular}

Na tabela 7, foi constatado que as duas configurações de rede apresentam diferenças estatisticamente significativas ao nível de 99\% por meio de uma análise de variância (ANOVA) de fator único. O Valor-P obtido foi de 39.01, superior ao valor F-crítico mínimo de 9.33. Além disso, rejeitamos a hipótese nula a $\alpha(1-1 \%)$ pois o valor-P obtido, 0.000043 é significativamente menor que 0.01 .

Tabela 7 - Teste ANOVA sobre formato de rede:Aglomerado x Não-aglomerado

\begin{tabular}{ccccccc}
\hline Fonte de variação & SQ & Gl & MQ & F & Valor-P & F-Crítico \\
\hline Entre grupos & 0.0014 & 1 & 0.00014 & 39.01 & 0.000043 & 9.33 \\
Dentro dos grupos & 0.000043 & 59 & 0.000036 & & & \\
Total & 0.00182 & 60 & & & &
\end{tabular}

Os efeitos das três diferentes estratégias de precificação sobre diferentes cenários de demanda por combustível fóssil também foram testados afim de identificar se há diferença estatisticamente significativa entre as suas médias em termos de participação do mercado e faturamento.A análise de variância (ANOVA) foi selecionada novamente, mais especificamente o teste Fischer(MALHOTRA, 2012). Esta variante é capaz de controlar os erros residuais gerados ao serem testados mais de 2 níveis de resposta em uma varável. Neste caso, testaremos 3 níveis de resposta de uma variável (Estratégia de preço: desnatação, aprendizado e penetração).

O método de Fisher, para comparar todos pares de médias, controla a taxa de erro ao nível de significância $\alpha$ para cada comparação dois a dois, mas não controla a taxa de erro do experimento. Esse procedimento usa a estatística $t$ para testar $\mu_{i}=\mu_{j}=\mu_{k}$, em que:

$$
L S D=\frac{\overline{y_{i .}}-\overline{y_{j}}}{\sqrt{Q M E\left(\frac{1}{n_{i}}+\frac{1}{n_{j}}\right)}}
$$


O procedimento de Fisher consiste em realizar testes t múltiplos, cada um ao nível de significância $\alpha$,somente se o teste $\mathrm{F}$ preliminar é significante ao nível $\alpha$. Este pode ser visto como um procedimento de duas etapas em que a hipótese nula $H_{0}$ é testada no primeiro passo por um teste $\mathrm{F}$ de nível $\alpha$. Se o teste $\mathrm{F}$ não é significativo, o procedimento termina sem precisar fazer inferências detalhadas nas diferenças dos pares das médias; caso contrário, cada diferença de par é testada por um teste t com nível $\alpha$ de significância(MALHOTRA, 2012; MCCLAVE; SINCICH, 2005).

Para testar a hipótese de que as estratégias de precificação possuem médias significativamente diferentes em termos estatísticos, foram realizados 120 simulações ao total.

Tabela 8 - Teste Fischer sobre estratégia de preço

\begin{tabular}{ccc}
\hline Estratégia de precificação & Aglomerado & Não-aglomerado \\
\hline Desnatação & 20 & 20 \\
Penetração & 20 & 20 \\
Aprendizado & 20 & 20 \\
\hline Sub-total de simulações & 60 & 60
\end{tabular}

Foram realizados testes para a \% na participação do mercado assim como em faturamento.Em ambos os casos, não rejeitamos a hipótese nula em todos os níveis. Na terceira coluna da tabela 9,podemos notar os P-valores acima do nível do nível de significância de $5 \%$.

Tabela 9 - Tabela de processo Fischer

\begin{tabular}{ccccc}
\hline Diferença entre níveis & Média & $L_{i}$ & $L_{s}$ & P-Valor \\
\hline Desnatação-Penetração & $\mathrm{R} \$ 600.815$ & $\mathrm{R} \$ 560.320$ & $\mathrm{R} \$ 645.000$ & 0.234 \\
Desnatação-Aprendizado & 588.650 & 540.270 & 622.430 & 0.147 \\
Penetração - Aprendizado & 605.040 & 585.480 & 630.510 & 0.34
\end{tabular}

Desta forma, não rejeitamos a hipótese de igualdade entre as médias dos três níveis.As estratégias de precificação em conjunto com os diversos cenários para demanda energética junto com a fixação dos parâmetros para composição social dos agentes exibiram diferenças insuficientes em termos estatísticos quanto ao seu faturamento e \% na participação do mercado ao fim de $\tau=144$ semanas. As estratégias de penetração e aprendizado apresentaram-se com melhor desempenho por alcançar com mais rapidez, grande parcela do mercado de automóveis e faturamento similar as outras estratégias. Os resultados provenientes deste modelo são diferentes aos indicados nos estudos empíricos de Beard e Easingwood (1996), Hultink e Schoormans (1995),cuja investigação menciona a desnatação de preço pelo seu melhor desempenho ao desconsiderar os efeitos de rede a heterogeneidade dos agentes. 


\subsubsection{Simulação II: Difusão em diferentes composições sociais}

Diferentes composições sociais,conforme a tabela 3, foram simuladas com o proposito de compreender a influência da heterogeneidade no processo de difusão.A demanda por combustível foi fixado em estado de desabastecimento e formato de rede aglomerado. Os mesmos parâmetros para estratégia de preço presentes no modelo I (tópico 3.1.2) foram empregados.

Na figura 18, as estratégias apresentadas em sociedades parcialmente racionais não apresentaram diferenças significativas em sua evolução.Produtos concorrentes ao carro elétrico também seguiram tendências similares nas três estratégias.

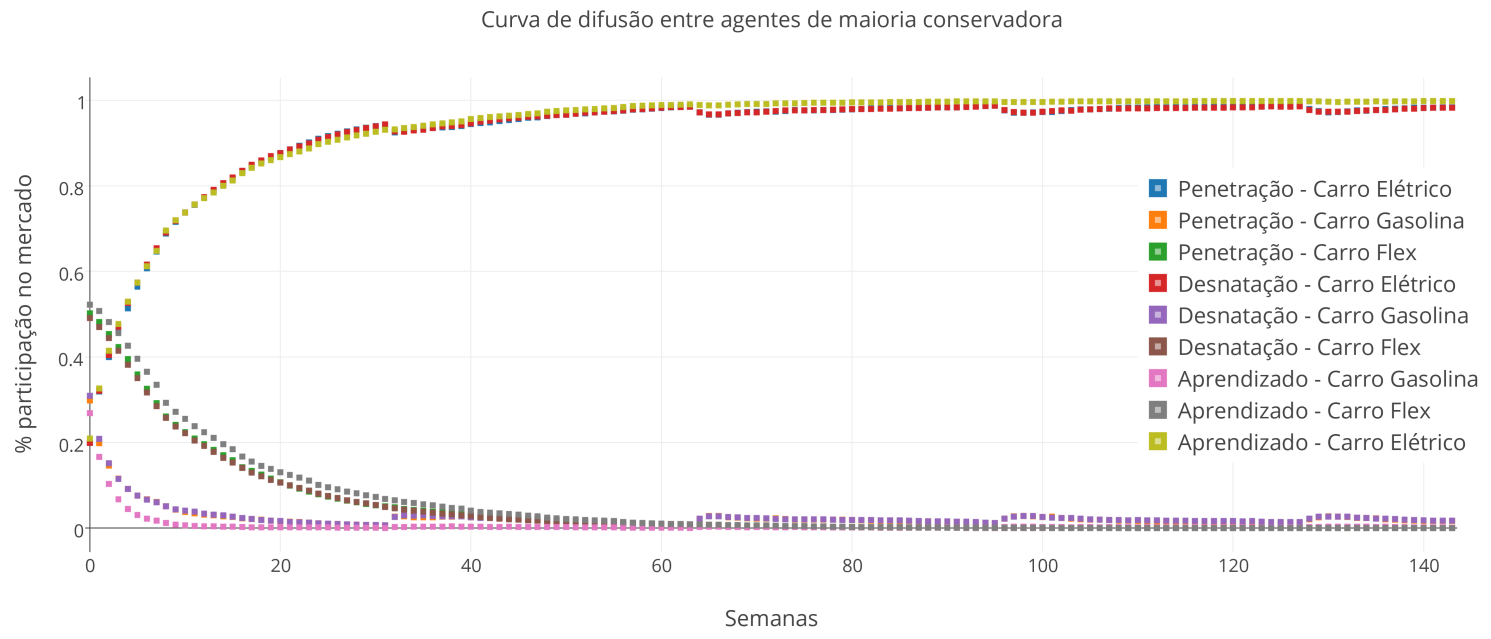

Figura 18 - Curva parcialmente conservadora - 60\% dos agentes são conservadores

Já em sociedades parcialmente racionais, as estratégias de precificação não apresentaram diferença perceptível visualmente quanto aos seus resultados. No entanto foi notado na figura 19 a adoção sensivelmente mais rápida do carro elétrico. Outro ponto, vendas marginais do carro com motor a gasolina ocorreram ao longo das interações.

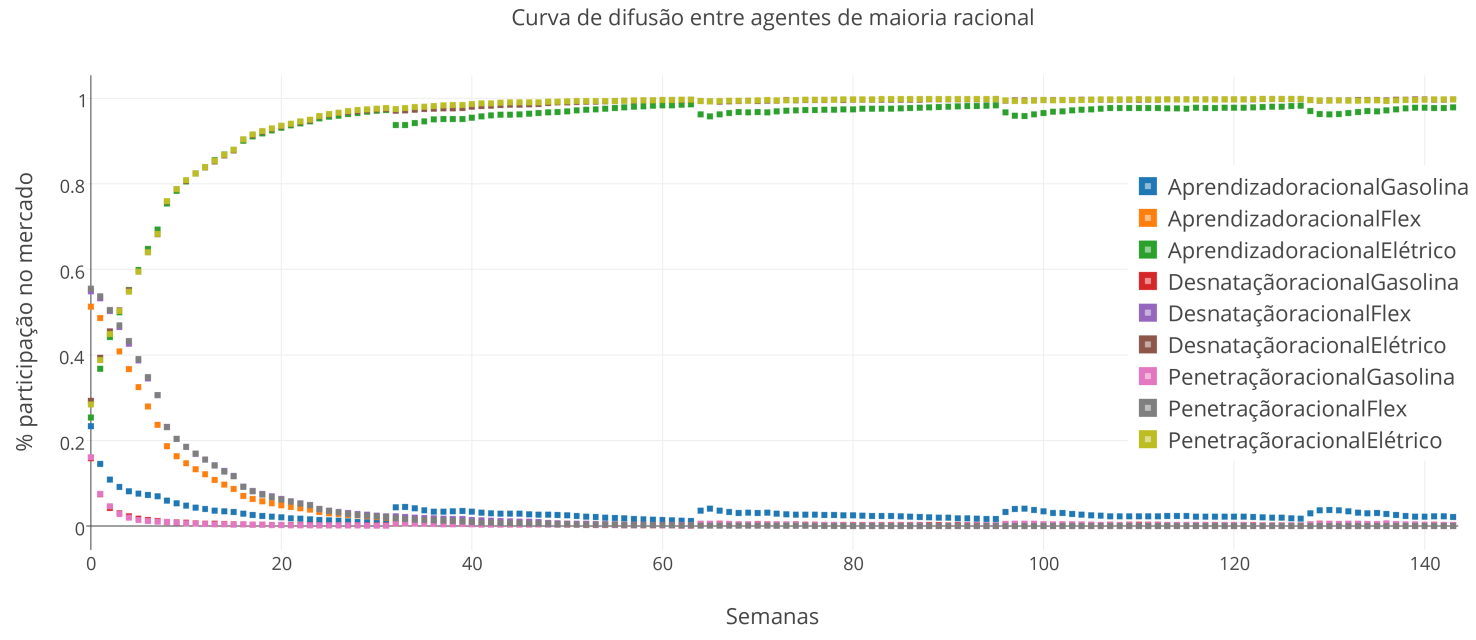

Figura 19 - Curva parcialmente racional - 60\% dos agentes são racionais 
Sociedades parcialmente sociais apresentam o maior tempo necessário para que o carro elétrico atinja a participação maior que $95 \%$ do mercado, conforme indica a figura 20.A pressão social desempenha papel-chave nesta dinâmica. Ao iniciar a simulação, poucos agentes adquirem ou possuem um carro elétrico. Tendo como parâmetro de decisão sobre novas tecnologias, a proporção de usuários ligados em sua rede direita de contatos, muitos agentes acabam consumindo carros de gasolina e flex dada sua estrutura social vigente. No entanto, a medida que mais agentes adotam carros elétricos, seus pares são compelidos a fazerem o mesmo dado a pressão social exercida.

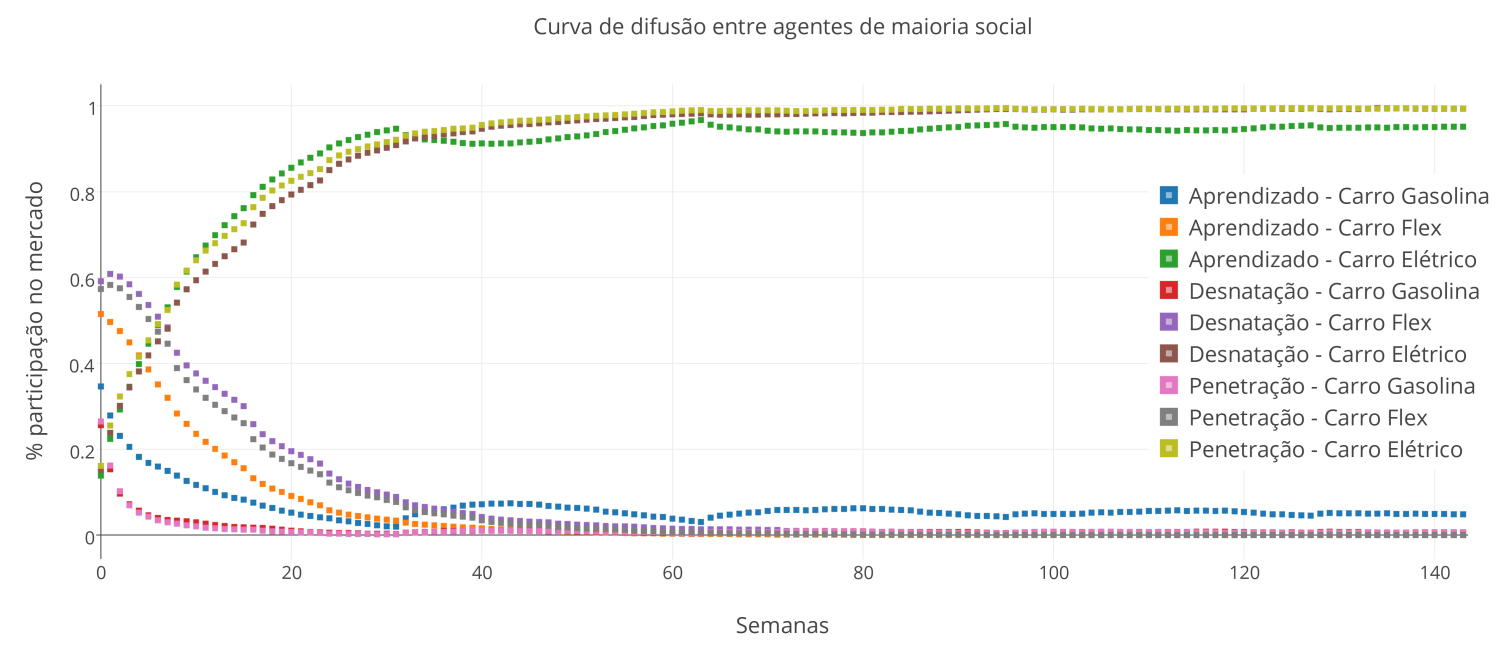

Figura 20 - Curva parcialmente social - 60\% dos agentes são sociais

Por meio da análise descrita, podemos notar que as redes com parcela maior de agentes com comportamento social possuem um processo de difusão mais moroso, seguido pelos conservadores. Já os agentes racionais adotaram mais prontamente o carro elétrico em detrimento de todos os outros produtos dado sua percepção sobre os benefícios/custos serem superiores ao longo prazo mesmo quando o carro elétrico seja o mais caro.

Nas figuras 22,23 e 22, os quadros apresentam sequências de estados discretos diferentes (tipo de carro) para cada $\tau$ pelos quais cada agente passou. Eles foram divididos nos diferentes comportamento sociais investigados. Cada cor representa um determinado produto:vermelho, laranja e verde são gasolina, flex e elétrico respectivamente. Cada retângulo , representa um momento em que o agente é indagado se continuará ou não com determinada tecnologia.

Por exemplo, em $\tau=1$, o agente $n$ estava com a tecnologia laranja. Em $\tau=12$ ele é novamente indagado por seus pares e/ou a vida útil de seu automóvel se extinguiu.Assim o agente irá tomar decisão de acordo com seu perfil. Caso ele opte em continuar, o quadrado seguinte será laranja caso contrário será de outra cor.

No histórico conservador da figura 21, podemos notar uma maior volatilidade inicial de diferentes produtos e por fim uma convergência para o carro elétrico. Esta 
maior volatilidade é carregada especialmente pelo comportamento conservador do agente em não realizar substituições de sua tecnologia mas sim somente atualizando ela. O agente irá realizar mudança tecnológica somente quando a vida útil do carro extinguir.

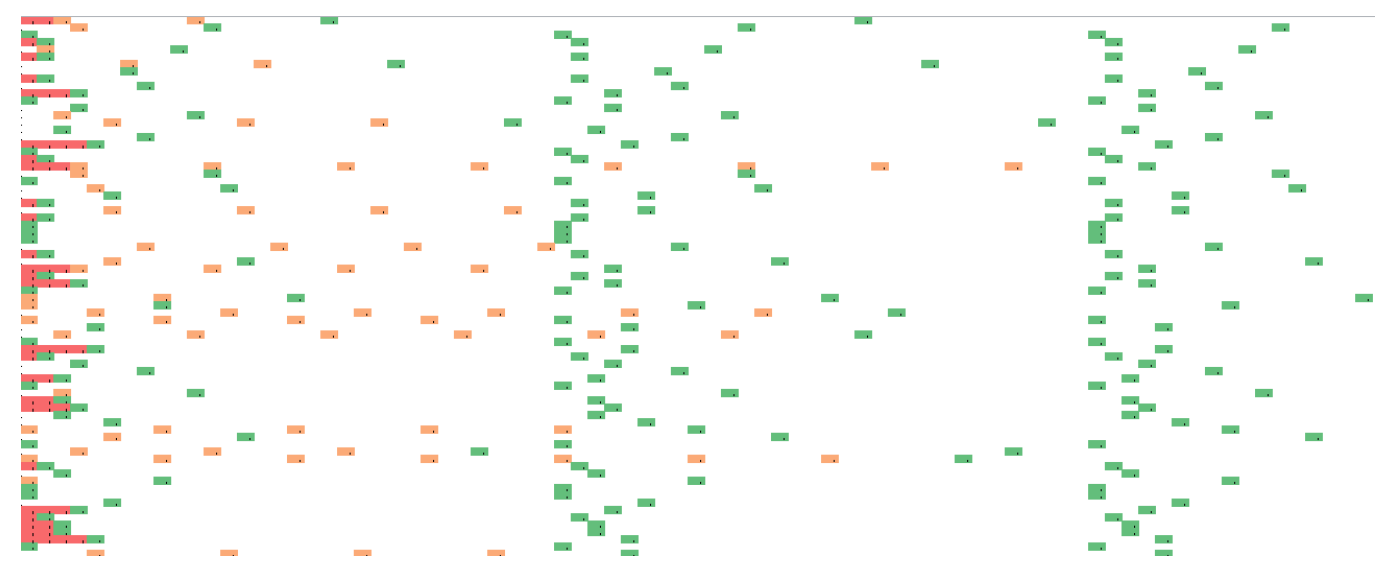

Figura 21 - Histórico conservador

Podemos ver que o tempo e padrão de adoção muda fortemente ao caracterizarmos todos os agentes como racionais. No histórico racional, podemos notar uma menor volatilidade inicial de diferentes produtos e por fim uma convergência muito rápida para o carro elétrico. Esta menor volatilidade é carregada especialmente pelo comportamento racional do agente em realizar substituições de sua tecnologia assim que notar um maior gasto ocasionado pelo seu comportamento de consumo e custo do combustível passado e seu viés perceptivo quanto ao custo futuro do combustível.
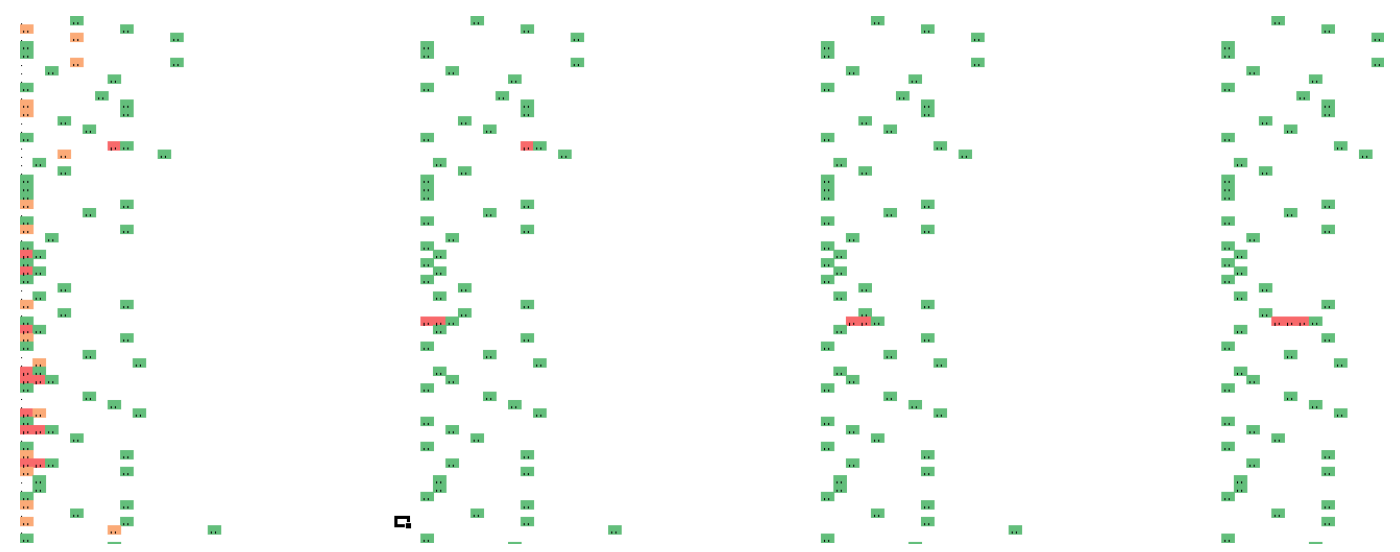

Figura 22 - Historico racional

No histórico social, podemos notar uma maior volatilidade temporária de alguns agentes e a sua influência sobre os demais. Esta maior volatilidade temporal é carregada especialmente pelo comportamento social do agente em realizar substituições de sua tecnologia somente quando seus pares diretamente conectados são também adotantes e proporção deles sobre a sua rede é maior que seu limiar. Podemos ver longos riscos horizontais do carro a gasolina(vermelho). Isto se deve ao constante indagamento que os agentes passam sobre seus contatos diretos a cada rodada. Caso ele não tenha contato 
suficiente, ele pontuará como vermelho. Caso ele não seja indagado, nenhuma cor irá aparecer no próximo $\tau+1$ mas sua cor irá mudar se ele adotar outra tecnologia.
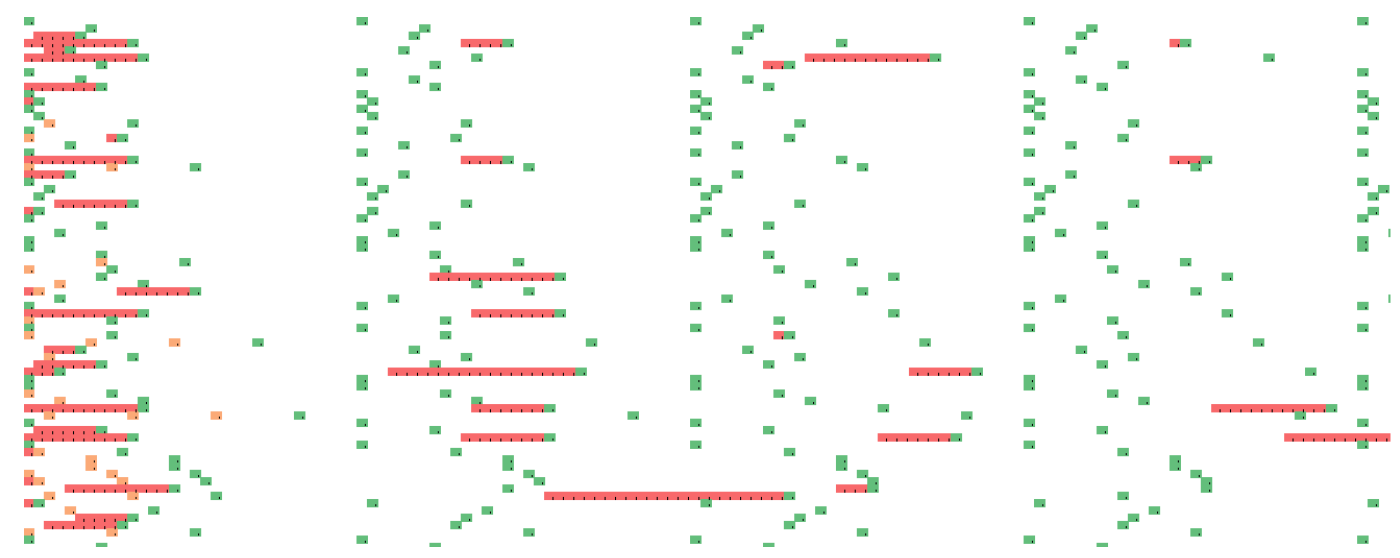

Figura 23 - Historico social

A análise sequencial de eventos discretos virou um tema popular nos últimos anos. Especialmente em decorrência dos pacotes estatísticos desenvolvidos para essa finalidade, especialmente no ramo da análise genética, em sua busca por padrões sequencias transversais e longitudinais dos 5 elementos básicos que compõe uma fita genética (A,T,C,G e $\mathrm{U})$.

Na literatura das ciências sociais aplicadas, as mudanças de estado (tipo de carro adquirido ao longo do tempo)podem ser identificados como eventos discretos provedoras de informações pertinentes sobre o comportamento dos agentes e se há diferença estatisticamente significativas entre os distintos comportamentos sociais apresentados.

Entropia,conceito da física, mais especificamente na termodinâmica, mede a desordem das partículas de um sistema físico. O cálculo de entropia de Shannon é um importante método na análise de sequência.Ela pode ser vista como uma medida de diversidade de estados observados em determinada posição $t$.

Esta medida providencia em cada posição $t$ da sequência, o valor de entropia de Shannon para distribuições transversais(LIN, 1991). Esta medida tem sido utilizada nas ciências sociais, por exemplo, em evolução de carreira de cidadãos americanos (BARBAN; BILLARI, 2012). Sendo que $p_{i}$ denota a proporção de estados $i$ em posição $t$, assim, a entropia é dada por:

$$
h\left(p_{1}, \ldots, p_{a}\right)=-\sum_{i=1}^{a} p_{i} \log \left(p_{i}\right)
$$

Da qual $a$ é a quantidade de níveis para cada estado. A entropia será 0 quando todos os resultados futuros são previsíveis, e ela será 1 ao demonstrar instabilidade máxima quanto aos estados em cada posição $t$. Por exemplo, a língua inglesa possui um baixo de valor de entropia, ou seja, ele é altamente previsível. Após o conhecimento das letras inicias 
de uma palavra, é muito provável acertar o restante da palavra. Seu valor de entropia é 0.6 aproximadamente. Já o Mandarim, alfabeto que emprega ideogramas independentes, possui $-\log 2(1 / 2500)=11.3$ de entropia.

O quadro abaixo mostra diferenças quanto ao valor de entropia de Shannon. De acordo com a média aritmética obtida em 30 simulações para cada parâmetro,notou-se um aumento significativo da entropia quando todos os agentes adotavam comportamentos sociais iguais nas três dinâmicas.

\begin{tabular}{ccc}
\hline Tipo & Parcial & Integral \\
\hline racional & 0.77 & 0.83 \\
Social & 0.64 & 0.91 \\
Racional & 0.51 & 0.88
\end{tabular}

Na tabela 10, foi constatado que as três configurações sociais apresentam diferenças estatisticamente significativas ao nível de $95 \%$ por meio de uma análise de variância (ANOVA) de fator único.

Tabela 10 - Teste ANOVA sobre composição social:parcial x integral

\begin{tabular}{ccccccc}
\hline Fonte de variação & SQ & Gl & MQ & F & Valor-P & F-Crítico \\
\hline Entre grupos & 0.084 & 1 & 0.084 & 9.324 & 0.037 & 7.70 \\
Dentro dos grupos & 0.036 & 4 & 0.009 & & & \\
Total & 0.1207 & 5 & & & &
\end{tabular}

O Valor-P obtido foi de 9.324, superior ao valor F-crítico mínimo de 7.70. Além disso, rejeitamos a hipótese nula a $\alpha(1-1 \%)$ pois o valor-P obtido, 0.0378 é significativamente menor que 0.05 .

Também foi realizado um outro experimento comparativo afim de entender comparativamente, a evolução da curva de adoção em diferentes cenários de heterogeneidade junto as três estratégias de precificação.Uma rede composta integralmente por agentes com perfil conservador não apresentaram indícios de diferença significativa sobre uma sociedade parcialmente conservadora conforme mostra o gráfico 24. 


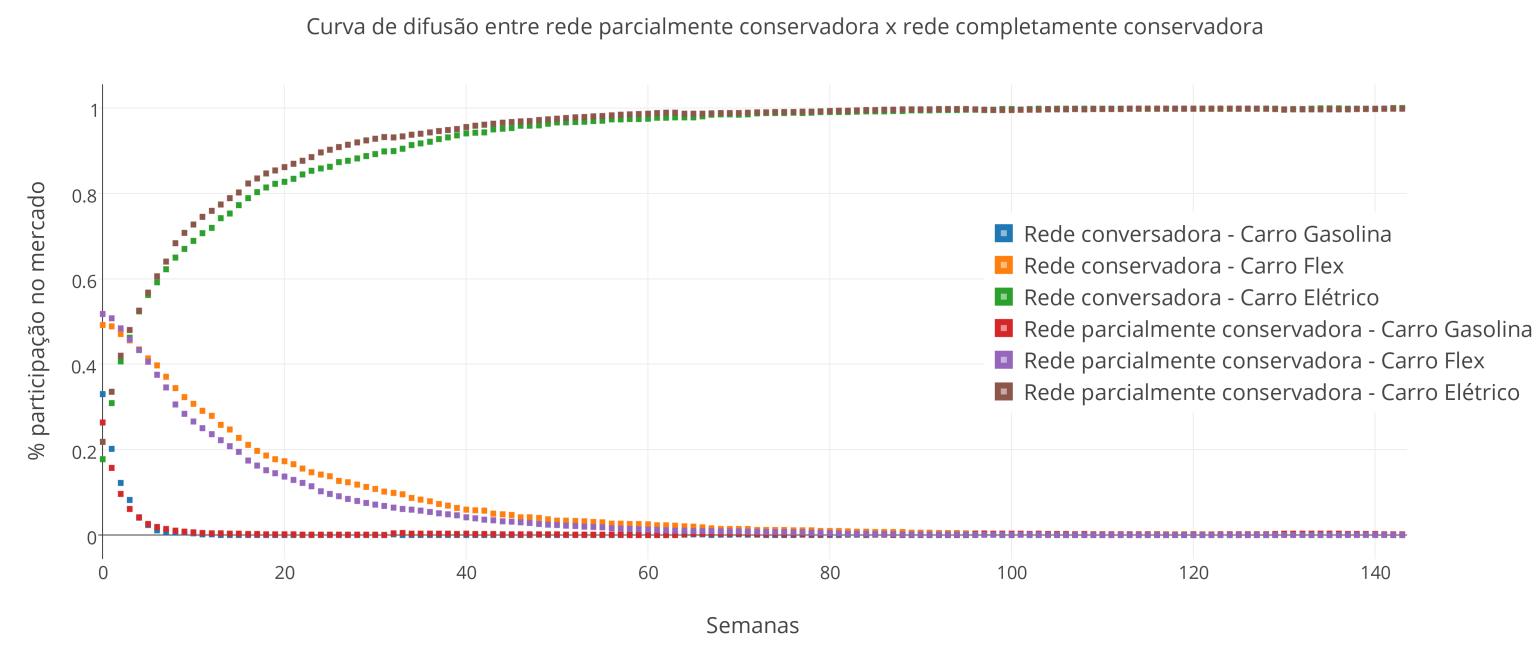

Figura 24 - Curva parcialmente x total conservadora

Diferente do gráfico 24, as redes composta integralmente por agentes racionais e sociais apresentaram características significativamente diferentes.Redes compostas inteiramente por agentes racionais, como mostra o gráfico 25 adotaram com maior velocidade o carro elétrico em detrimento aos outros produtos menos eficientes, ainda que mais baratos.

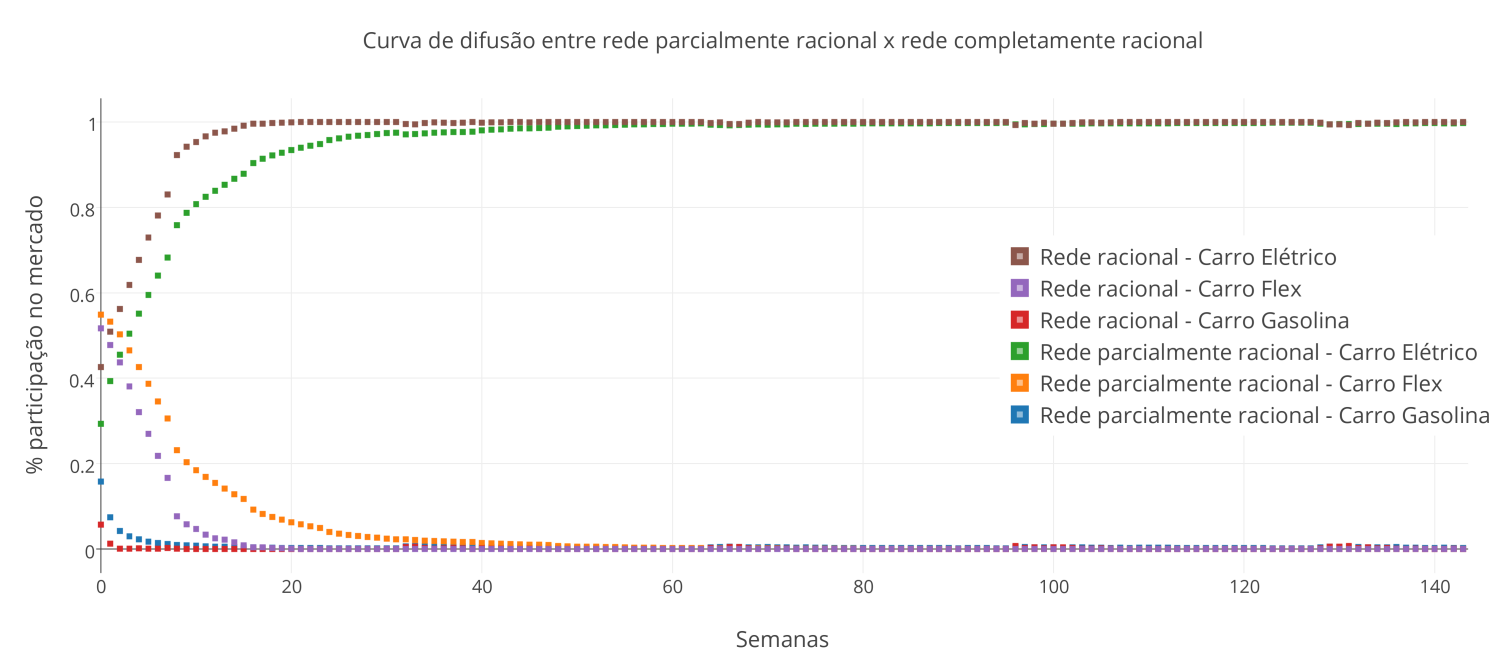

Figura 25 - Curva parcialmente x total racional

No gráfico 26, a rede em que sua totalidade é composta por agentes sociais, a taxa de adoção do carro elétrico foi mais acentuada se comparada a rede parcial.Os valores de entropia de Shannon para estas duas configurações, foram a que apresentaram maior crescimento se comparado ao comportamento racional. 


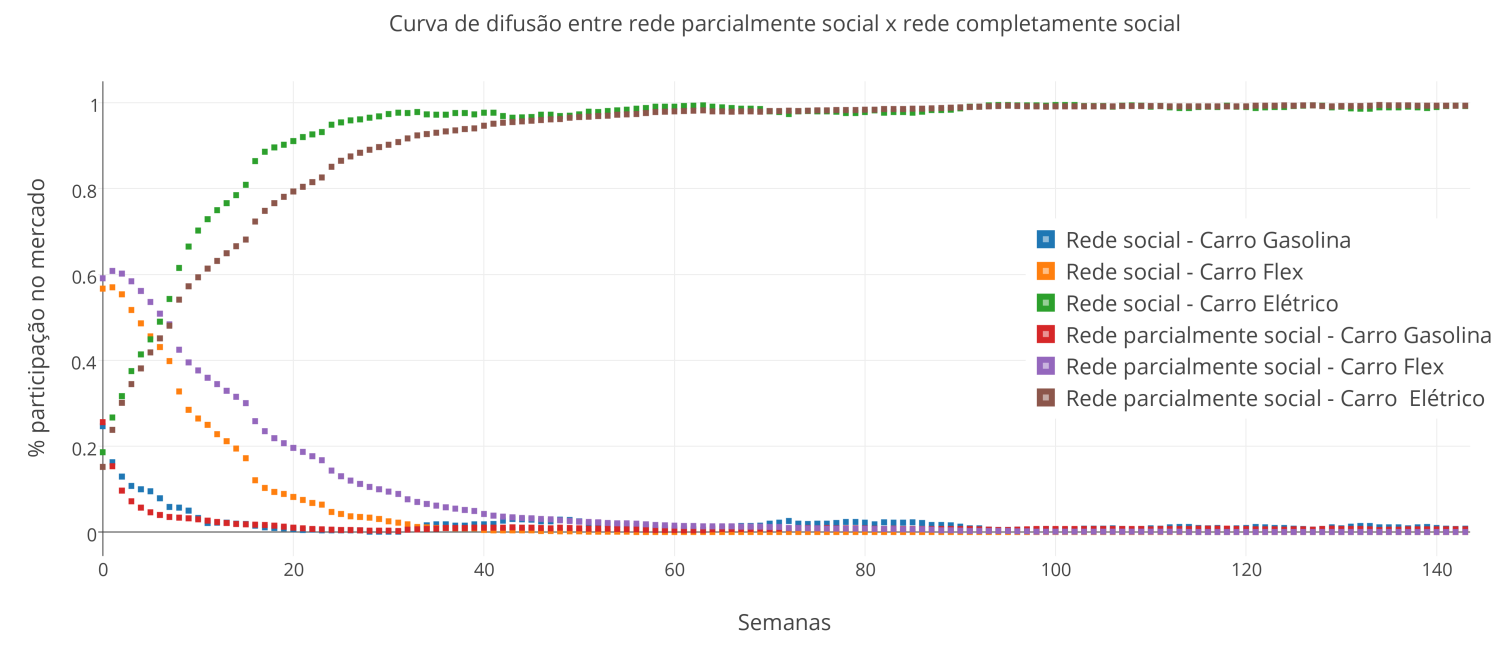

Figura 26 - Curva parcialmente x total social

A média resultante de 50 simulações para cada parâmetro foram compputadas com o intuito de aferir o faturamento e \% na participação do mercado. A estratégia de desnatação apresentou a melhor performance em termos de faturamento em todos os cenários simulados, tanto em sociedades parciais quanto integrais.

\begin{tabular}{|c|c|c|c|c|c|c|c|c|c|}
\hline \multicolumn{10}{|c|}{ Cenário com agentes conservadores } \\
\hline \multicolumn{4}{|c|}{ \% Participação no mercado } & \multicolumn{6}{|c|}{ Faturamento bruto em $\mathrm{R} \$$} \\
\hline Tipo & Gasolina & Flex & Elétrico & & Gasolina & & & & Elétrico \\
\hline Aprendizado - Conservador parcial & $1.6 \%$ & $0.0 \%$ & $98.4 \%$ & $\mathrm{R} \$$ & $14,994,000.0$ & $\mathrm{R} \$$ & - & $\mathrm{R} \$$ & $389,542,952.1$ \\
\hline Penetração - Conservador parcial & $1.5 \%$ & $0.0 \%$ & $98.5 \%$ & $\mathrm{RS}$ & $15,084,000.0$ & $\mathrm{R} \$$ & - & $\mathrm{RS}$ & $391,251,237.8$ \\
\hline Desnatação - Conservador parcial & $1.7 \%$ & $0.0 \%$ & $98.3 \%$ & $\mathrm{R} \$$ & $15,354,000.0$ & $\mathrm{R} \$$ & - & $\mathrm{R} \$$ & $644,118,269.1$ \\
\hline Aprendizado - Conservador integral & $0.2 \%$ & $0.0 \%$ & $99.7 \%$ & $\mathrm{R} \$$ & $9,774,000.0$ & $\mathrm{R} \$$ & - & $\mathrm{R} \$$ & $391,661,461.2$ \\
\hline Desnatação - Conservador integral & $0.3 \%$ & $0.0 \%$ & $99.7 \%$ & $R \$$ & $9,423,000.0$ & $R \$$ & - & $\mathrm{R} \$$ & $650,486,319.2$ \\
\hline Penetração - Conservador integral & $0.2 \%$ & $0.0 \%$ & $99.8 \%$ & RS & $9,333,000.0$ & $\mathrm{R} \$$ & - & $\mathrm{R} \$$ & $647,396,688.3$ \\
\hline
\end{tabular}

Figura 27 - Tabela de performance - Conservador x Parcialmente conservador

O ambiente social foi a mais gerou receita. Sociedades composta integralmente por um único tipo social foram as que mais geraram receita. Já a estratégia de penetração foram igualmente eficientes em todos os cenários sociais compostos integralmente por um único tipo de comportamento social.

\begin{tabular}{|c|c|c|c|c|c|c|c|c|c|}
\hline \multicolumn{10}{|c|}{ Cenário com agentes racionais } \\
\hline \multicolumn{4}{|c|}{ \% Participação no mercado } & \multicolumn{6}{|c|}{ Faturamento bruto em $\mathrm{R} \$$} \\
\hline Tipo & Gasolina & Flex & Elétrico & & Gasolina & & & & Elétrico \\
\hline Aprendizado - Racional parcial & $0.0 \%$ & $0.0 \%$ & $100.0 \%$ & $\mathrm{R} \$$ & $29,232,000.0$ & $R S$ & - & $\mathrm{R} \$$ & $371,666,029.8$ \\
\hline Penetração - Racional parcial & $1.9 \%$ & $0.0 \%$ & $98.1 \%$ & $\mathrm{R} \$$ & $23,616,000.0$ & $\mathrm{R} \$$ & - & $\mathrm{R} \$$ & $334,720,000.0$ \\
\hline Desnatação - Racional parcial & $2.2 \%$ & $0.0 \%$ & $97.8 \%$ & $\mathrm{RS}$ & $23,742,000.0$ & $\mathrm{RS}$ & - & $\mathrm{R} \$$ & $635,163,430.2$ \\
\hline Aprendizado - Racional integral & $2.1 \%$ & $0.0 \%$ & $97.9 \%$ & $\mathrm{R} \$$ & $23,400,000.0$ & $\mathrm{R} \$$ & - & $R \$$ & $386,688,492.3$ \\
\hline Desnatação - Racional integral & $0.0 \%$ & $0.0 \%$ & $100.0 \%$ & $R \$$ & $29,160,000.0$ & $\mathrm{RS}$ & - & $\mathrm{R} \$$ & $590,906,399.3$ \\
\hline Penetração - Racional integral & $0.0 \%$ & $0.0 \%$ & $100.0 \%$ & $\mathrm{R} \$$ & $30,654,000.0$ & $\mathrm{R} \$$ & - & $\mathrm{R} \$$ & $593,145,651.1$ \\
\hline
\end{tabular}

Figura 28 - Tabela de performance - Racional x Parcialmente racional 
Enquanto a estratégia de aprendizado apresentou a menor performance em todos os cenários analisados.

\begin{tabular}{|c|c|c|c|c|c|c|c|c|c|}
\hline \multicolumn{10}{|c|}{ Cenário com agentes sociais } \\
\hline \multicolumn{4}{|c|}{ \% Participação no mercado } & \multicolumn{6}{|c|}{ Faturamento bruto em $\mathrm{R} \$$} \\
\hline Tipo & Gasolina & Flex & Elétrico & & Gasolina & & Flex & & Elétrico \\
\hline Aprendizado - Social parcial & $5.6 \%$ & $0.0 \%$ & $94.4 \%$ & $\mathrm{RS}$ & $23,058,000.0$ & $\mathrm{R} \$$ & - & $\mathrm{R} \$$ & $415,068,670.0$ \\
\hline Penetração - Social parcial & $5.6 \%$ & $0.0 \%$ & $94.4 \%$ & $\mathrm{R} \$$ & $22,644,000.0$ & $\mathrm{R} \$$ & $320,000.0$ & $\mathrm{R} \$$ & $362,800,000.0$ \\
\hline Desnatação - Social parcial & $5.3 \%$ & $0.0 \%$ & $94.7 \%$ & $\mathrm{R} \$$ & $24,192,000.0$ & $\mathrm{R} \$$ & - & $\mathrm{R} \$$ & $689,491,315.3$ \\
\hline Aprendizado - Social integral & $8.6 \%$ & $0.0 \%$ & $91.4 \%$ & $R \$$ & $32,418,000.0$ & $\mathrm{R} \$$ & $1,984,000.0$ & $\mathrm{R} \$$ & $469,653,490.6$ \\
\hline Desnatação - Social integral & $8.6 \%$ & $0.0 \%$ & $91.4 \%$ & $\mathrm{R} \$$ & $32,895,000.0$ & $\mathrm{R} \$$ & - & $\mathrm{R} \$$ & $743,630,499.4$ \\
\hline Penetração - Social integral & $8.5 \%$ & $0.0 \%$ & $91.5 \%$ & $\mathrm{RS}$ & $32,418,000.0$ & $\mathrm{RS}$ & - & $\mathrm{RS}$ & $752,983,676.7$ \\
\hline
\end{tabular}

Figura 29 - Tabela de performance - Social x Parcialmente social

Encontramos pulo de geração de tecnologia em todos os cenários, ainda que haja vendas residuais de carros flexíveis no ambiente social. Embora a grande totalidade dos veículos em $\tau=144$ sejam elétricos, os veículos mais baratos - motor a gasolina, registraram vendas maiores que os veículos Flex.

Afim de testar a hipótese de que as estratégias de precificação possuem médias significativamente diferentes ao considerar diferentes formatos sociais, 3 etapas foram utilizadas. A primeira consiste na análise de agrupamento por K-médias utilizando dados categóricas e numéricos das tabelas 27,28 e 29.

\section{Dendograma}

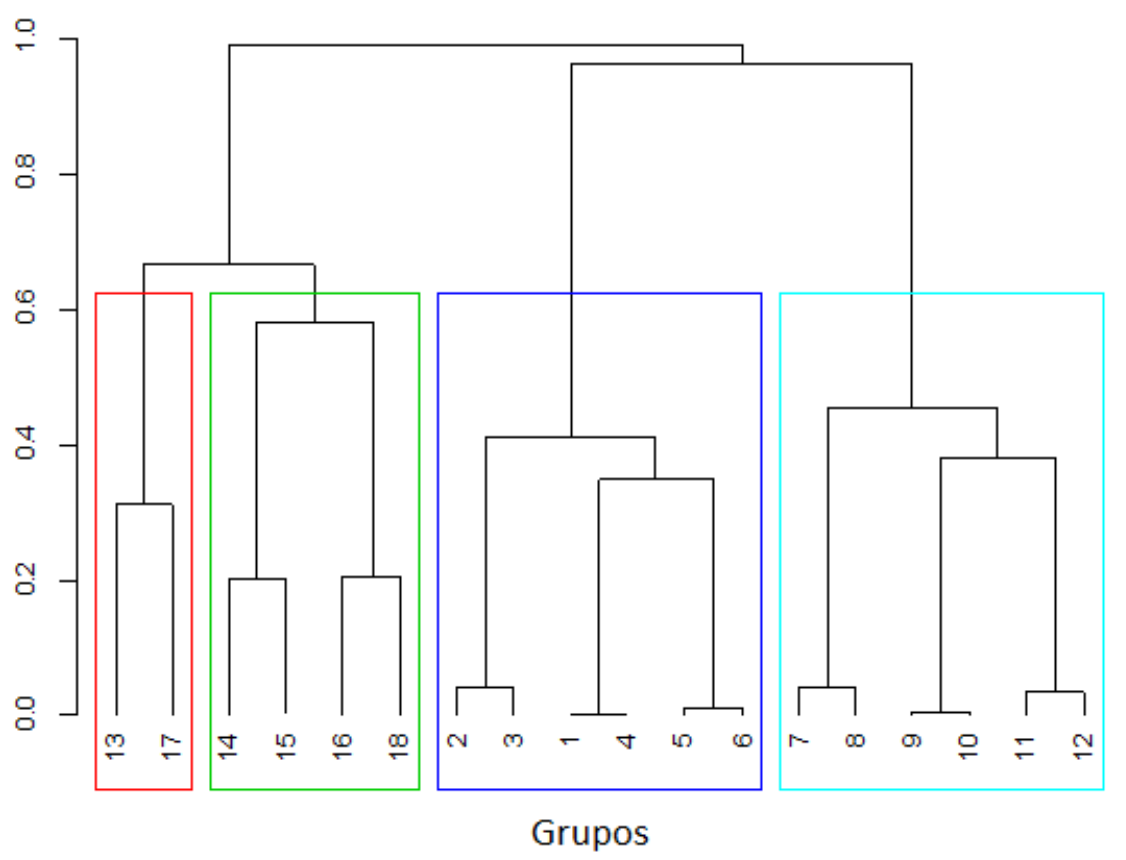

Figura 30 - Dendograma

Na figura 31, temos um consolidação da análise de agrupamento. A estratégia 
de desnatação apresentou a melhor performance em termos de faturamento em todos os cenários simulados, tanto em sociedades parciais quanto integrais e ela se encontra no grupo 1, representado pelo agrupamento azul claro do dendograma. A estratégia de penetração também no mesmo grupo mas com suas variantes com uma sociedade integral. No grupo 2,destacado pelo bloco de cor azul escuro, podemos ver melhora das redes racionais com desnatação e penetração enquanto em redes sociais uma melhora pela estratégia de aprendizado. Grupo 3 e 4,destacado pela cor vermelha e verde respectivamente, possuem sobreposição e as redes parciais geram a menor receita para todas as estratégias exceto desnatação. Podemos ver as diferenças entre os grupos gerados no boxplot 32

\begin{tabular}{|c|c|c|c|c|}
\hline Grupo & Sociedade & tipo & Estratégia & Faturamento \\
\hline 1 & Social & integral & Penetração & $\mathrm{R} \$ \mathbf{7 5 2 , 9 8 3 , 6 7 7}$ \\
\hline 1 & Social & integral & Desnatação & $\mathrm{R} \$ 743,630,499$ \\
\hline 1 & Social & parcial & Desnatação & $\mathrm{R} \$ \quad 689,491,315$ \\
\hline 1 & Conservador & integral & Desnatação & $\mathrm{R} \$ \quad 650,486,319$ \\
\hline 1 & Conservador & integral & Penetração & $\mathrm{R} \$ \quad 647,396,688$ \\
\hline 1 & Conservador & parcial & Desnatação & $\mathrm{RS} \quad 644,118,269$ \\
\hline 2 & Racional & parcial & Desnatação & $\mathrm{R} \$ \mathbf{6 3 5 , 1 6 3 , 4 3 0}$ \\
\hline 2 & Racional & integral & Penetração & $\mathrm{RS} \quad 593,145,651$ \\
\hline 2 & Racional & integral & Desnatação & $\mathrm{R} \$ 590,906,399$ \\
\hline 2 & Social & integral & Aprendizado & $\mathrm{RS} \quad 469,653,491$ \\
\hline 2 & Social & parcial & Aprendizado & $\mathrm{R} \$ 415,068,670$ \\
\hline 2 & Conservador & integral & Aprendizado & $\mathrm{R} \$ 391,661,461$ \\
\hline 3 & Conservador & parcial & Penetração & $\mathrm{R} \$ 391,251,238$ \\
\hline 4 & Conservador & parcial & Aprendizado & $\mathrm{R} \$ 389,542,952$ \\
\hline 4 & Racional & integral & Aprendizado & $\mathrm{R} \$ 386,688,492$ \\
\hline 4 & Racional & parcial & Aprendizado & $\mathrm{R} \$ \$ 371,666,030$ \\
\hline 3 & Social & parcial & Penetração & $\mathrm{R} \$ 362,800,000$ \\
\hline 4 & Racional & parcial & Penetração & $\mathrm{R} \$ 334,720,000$ \\
\hline
\end{tabular}

Figura 31 - Grupo formado pela análise de agrupamento - K=4

Estratégia de penetração é super forte em qualquer tipo de sociedade exceto redes parciais pois ela é composta por diversos agentes com diferentes comportamentos. Como a estratégia é baseada em atingir escala de vendas no menor tempo possível e assim recuperar o faturamento no decorrer das interações. Na estratégia de aprendizado apresentou característica menos robusta, sendo ele fraca para redes racionais(agentes que buscam otimizar o menor preço o quanto antes).

O ambiente social foi a maior geradora de receita. Sociedades compostas integralmente por um único tipo social foram as que mais geraram receitas em sua totalidade se comparadas as redes parciais.Já a estratégia de penetração foi igualmente eficiente em todos os cenários sociais em que todos os agentes possuíam apenas um único comportamento social. Enquanto a estratégia de aprendizado apresentou a menor performance em todos os cenários analisados.

Testes foram realizados para mensurar a diferença das estratégias quanto à \% na participação do mercado e no faturamento.Na terceira coluna da tabela 9,podemos notar os P-valores acima do nível do nível de significância de $5 \%$. 


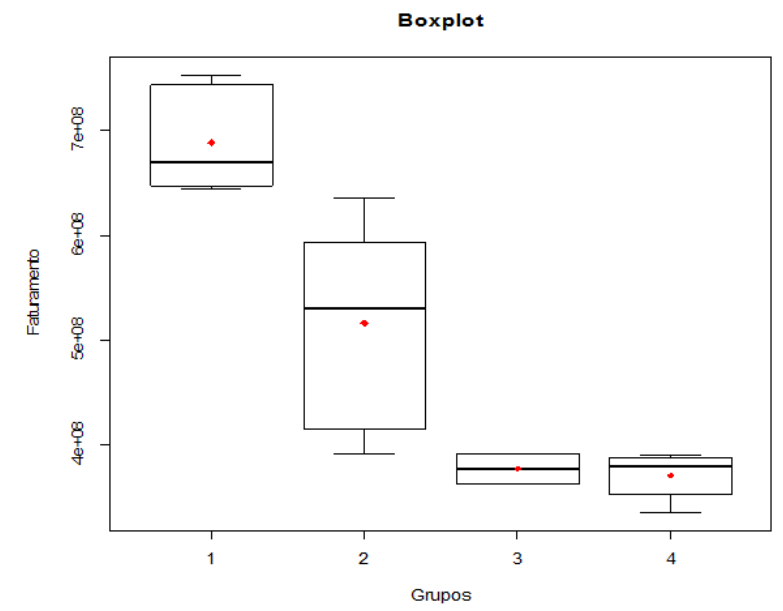

Figura 32 - BoxPlot

Tabela 11 - Tabela de processo Fischer - Sim2

\begin{tabular}{ccccc}
\hline Diferença entre níveis(grupos) & Média & $L_{i}$ & $L_{s}$ & P-Valor \\
\hline $1-2$ & $\mathrm{R} \$ 172.084$ & $\mathrm{R} \$ 850.676$ & $\mathrm{R} \$ 258.492$ & 0.0008 \\
$1-3$ & $\mathrm{R} \$ 310.992$ & $\mathrm{R} \$ 188.792$ & $\mathrm{R} \$ 433.191$ & 0.0000001 \\
$1-4$ & $\mathrm{R} \$ 317.363$ & $\mathrm{R} \$ 220.756$ & 413.970 & 0.0000002 \\
$2-3$ & $\mathrm{R} \$ 138.907$ & $\mathrm{R} \$ 16.707$ & 261.107 & 0.0039 \\
$2-4$ & $\mathrm{R} \$ 145.278$ & $\mathrm{R} \$ 48.671$ & 241.886 & 0.0029 \\
$3-4$ & $\mathrm{R} \$ 6.371$ & $-\mathrm{R} \$ 123.241$ & 135.983 & 0.8766
\end{tabular}

Desta forma, rejeitamos a hipótese de igualdade entre todos os níveis exceto ao nível 3-4 dado seu p-valor se acima da taxa de significância $\alpha=95 \%$.

Embora a bibliografia indique que a heterogeneidade afeta positivamente o processo de adoção, neste caso podemos dizer que agentes comportamentos similares contribuíram para aumentar a propagação.Uma possível explicação está na dinâmica social de tribos e suas aglutinações junto a agentes similares embarcados em uma rede composta por outras diversos tribos (WEISS, 2000). 
Intervalos de Confiança (95\%)

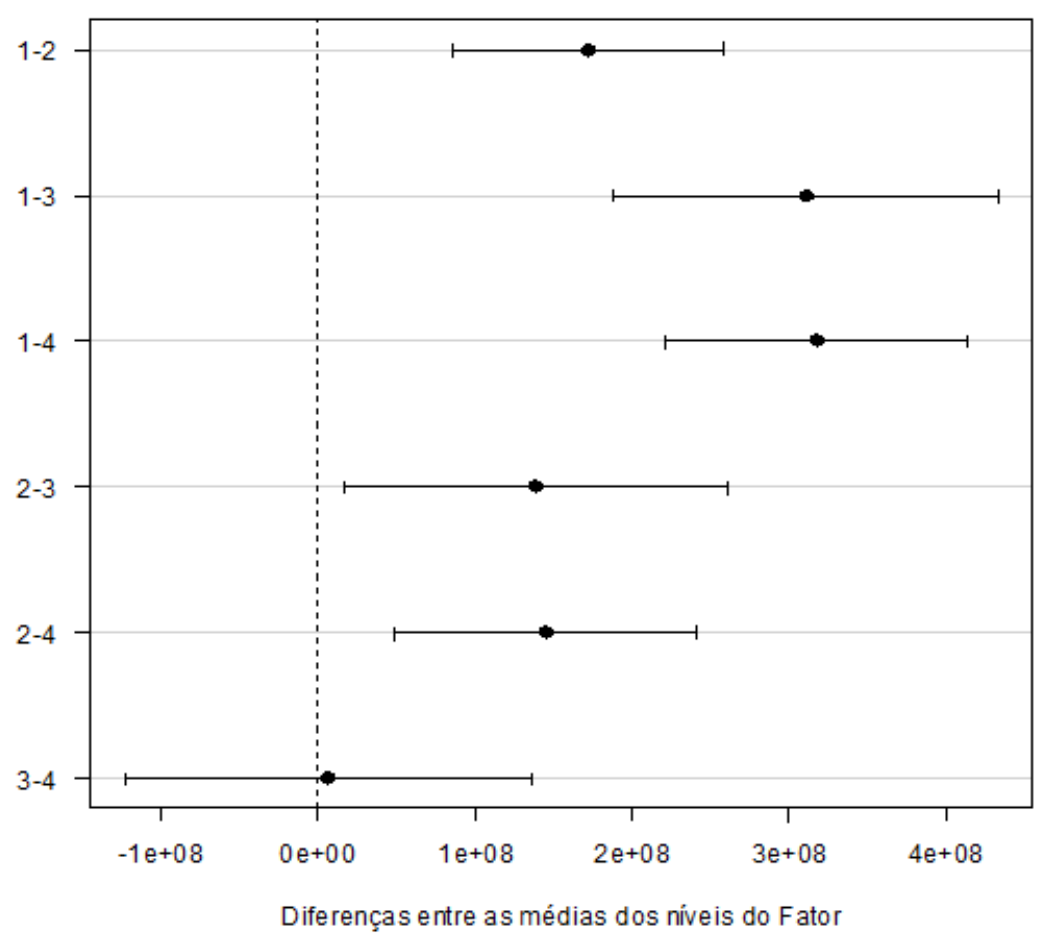

Figura 33 - Intervalo de confiança 



\section{Conclusão}

Neste trabalho, buscou-se preencher uma lacuna na literatura de estratégias para lançamento de novos produtos. Recentemente, muitos pesquisadores e acadêmicos da área de marketing têm demonstrado um maior grau de interesse na comercialização de produtos de alta tecnologia e valor agregado. Um sub-conjunto desta linha de pesquisa está na influência das variáveis que estão à mão das empresas sobre este fenômeno.

Um dos assuntos que interessam acadêmicos, pesquisadores e o mercado privado é se as estratégias de lançamento de novos produtos baseado nos trabalhos anteriores são apropriados para a realidade atual.O ponto de vista teórico e aplicado dos sistemas complexos utilizado neste trabalho é mais um esforço para diminuir esta dúvida.

Diversos trabalhos gerais em sistemas complexos com enfoque em difusão, informação, epidemias,crises e traços genéticos foram desenvolvidos e muitas vezes influenciaram trabalhos posteriores na área de economia e administração. No entanto, há escassez visível de trabalhos que envolvem a difusão de novos produtos direcionados à literatura de marketing. Esta investigação focou em três elementos fundamentais no processo de difusão: estratégias de precificação,influência da heterogeneidade e comportamento do consumidor e os efeitos provenientes das ligações e interações entre os agentes.

Embora o carro tenha evoluído em diferentes formas e utilidades, ainda dependemos majoritariamente de um único tipo de combustível, por isso, os desenrolares potenciais sobre a adoção do veículo elétrico e a sua repercussão dentro da cadeia produtiva e cultural, fazem desta tecnologia e a sua dinâmica de adoção, foco em diversos estudos nas ciências sociais aplicadas (PEREIRA, 2000; GRÜBLER, 1996; ZHANG; GENSLER; GARCIA, 2011)

Este estudo focou em três estratégias de precificação extensamente utilizado pela indústria automotiva (1)Desnatação (2)Penetração e (3)Aprendizado. Foram mensurados a participação final do mercado,faturamento bruto atingido e a evolução da taxa de adoção. Tivemos como base e parâmetro geral o mercado brasileiro de 2014 de automóveis de passeio com três diferentes tecnologias de combustível (1)Gasolina (2)Flex e (3) Elétrico. Embora haja diferentes fatores em que o consumidor pondera em sua tomada de decisão, a investigação limitou-se a entender sobre as diferentes categorias de combustível na qual os veículos de passeios se encaixam. Desta forma, o desempenho e a eficiência energética dos veículos são variáveis chaves para atender esta questão, especialmente quando notamos alta dependência da matriz energética não-renovável fóssil.

O aspecto de alta dependência foi trabalhado no modelo como um fator externo ponderante e influenciador para a adoção de produtos ao questionar sua eficiência ener- 
gética para cada tipo de veículo. Outro ponto importante considerado neste trabalho esta nas diferentes composições sociais dos agentes afim de explorar o papel da diversidade comportamental na dinâmica de difusão.

O sucesso efetivo dos produtos não depende apenas do custo/benefício proposto pelo produto mas também pelo valor derivado oriundo da aceitação dos outros agentes.Notase claramente este aspecto no segundo modelo, ao explorarmos a heterogeneidade dos agentes. Ao alterar os parâmetros comportamentais dos agentes no modelo, as três estratégias de precificação obtiveram desempenhos distintos para cada tipo de segmento, cada qual com suas características e padrões.

O modelo desenvolvido neste trabalho pode contribuir na melhoria da tomada de decisão ao oferecer suporte teórico advindo dos resultados coletados de diferentes dinâmicas de mercado.Ocasionando assim, a identificação de estratégias apropriadas para cada tipo de conjuntura. Administradores devem se atentar nas diferenças para cada estratégia ao introduzir produtos que possuam efeitos de rede, pois a dinâmica de competição e comportamento do consumo são muito diferentes aos dos produtos que não possuem efeitos de rede.

Os resultados do modelo conceitual proposto sugere que a estratégia de desnatação possui o melhor desempenho financeiro e igualmente mostrou-se a estratégia mais versátil em todas as composições sociais testadas. No entanto a sua curva de adoção pelos usuários foi a menos acentuada entre as três. Outro aspecto notado nesta estratégia, está na compra recorrente do produto mais barato(carro à gasolina), ainda que marginal, e o desaparecimento do carro mediano (Flex). Ainda que não seja conclusivo, a emergência deste comportamento pode ser baseado na liderança por custo e produto(KOTLER; KELLER, 2006; ??).

O mesmo não é visto na estratégia de penetração. Ela apresenta a maior taxa de adoção do carro elétrico no entanto apresenta performance distinta em faturamento. A estratégia de penetração apresentou faturamento maior comparado à estratégia de desnatação mas somente quando a composição social dos agentes eram completamente iguais. Caso elas fossem configuradas como parciais, seu desempenho deteriorava muito, tornando-se similar à estratégia de aprendizado. Uma das possíveis hipóteses deste comportamento está na entrada do mercado através da redução da sensibilidade do consumidor ao preço.Contudo, com o aumento de diferentes condutas sociais, outros requisitos comportamentais devem ser preenchidos igualmente, retardando a taxa de adoção. Por outro lado, quando a rede é formada por agentes dotados de atitudes similares, notamos a rápida convergência dada a pressão social exercida por seus pares similares e diretos. Desta forma, exploramos, ainda que indiretamente, os efeitos positivos na adoção oriundo das tribos formados por agentes similares Weiss (2000).

Ao mesmo tempo que a estratégia de penetração explora os ganhos de escala, a 
estratégia de aprendizado busca diminuir seus custos à medida que otimiza suas operações por meio da experiência. Embora ela tenha sido a estratégia com menor faturamento em todos as conjunturas sociais e energéticas, ainda assim, ela apresentou taxas de adoção tão acentuadas quanto ao da estratégia de penetração. De acordo com o porte da empresa, recursos e objetivos empresariais, ela pode ser a estratégia mais adequada para companhias que não possuem uma marca ou estrutura operacional inicial vantajosa o suficiente para usá-la em estratégias de desnatação ou penetração.

Conforme destacado na estratégia de desnatação, a contínua compra de carros baratos pelos agentes pode ser uma caminho a ser explorado por uma empresa concorrente neste ambiente.Sua entrada seria dado pela oferta de produtos mais baratos e a medida que sua curva de aprendizado progredi, ajustes posteriores podem ser realizados para concorrer diretamente à empresa que baseava-se somente na estratégia de desnatação. Podemos ver este fenômeno no mercado de celulares brasileiros. Liderado pela multinacional coreana Samsung, o surgimento de uma linha de celulares concorrente (Motorola), ambas com performance similar mas sendo esta vendida pela metade do preço, tem apresentado uma séria ameaça a hegemonia da marca no mercado nacional.

A primeira e segunda simulação apresentam diferenças significativas quanto ao faturamento.Isto se deve pelo uso apropriado de uma estratégia de precificação para cada tipo conjuntura social. Ambos os modelos utilizaram os mesmos parâmetros gerais porém, enquanto o primeiro modelo tinha os parâmetros de comportamento social fixo, o segundo modelo explorava diferentes estratégias de precificação para diferentes conjunturas sociais. O exercício da simulação foi capaz de gerar a emergência espontânea de diferentes montantes de faturamento ao explorar a técnica de segmentação por comportamento social.

O Mercado de automóveis de carro elétrico ainda é incipiente e serviu como contexto para investigação mais aprofundada sobre estratégias de precificação no lançamento de novos produtos com o olhar dos sistemas complexos, mais especificamente na teoria de redes complexas. Ele também foi utilizado para delimitar o propósito de estudo e consequentemente as limitações do modelo podem ser usadas para futuras pesquisas. A primeira está na questão orçamentária dos agentes. No modelo, os agentes podem comprar o carro sempre que o seu modelo de decisão pessoal permitir, independente de sua situação econômica. Outro ponto a ser discutido futuramente está no desenvolvimento de um modelo reativo dos produtos concorrentes perante as ações de precificação do carro elétrico. O modelo fixou os preço de carros flex e de gasolina por 3 anos, considerando sua categoria de motor e não pelo modelo de carro. No entanto, explorar o desenvolvimento de diversos modelos de carro com diferentes matrizes energéticas podem gerar investigações importantes e pertinentes ao tema do processo de difusão de novos produtos.

A difusão de novos produtos embora não seja um assunto novo a ser estudado, sempre foi uma fonte de estímulo aos pesquisadores das ciências econômicas.Buscar com- 
preender e empregar ferramentas de análise para melhorar o desempenho das decisões tomadas é o principal objetivo. O presente estudo buscou se esforçar nessa direção ao empregar o ponto de vista dos sistemas complexos diretamente sobre a literatura de marketing e administração. 


\section{Referências}

ABELL, P. M.; FELIN, T.; FOSS, N. J. Building micro-foundations for the routines, capabilities, and performance links. Capabilities, and Performance Links (February 2007), 2007. Citado na página 22.

ADAMIC, L. A. et al. Knowledge sharing and yahoo answers: everyone knows something. In: ACM. Proceedings of the 17th international conference on World Wide Web. [S.1.], 2008. p. 665-674. Citado na página 21.

ALI, A.; KRAPFEL, R.; LABAHN, D. Product innovativeness and entry strategy: impact on cycle time and break-even time. Journal of product innovation management, Wiley Online Library, v. 12, n. 1, p. 54-69, 1995. Citado na página 39.

ANDERIES, J. M.; JANSSEN, M. A.; OSTROM, E. A framework to analyze the robustness of social-ecological systems from an institutional perspective. Ecology and society, v. 9, n. 1, p. 18, 2004. Citado na página 26.

ARTHUR, W. B. Inductive reasoning and bounded rationality. The American economic review, JSTOR, p. 406-411, 1994. Citado na página 43.

ARTHUR, W. B. Increasing returns and. Harvard business review, v. 74, n. 4, p. 100-109, 1996. Citado na página 42.

ARTHUR, W. B. Complexity and the economy. science, American Association for the Advancement of Science, v. 284, n. 5411, p. 107-109, 1999. Citado 2 vezes nas páginas 22 e 43.

BARABÁSI, A.-L. Linked: How everything is connected to everything else and what it means for business, science, and everyday life. [S.1.]: Basic Books, 2014. Citado na página 27.

BARABÁSI, A.-L.; ALBERT, R. Emergence of scaling in random networks. science, American Association for the Advancement of Science, v. 286, n. 5439, p. 509-512, 1999. Citado 6 vezes nas páginas 21, 25, 27, 28, 29 e 33.

BARABASI, A.-L.; OLTVAI, Z. N. Network biology: understanding the cell's functional organization. Nature Reviews Genetics, Nature Publishing Group, v. 5, n. 2, p. 101-113, 2004. Citado na página 21.

BARBAN, N.; BILLARI, F. C. Classifying life course trajectories: a comparison of latent class and sequence analysis. Journal of the Royal Statistical Society: Series C (Applied Statistics), Wiley Online Library, v. 61, n. 5, p. 765-784, 2012. Citado na página 62.

BASS, F. M. Comments on "a new product growth for model consumer durables the bass model". Management science, INFORMS, v. 50, n. 12_supplement, p. 1833-1840, 2004. Citado 4 vezes nas páginas 31, 32, 37 e 38.

BASS, F. M. et al. Directv: Forecasting diffusion of a new technology prior to product launch. Interfaces, INFORMS, v. 31, n. 3_supplement, p. S82-S93, 2001. Citado na página 56. 
BASS, F. M.; JAIN, D.; KRISHNAN, T. Modeling the marketing-mix influence in new-product diffusion. [S.l.]: Kluwer Academic Publishers: Boston, MA, 2000. Citado na página 32.

BAYUS, B. L. Are product life cycles really getting shorter? Journal of Product Innovation Management, Wiley Online Library, v. 11, n. 4, p. 300-308, 1994. Citado na página 38.

BEARD, C.; EASINGWOOD, C. New product launch: marketing action and launch tactics for high-technology products. Industrial Marketing Management, Elsevier, v. 25, n. 2, p. 87-103, 1996. Citado 3 vezes nas páginas 40, 41 e 58.

BEINHOCKER, E. D. The origin of wealth. Harvard Business School Press, Boston, p. 254-258, 2006. Citado 2 vezes nas páginas 22 e 43.

BEMMAOR, A. C. Modeling the diffusion of new durable goods: Word-of-mouth effect versus consumer heterogeneity. In: Research traditions in marketing. [S.l.]: Springer, 1994. p. 201-229. Citado na página 36.

BERGER, J.; HEATH, C. Who drives divergence? identity signaling, outgroup dissimilarity, and the abandonment of cultural tastes. Journal of personality and social psychology, American Psychological Association, v. 95, n. 3, p. 593, 2008. Citado na página 35.

BERNARD, H. R. et al. Comparing four different methods for measuring personal social networks. Social Networks, Elsevier, v. 12, n. 3, p. 179-215, 1990. Citado na página 21.

BERTALANFFY, L. V. The meaning of general system theory. General system theory: Foundations, development, applications, p. 30-53, 1973. Citado na página 25.

BINKEN, J. L.; STREMERSCH, S. The effect of superstar software on hardware sales in system markets. Journal of Marketing, American Marketing Association, v. 73, n. 2, p. 88-104, 2009. Citado 3 vezes nas páginas 33, 34 e 35.

BOCCALETTI, S. et al. Complex networks: Structure and dynamics. Physics reports, Elsevier, v. 424, n. 4, p. 175-308, 2006. Citado 3 vezes nas páginas 25, 27 e 28.

BOHLMANN, J. D.; CALANTONE, R. J.; ZHAO, M. The effects of market network heterogeneity on innovation diffusion: An agent-based modeling approach. Journal of Product Innovation Management, Wiley Online Library, v. 27, n. 5, p. 741-760, 2010. Citado 2 vezes nas páginas 36 e 40.

BOURDIEU, P. Distinction: A social critique of the judgement of taste. [S.l.]: Harvard University Press, 1984. Citado na página 40.

BOWLES, S. Microeconomics: behavior, institutions, and evolution. [S.l.]: Princeton University Press, 2009. Citado na página 43.

BRYNJOLFSSON, E.; KEMERER, C. F. Network externalities in microcomputer software: An econometric analysis of the spreadsheet market. Management Science, INFORMS, v. 42, n. 12, p. 1627-1647, 1996. Citado na página 42. 
BULTE, C. Van den; LILIEN, G. L. Medical innovation revisited: Social contagion versus marketing effort1. American Journal of Sociology, JSTOR, v. 106, n. 5, p. 1409-1435, 2001. Citado 2 vezes nas páginas 32 e 38.

BULTE, C. Van den; STREMERSCH, S. Contrasting early and late new product diffusion: Speed across time, products. [S.1.], 2006. Citado 4 vezes nas páginas 34, 35, 38 e 41.

CASTEllano, C.; FORTUNATO, S.; LORETO, V. Statistical physics of social dynamics. Reviews of modern physics, APS, v. 81, n. 2, p. 591, 2009. Citado na página 22 .

CHAMORRO; GONçALVES. Agent-based model for the technology adoption and diffusion processes in the residential sector:integration of social,technological and economic factors. Journal of Economy and Energy, Latin American Energy Association, v. 51, n. 4, p. 1-16, 2015. Citado na página 43.

CHANDRASEKARAN, D.; TELLIS, G. J. Getting a grip on the saddle: Cycles, chasms, or cascades. In: PDMA Research Forum, Atlanta, 21-22 October. [S.l.: s.n.], 2006. Citado na página 37.

CHANDY, R. K.; TELLIS, G. J. Organizing for radical product innovation: The overlooked role of willingness to cannibalize. Journal of marketing research, JSTOR, p. 474-487, 1998. Citado na página 41.

CHANG, M.-H. The effects of product differentiation on collusive pricing. International Journal of Industrial Organization, Elsevier, v. 9, n. 3, p. 453-469, 1991. Citado na página 22.

CHARLET, B.; LÉVINE, J.; MARINO, R. On dynamic feedback linearization. Systems \&6 Control Letters, Elsevier, v. 13, n. 2, p. 143-151, 1989. Citado na página 26.

CIALDINI, R. B.; GOLDSTEIN, N. J. Social influence: Compliance and conformity. Annu. Rev. Psychol., Annual Reviews, v. 55, p. 591-621, 2004. Citado na página 40.

CILlIERS, P.; SPURRETT, D. Complexity and post-modernism: Understanding complex systems. South African Journal of Philosophy, Taylor \& Francis, v. 18, n. 2, p. 258-274, 1999. Citado na página 26.

COOKE, P.; MORGAN, K. The associational economy: firms, regions, and innovation. OUP Catalogue, Oxford University Press, 1999. Citado na página 41.

COOPER, R. G. Winning at new products: Accelerating the process from idea to launch. [S.1.]: Basic Books, 2001. Citado na página 30.

COOPER, R. G.; EDGETT, S. J. Critical success factors for new financial services. Marketing Management, American Marketing Association, v. 5, n. 3, p. 26, 1996. Citado na página 38.

COOPER, R. G.; EDGETT, S. J. Best practices in the idea-to-launch process and its governance. Research-Technology Management, Industrial Research Institute, Inc, v. 55, n. 2, p. 43-54, 2012. Citado na página 38. 
COOPER, R. G.; KLEINSCHMIDT, E. J. New products: The key factors in success. [S.1.]: Marketing Classics Press, 2011. Citado na página 38.

COUGHLAN, A. T. et al. Marketing channels. [S.l.]: Pearson/Prentice Hall Upper Saddle River, NJ, 2006. Citado na página 42.

CUSUMANO, M. A.; MYLONADIS, Y.; ROSENBLOOM, R. S. Strategic maneuvering and mass-market dynamics: The triumph of vhs over beta. Business history review, Cambridge Univ Press, v. 66, n. 01, p. 51-94, 1992. Citado na página 41.

DANAHER, P. J.; HARDIE, B. G.; JR, W. P. P. Marketing-mix variables and the diffusion of successive generations of a technological innovation. Journal of Marketing Research, American Marketing Association, v. 38, n. 4, p. 501-514, 2001. Citado na página 56.

DEFFUANT, G.; HUET, S.; AMBLARD, F. An individual-based model of innovation diffusion mixing social value and individual benefit1. American Journal of Sociology, JSTOR, v. 110, n. 4, p. 1041-1069, 2005. Citado na página 22.

DELRE, S. A. The effects of social networks on innovation diffusion and market dynamics. [S.1.]: Labyrinth Publications, 2007. Citado na página 22.

DELRE, S. A.; JAGER, W.; JANSSEN, M. A. Diffusion dynamics in small-world networks with heterogeneous consumers. Computational and Mathematical Organization Theory, Springer, v. 13, n. 2, p. 185-202, 2007. Citado 3 vezes nas páginas 34, 39 e 46.

DHEBAR, A.; OREN, S. S. Dynamic nonlinear pricing in networks with interdependent demand. Operations Research, INFORMS, v. 34, n. 3, p. 384-394, 1986 . Citado 2 vezes nas páginas 25 e 42 .

DOROGOVTSEV, S. N.; MENDES, J. F. Evolution of networks. Advances in physics, Taylor \& Francis, v. 51, n. 4, p. 1079-1187, 2002. Citado 2 vezes nas páginas 25 e 28.

DORWARD, N. The pricing decision: economic theory and business practice. [S.l.: s.n.], 1987. Citado na página 41.

ECK, P. S. V.; JAGER, W.; LEEFLANG, P. S. Opinion leaders' role in innovation diffusion: A simulation study. Journal of Product Innovation Management, Wiley Online Library, v. 28, n. 2, p. 187-203, 2011. Citado na página 22.

ECONOMIDES, N.; HIMMELBERG, C. P. Critical mass and network size with application to the us fax market. NYU Stern School of Business EC-95-11, 1995. Citado na página 42 .

EMMANOUILIDES, C. J.; DAVIES, R. B. Modelling and estimation of social interaction effects in new product diffusion. European Journal of Operational Research, Elsevier, v. 177, n. 2, p. 1253-1274, 2007. Citado 2 vezes nas páginas 36 e 43.

ERDOS, P.; RÉNYI, A. On the evolution of random graphs. Publ. Math. Inst. Hungar. Acad. Sci, Citeseer, v. 5, p. 17-61, 1960. Citado na página 28.

ERDÖS, P.; RÉNYI, A.; SÓS, V. On a problem of graph theory. Studia Sci. Math. Hungar, v. 1, p. 215-235, 1966. Citado na página 28. 
GATIGNON, H. Commentary on jacob goldenberg, barak libai and eitan muller's "the chilling effects of network externalities". International Journal of Research in Marketing, Elsevier, v. 27, n. 1, p. 16-17, 2010. Citado na página 35.

GOLDBERGER, A. L. et al. Physiobank, physiotoolkit, and physionet components of a new research resource for complex physiologic signals. Circulation, Am Heart Assoc, v. 101, n. 23, p. e215-e220, 2000. Citado 2 vezes nas páginas 21 e 36.

GOLDENBERG, J. et al. The role of hubs in the adoption process. Journal of Marketing, American Marketing Association, v. 73, n. 2, p. 1-13, 2009. Citado 3 vezes nas páginas 32,33 e 35.

GOLDENBERG, J. et al. The npv of bad news. International Journal of Research in Marketing, Elsevier, v. 24, n. 3, p. 186-200, 2007. Citado 2 vezes nas páginas 33 e 37.

GOLDENBERG, J.; LIBAI, B.; MULLER, E. Riding the saddle: How cross-market communications can create a major slump in sales. Journal of Marketing, American Marketing Association, v. 66, n. 2, p. 1-16, 2002. Citado 2 vezes nas páginas 33 e 37.

GOLDENBERG, J.; OREG, S. Laggards in disguise: Resistance to adopt and the leapfrogging effect. Technological Forecasting and Social Change, Elsevier, v. 74, n. 8, p. 1272-1281, 2007. Citado na página 55.

GOLDER, P. N.; TELLIS, G. J. Will it ever fly? modeling the takeoff of really new consumer durables. Marketing Science, INFORMS, v. 16, n. 3, p. 256-270, 1997. Citado 3 vezes nas páginas 26,36 e 39 .

GOLDER, P. N.; TELLIS, G. J. Growing, growing, gone: Cascades, diffusion, and turning points in the product life cycle. Marketing Science, INFORMS, v. 23, n. 2, p. 207-218, 2004. Citado na página 39.

GOLDSMITH, R. E.; NEWELL, S. J. Innovativeness and price sensitivity: managerial, theoretical and methodological issues. Journal of Product $\&$ Brand Management, MCB UP Ltd, v. 6, n. 3, p. 163-174, 1997. Citado na página 39.

GRIMM, V. et al. Pattern-oriented modeling of agent-based complex systems: lessons from ecology. science, American Association for the Advancement of Science, v. 310, n. 5750, p. 987-991, 2005. Citado 2 vezes nas páginas 21 e 27.

GRÜBLER, A. Time for a change: on the patterns of diffusion of innovation. Daedalus, JSTOR, p. 19-42, 1996. Citado na página 71.

GRUNENWALD, J. P.; VERNON, T. T. Pricing decision making for high-technology products and services. Journal of Business 8 Industrial Marketing, MCB UP Ltd, v. 3, n. 1, p. 61-70, 1988. Citado na página 41.

HAGBERG, A.; SWART, P.; CHULT, D. S. Exploring network structure, dynamics, and function using NetworkX. [S.1.], 2008. Citado na página 43.

HARTMAN, R. S.; TEECE, D. J. Product emulation strategies in the presence of reputation effects and network externalities: some evidence from the minicomputer industry. Economics of innovation and new technology, Taylor \& Francis, v. 1, n. 1-2, p. 157-182, 1990. Citado 2 vezes nas páginas 41 e 42. 
HO, T.-H.; SAVIN, S.; TERWIESCH, C. Managing demand and sales dynamics in new product diffusion under supply constraint. Management Science, INFORMS, v. 48, n. 2, p. 187-206, 2002. Citado na página 32.

HULTINK, E. J. et al. Industrial new product launch strategies and product development performance. Journal of product innovation management, Wiley Online Library, v. 14, n. 4, p. 243-257, 1997. Citado na página 40.

HULTINK, E. J.; SCHOORMANS, J. P. How to launch a high-tech product successfully: an analysis of marketing managers' strategy choices. The journal of high technology management research, Elsevier, v. 6, n. 2, p. 229-242, 1995. Citado 2 vezes nas páginas 41 e 58.

HUNTINGTON, J.; GILLAM, S.; ROSEN, R. Organisational development for clinical governance. BMJ, BMJ Publishing Group Ltd, v. 321, n. 7262, p. 679-682, 2000. Citado na página 40 .

IYENGAR, R.; BULTE, C. Van den; VALENTE, T. W. Opinion leadership and social contagion in new product diffusion. Marketing Science, INFORMS, v. 30, n. 2, p. 195-212, 2011. Citado 2 vezes nas páginas 36 e 38.

JENNINGS, N. R. An agent-based approach for building complex software systems. Communications of the ACM, ACM, v. 44, n. 4, p. 35-41, 2001. Citado na página 21.

JIANG, Z.; BASS, F. M.; BASS, P. I. Virtual bass model and the left-hand datatruncation bias in diffusion of innovation studies. International Journal of Research in Marketing, Elsevier, v. 23, n. 1, p. 93-106, 2006. Citado 4 vezes nas páginas 31, 32, 36 e 37 .

JONES, C.; HESTERLY, W. S.; BORGATTI, S. P. A general theory of network governance: Exchange conditions and social mechanisms. Academy of management review, Academy of Management, v. 22, n. 4, p. 911-945, 1997. Citado na página 41.

KEEN, S. Debunking economics: The naked emperor of the social sciences. [S.1.]: Zed Books, 2001. Citado 2 vezes nas páginas 22 e 43.

KIESLING, E. et al. Agent-based simulation of innovation diffusion: a review. Central European Journal of Operations Research, Springer, v. 20, n. 2, p. 183-230, 2012. Citado 3 vezes nas páginas 33, 36 e 46 .

KILLWORTH, P. D. et al. Estimating the size of personal networks. Social Networks, Elsevier, v. 12, n. 4, p. 289-312, 1990. Citado na página 21.

KIM, N.; CHANG, D. R.; SHOCKER, A. D. Modeling intercategory and generational dynamics for a growing information technology industry. Management Science, INFORMS, v. 46, n. 4, p. 496-512, 2000. Citado na página 38.

KLEIN, K. J.; DANSEREAU, F.; HALL, R. J. Levels issues in theory development, data collection, and analysis. Academy of Management Review, Academy of Management, v. 19, n. 2, p. 195-229, 1994. Citado na página 22.

KOCSIS, G.; KUN, F. The effect of network topologies on the spreading of technological developments. Journal of Statistical Mechanics: Theory and Experiment, IOP Publishing, v. 2008, n. 10, p. P10014, 2008. Citado na página 25. 
KOHLI, R.; LEHMANN, D. R.; PAE, J. Extent and impact of incubation time in new product diffusion. Journal of product innovation management, Wiley Online Library, v. 16, n. 2, p. 134-144, 1999. Citado na página 38.

KOSSINETS, G.; WATTS, D. J. Empirical analysis of an evolving social network. Science, American Association for the Advancement of Science, v. 311, n. 5757, p. 88-90, 2006. Citado 2 vezes nas páginas 32 e 39.

KOTLER, P.; KELLER, K. L. Administração de marketing. São Paulo, 2006. Citado 5 vezes nas páginas 39, 40, 41, 48 e 72 .

KUMAR, V.; PETERSEN, J. A.; LEONE, R. P. How valuable is word of mouth? Harvard business review, v. 85, n. 10, p. 139, 2007. Citado na página 33.

LAMBERTINI, L.; ORSINI, R. Process and product innovation in a vertically differentiated monopoly. Economics Letters, Elsevier, v. 68, n. 3, p. 333-337, 2000. Citado na página 39.

LEE, Y.; O'CONNOR, G. C. New product launch strategy for network effects products. Journal of the Academy of Marketing Science, SAGE Publications, v. 31, n. 3, p. 241-255, 2003. Citado na página 42.

LEHMANN, D. R.; ESTEBAN-BRAVO, M. When giving some away makes sense to jump-start the diffusion process. Marketing Letters, Springer, v. 17, n. 4, p. 243-254, 2006. Citado na página 56.

LEVIN, S. A.; LUBCHENCO, J. Resilience, robustness, and marine ecosystem-based management. Bioscience, Oxford University Press, v. 58, n. 1, p. 27-32, 2008. Citado na página 26.

LIBAI, B.; MULLER, E.; PERES, R. The role of seeding in multi-market entry. International Journal of Research in Marketing, Elsevier, v. 22, n. 4, p. 375-393, 2005. Citado na página 33.

LIN, J. Divergence measures based on the shannon entropy. Information Theory, IEEE Transactions on, IEEE, v. 37, n. 1, p. 145-151, 1991. Citado na página 62.

LÓPEZ, L.; SANJUÁN, M. A. Relation between structure and size in social networks. Physical Review E, APS, v. 65, n. 3, p. 036107, 2002. Citado na página 21.

MACY, M. W.; WILLER, R. From factors to actors: Computational sociology and agent-based modeling. Annual review of sociology, JSTOR, p. 143-166, 2002. Citado na página 43.

MAHAJAN, V.; MULLER, E. When is it worthwhile targeting the majority instead of the innovators in a new product launch? Journal of Marketing Research, JSTOR, p. 488-495, 1998. Citado 2 vezes nas páginas 37 e 56.

MAHAJAN, V.; MULLER, E.; BASS, F. M. New product diffusion models in marketing: A review and directions for research. The Journal of Marketing, JSTOR, p. 1-26, 1990. Citado 5 vezes nas páginas 31, 32, 37, 38 e 49.

MAINZER, K. Thinking in complexity: The computational dynamics of matter, mind, and mankind. [S.1.]: Springer Science \& Business Media, 2007. Citado na página 25. 
MALHOTRA, N. K. Pesquisa de marketing: uma orientação aplicada. [S.1.]: Bookman, 2012. Citado 5 vezes nas páginas 41, 46, 48, 57 e 58.

MANGOLD, W. G.; FAULDS, D. J. Social media: The new hybrid element of the promotion mix. Business horizons, Elsevier, v. 52, n. 4, p. 357-365, 2009. Citado na página 39.

MCCARTY, C.; KILLWORTH, P. D.; RENNELL, J. Impact of methods for reducing respondent burden on personal network structural measures. Social Networks, Elsevier, v. 29, n. 2, p. 300-315, 2007. Citado na página 21.

MCCLAVE, J. T.; SINCICH, T. Statistics. [S.l.]: Prentice Hall, 2005. Citado 3 vezes nas páginas 46, 48 e 58 .

MIROWSKI, P. More heat than light: economics as social physics, physics as nature's economics. [S.l.]: Cambridge University Press, 1991. Citado na página 43.

MITCHELL, M. Complex systems: Network thinking. Artificial Intelligence, Elsevier, v. 170, n. 18, p. 1194-1212, 2006. Citado 2 vezes nas páginas 22 e 25.

MOORE, C.; NEWMAN, M. E. Epidemics and percolation in small-world networks. Physical Review E, APS, v. 61, n. 5, p. 5678, 2000. Citado na página 21.

MOORE, G. C.; BENBASAT, I. Development of an instrument to measure the perceptions of adopting an information technology innovation. Information systems research, INFORMS, v. 2, n. 3, p. 192-222, 1991. Citado na página 37.

MOORE, M. J.; BOUldinG, W.; GOODSTEIN, R. C. Pioneering and market share: is entry time endogenous and does it matter? Journal of Marketing Research, JSTOR, p. 97-104, 1991. Citado na página 49.

MORENO, Y.; PASTOR-SATORRAS, R.; VESPIGNANI, A. Epidemic outbreaks in complex heterogeneous networks. The European Physical Journal B-Condensed Matter and Complex Systems, Springer, v. 26, n. 4, p. 521-529, 2002. Citado na página 45.

MORRIS, M. Epidemiology and social networks: Modeling structured diffusion. Sociological Methods \& Research, Sage Publications, v. 22, n. 1, p. 99-126, 1993. Citado na página 32 .

MULLER, E.; YOGEV, G. When does the majority become a majority? empirical analysis of the time at which main market adopters purchase the bulk of our sales. Technological Forecasting and Social Change, Elsevier, v. 73, n. 9, p. 1107-1120, 2006. Citado na página 37.

MURNANE, R. J.; NELSON, R. R. Production and innovation when techniques are tacit: The case of education. Journal of Economic Behavior \& Organization, Elsevier, v. 5, n. 3, p. 353-373, 1984. Citado na página 41.

NAGLE, T. T.; HOGAN, J. E.; ZALE, J. The strategy and tactics of pricing: A guide to growing more profitably. 5th ed., 2008. Citado 3 vezes nas páginas 41, 48 e 49.

NAIR, H.; CHINTAGUNTA, P.; DUBÉ, J.-P. Empirical analysis of indirect network effects in the market for personal digital assistants. Quantitative Marketing and Economics, Springer, v. 2, n. 1, p. 23-58, 2004. Citado na página 34. 
NEWMAN, M. E. The structure of scientific collaboration networks. Proceedings of the National Academy of Sciences, National Acad Sciences, v. 98, n. 2, p. 404-409, 2001. Citado 2 vezes nas páginas 21 e 27.

NEWMAN, M. E. The structure and function of complex networks. SIAM review, SIAM, v. 45, n. 2, p. 167-256, 2003. Citado na página 33.

NICHELE, M.; MILAN, G. Fundamentos, estratégias e decisões de preço. Administração mercadológica: teoria e pesquisas, v. 2, p. 151-180, 2006. Citado na página 48.

NORTH, M. J.; MACAL, C. M. Managing business complexity: discovering strategic solutions with agent-based modeling and simulation. [S.l.]: Oxford University Press, 2007. Citado na página 46.

NORTON, J. A.; BASS, F. M. A diffusion theory model of adoption and substitution for successive generations of high-technology products. Management science, INFORMS, v. 33, n. 9, p. 1069-1086, 1987. Citado 3 vezes nas páginas 32, 37 e 56.

PADMANABHAN, V.; BASS, F. M. Optimal pricing of successive generations of product advances. International Journal of Research in Marketing, Elsevier, v. 10, n. 2, p. 185-207, 1993. Citado na página 56.

PAGE, S. E. Diversity and complexity. [S.l.]: Princeton University Press, 2010. Citado na página 26.

PAN, W.; AHARONY, N.; PENTLAND, A. Composite social network for predicting mobile apps installation. In: AAAI. [S.l.: s.n.], 2011. Citado na página 34.

PARKER, P. M. Aggregate diffusion forecasting models in marketing: A critical review. International journal of forecasting, Elsevier, v. 10, n. 2, p. 353-380, 1994. Citado na página 32.

PARUNAK, H. V. D. "go to the ant": Engineering principles from natural multi-agent systems. Annals of Operations Research, Springer, v. 75, p. 69-101, 1997. Citado na página 26.

PENTLAND, B. T.; FELDMAN, M. S. Narrative networks: Patterns of technology and organization. Organization Science, INFORMS, v. 18, n. 5, p. 781-795, 2007. Citado na página 22.

PEREIRA, C. d. B. As faces de jano: sobre a possibilidade de mensuração do efeito veblen. As Faces de Jano: sobre a possibilidade de mensuração do efeito Veblen, 2000. Citado na página 71.

POWELL, J. H.; WAKELEY, T. M. Evolutionary concepts and business economics: Towards a normative approach. Journal of Business Research, Elsevier, v. 56, n. 2, p. 153-161, 2003. Citado na página 43.

RAMOS, P. M.; MAYA, P. C. da C.; BORNIA, A. C. Estratégias de preços praticadas pelas empresas do consórcio de exportação de calçados de são joão batista: análise da adoção nos mercados interno e externo. In: Anais do Congresso Brasileiro de Custos-ABC. [S.l.: s.n.], 2005. Citado na página 48. 
RAND, W.; RUST, R. T. Agent-based modeling in marketing: Guidelines for rigor. International Journal of Research in Marketing, Elsevier, v. 28, n. 3, p. 181-193, 2011. Citado 2 vezes nas páginas 32 e 35.

ROGERS, E. M. Diffusion of innovations. [S.1.]: Simon and Schuster, 2010. Citado 3 vezes nas páginas 39, 40 e 52 .

ROHLFS, M.; HOFFMEISTER, T. S. An evolutionary explanation of the aggregation model of species coexistence. Proceedings of the Royal Society of London B: Biological Sciences, The Royal Society, v. 270, n. Suppl 1, p. S33-S35, 2003. Citado na página 33.

SCHELLING, T. C. Dynamic models of segregation†. Journal of mathematical sociology, Taylor \& Francis, v. 1, n. 2, p. 143-186, 1971. Citado na página 43.

SCOTT, J.; CARRINGTON, P. J. The SAGE handbook of social network analysis. [S.1.]: SAGE publications, 2011. Citado na página 27.

SIMMEL, G. Fashion. American journal of sociology, JSTOR, p. 541-558, 1957. Citado 2 vezes nas páginas 35 e 40.

SIMON, H. A. The architecture of complexity. [S.1.]: Springer, 1991. Citado na página 27.

SONG, I.; CHINTAGUNTA, P. K. A micromodel of new product adoption with heterogeneous and forward-looking consumers: Application to the digital camera category. Quantitative Marketing and Economics, Springer, v. 1, n. 4, p. 371-407, 2003. Citado 2 vezes nas páginas 26 e 36.

SRINIVASAN, R.; LILIEN, G. L.; RANGASWAMY, A. First in, first out? the effects of network externalities on pioneer survival. Journal of Marketing, American Marketing Association, v. 68, n. 1, p. 41-58, 2004. Citado na página 34.

STARK, J. Product lifecycle management. [S.1.]: Springer, 2011. Citado na página 45.

STERMAN, J. D. Learning in and about complex systems. System Dynamics Review, Wiley Online Library, v. 10, n. 2-3, p. 291-330, 1994. Citado na página 25.

STREMERSCH, S.; TELLIS, G. J. Strategic bundling of products and prices: A new synthesis for marketing. Journal of Marketing, American Marketing Association, v. 66, n. 1, p. 55-72, 2002. Citado 3 vezes nas páginas 34, 37 e 38.

TEETOR, P. R cookbook. [S.1.]: "O’Reilly Media, Inc.", 2011. Citado na página 43.

TELLIS, G. J.; GOLDER, P. N.; FOSTER, J. A. Predicting sales takeoff for whirlpool's new personal valet. Marketing Science, v. 23, n. 2, p. 180-191, 2004. Citado 2 vezes nas páginas 36 e 37.

TENG, C.-Y.; LIN, Y.-R.; ADAMIC, L. A. Recipe recommendation using ingredient networks. In: ACM. Proceedings of the 3rd Annual ACM Web Science Conference. [S.1.], 2012. p. 298-307. Citado na página 21.

URRY, J. The complexity turn. Theory Culture and Society, Sage Publications, v. 22, n. 5, p. 1, 2005. Citado na página 26. 
VAKRATSAS, D.; KOLSARICI, C. A dual-market diffusion model for a new prescription pharmaceutical. International Journal of Research in Marketing, Elsevier, v. 25, n. 4, p. 282-293, 2008. Citado na página 37.

VALENTE, T. W. Network models of the diffusion of innovations. [S.l.]: Hampton Press Cresskill, NJ, 1995. Citado 2 vezes nas páginas 21 e 40.

VANY, A. D.; LEE, C. Quality signals in information cascades and the dynamics of the distribution of motion picture box office revenues. Journal of Economic Dynamics and Control, Elsevier, v. 25, n. 3, p. 593-614, 2001. Citado na página 43.

VANY, A. D.; WALLS, W. D. Bose-einstein dynamics and adaptive contracting in the motion picture industry. The Economic Journal, JSTOR, p. 1493-1514, 1996. Citado na página 43.

VARIAN, H. R.; REPCHECK, J. Intermediate microeconomics: a modern approach. [S.l.]: WW Norton \& Company New York, NY, 2010. Citado na página 43.

VELTHUIS, O. Talking Prices: Symbolic Meanings of Prices on the Market for Contemporary Art: Symbolic Meanings of Prices on the Market for Contemporary Art. [S.1.]: Princeton University Press, 2013. Citado na página 41.

WANG, X. F.; CHEN, G. Synchronization in scale-free dynamical networks: robustness and fragility. Circuits and Systems I: Fundamental Theory and Applications, IEEE Transactions on, IEEE, v. 49, n. 1, p. 54-62, 2002. Citado na página 26.

WATTS, D. J.; STROGATZ, S. H. Collective dynamics of 'small-world'networks. nature, Nature Publishing Group, v. 393, n. 6684, p. 440-442, 1998. Citado 3 vezes nas páginas 21,27 e 28.

WEISS, M. J. The clustered world: How we live, what we buy, and what it all means about who we are. [S.1.]: Little, Brown New York, 2000. Citado 2 vezes nas páginas 68 e 72 .

WHEELWRIGHT, S. C. Managing New Product and Process Development: Text Cases. [S.l.]: Simon and Schuster, 2010. Citado na página 30.

YANG, Y. et al. What are the effective strategic orientations for new product success under different environments? an empirical study of chinese businesses. Journal of Product Innovation Management, Wiley Online Library, v. 29, n. 2, p. 166-179, 2012. Citado na página 38.

YOUNG, H. P. The diffusion of innovations in social networks. The Economy As an Evolving Complex System III: Current Perspectives and Future Directions, v. 267, 2006. Citado na página 39.

ZHANG, T.; GENSLER, S.; GARCIA, R. A study of the diffusion of alternative fuel vehicles: An agent-based modeling approach*. Journal of Product Innovation Management, Wiley Online Library, v. 28, n. 2, p. 152-168, 2011. Citado na página 71.

ZHANG, T.; ZHANG, D. Agent-based simulation of consumer purchase decision-making and the decoy effect. Journal of business research, Elsevier, v. 60, n. 8, p. 912-922, 2007. Citado 2 vezes nas páginas 38 e 43. 